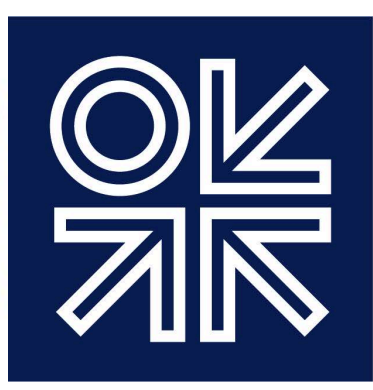

THE OXFORD

INSTITUTE

FOR ENERGY

STUDIES

February 2014

\title{
Challenges to JCC Pricing in Asian LNG Markets
}

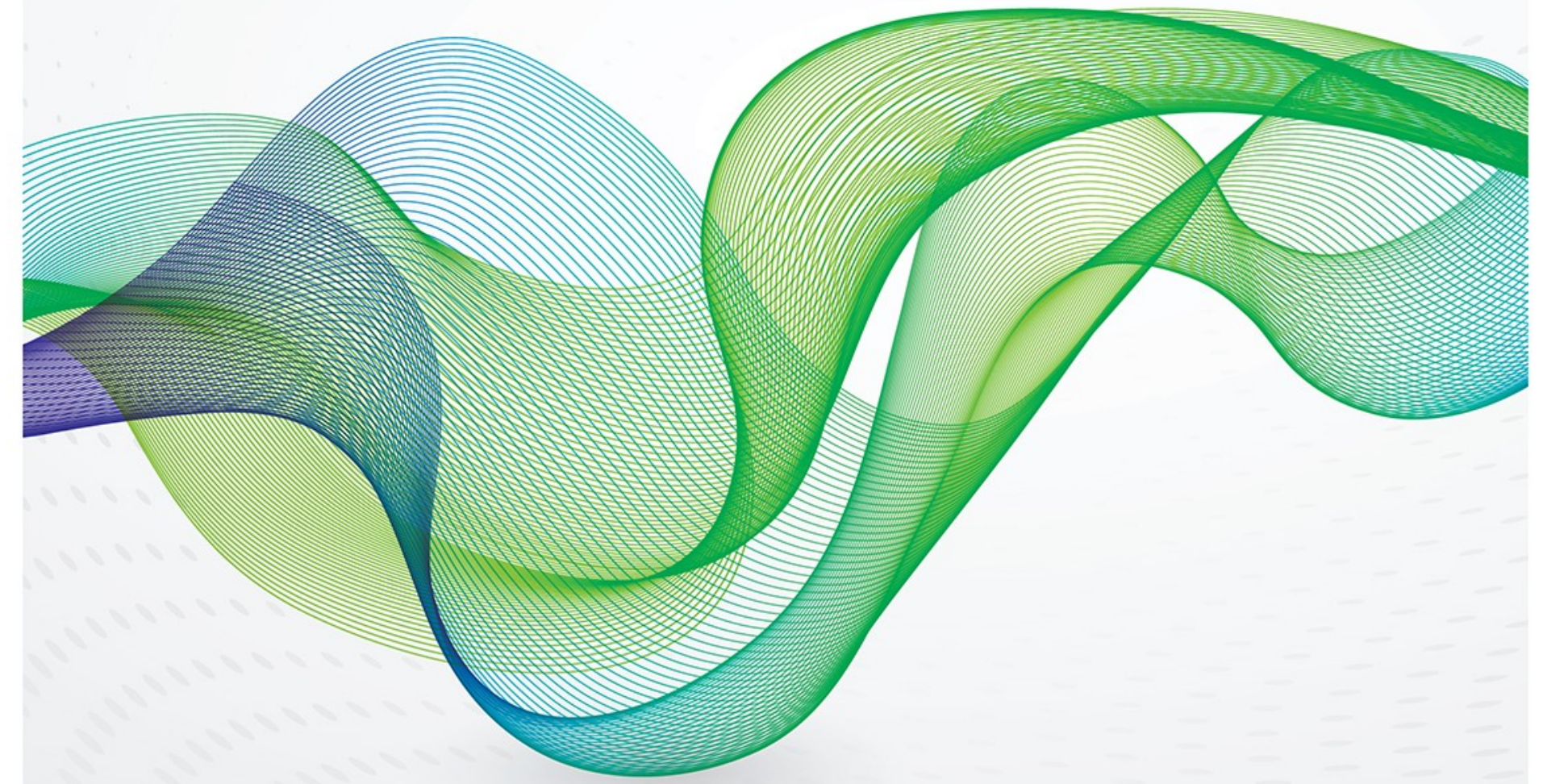

Howard V Rogers and Jonathan Stern 
The contents of this paper are the authors' sole responsibility. They do not necessarily represent the views of the Oxford Institute for Energy Studies or any of its members.

Copyright $\odot 2014$

Oxford Institute for Energy Studies

(Registered Charity, No. 286084)

This publication may be reproduced in part for educational or non-profit purposes without special permission from the copyright holder, provided acknowledgment of the source is made. No use of this publication may be made for resale or for any other commercial purpose whatsoever without prior permission in writing from the Oxford Institute for Energy Studies.

ISBN 978-1-907555-92-3 


\section{Contents}

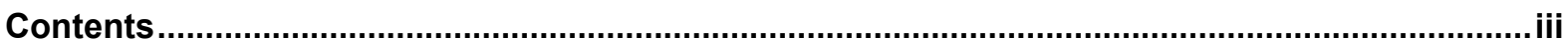

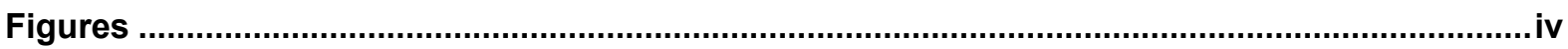

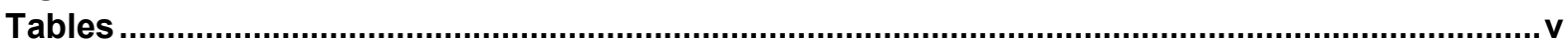

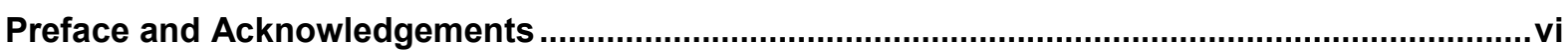

Introduction: the LNG price fundamentals challenge in Asia ...........................................................

Chapter 1. LNG trade in the 2000s: the emergence of flexibility and global market connectivity ..........3

Chapter 2. Gas demand trends and drivers for change in Asian LNG markets ..................................8

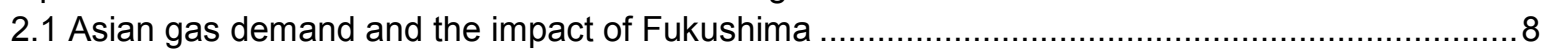

2.2 LNG import prices in Japan, South Korea, Taiwan and China ........................................... 11

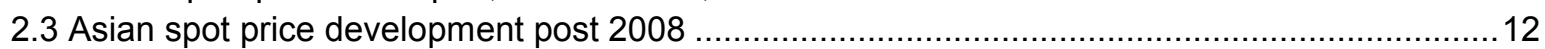

Chapter 3. The evolution of natural gas price formation: establishing market fundamentals for

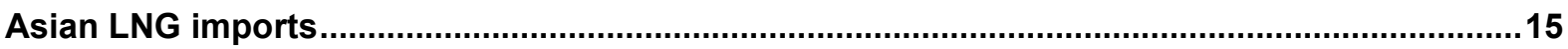

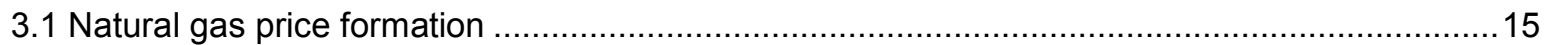

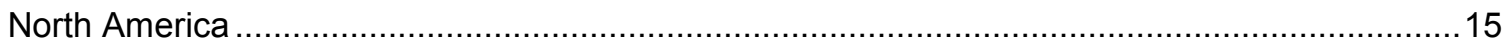

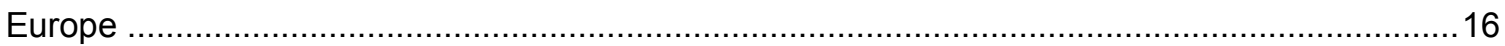

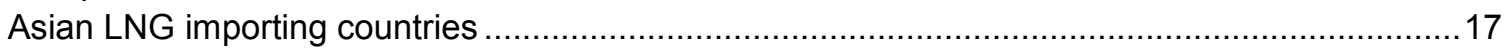

3.2 Economic and market fundamentals of Asian LNG projects and contracts ...........................18

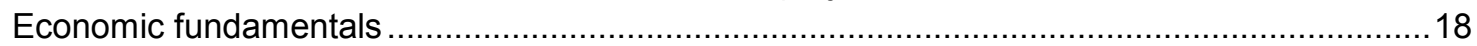

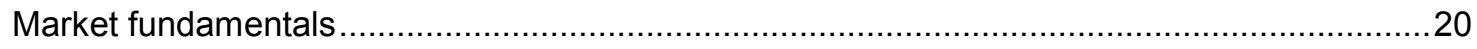

3.3 North American LNG exports at Henry Hub-related prices - hopes and risks.........................22

Chapter 4: The growth of spot and short term LNG trading in Asia 2006-12 ..........................28

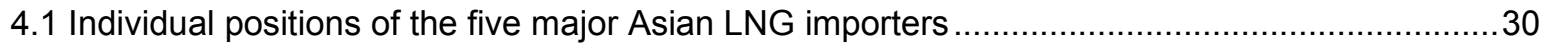

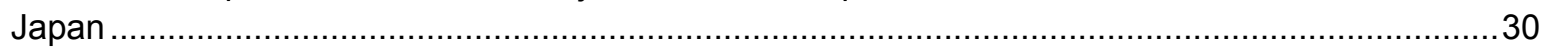

South Korea

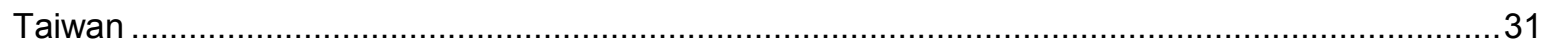

India

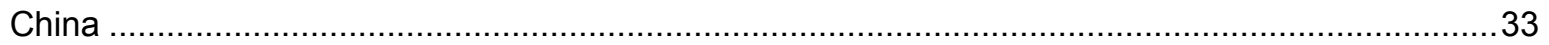

Chapter 5. The case for, and challenges facing, an Asian LNG trading hub .............................38

5.1 Differences between North American, European, and LNG importing Asian markets ...............39

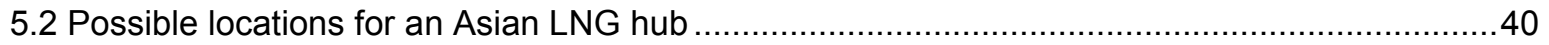

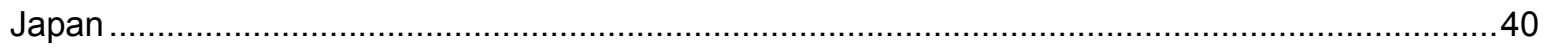

5.3 An Asian LNG hub - practical considerations and challenges............................................ 41

Chapter 6. Summary and Conclusions: scenarios for future Asian LNG pricing and contracting

Scenarios for Asian LNG pricing and contracting in the 2010s and beyond

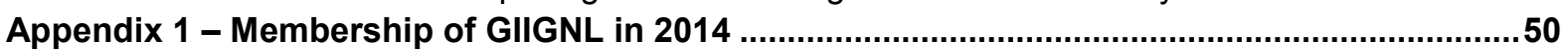

Appendix 2 - List of US LNG export Free Trade Agreement countries ...................................52

Appendix 3 - US LNG Project Application Status, $5^{\text {th }}$ October 2013 …...................................53

Appendix 4 - Assumptions used in Illustrative LNG demand projections ...............................55

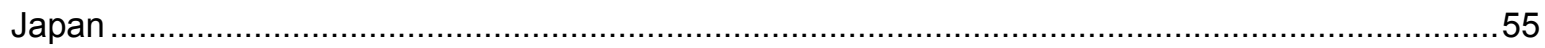

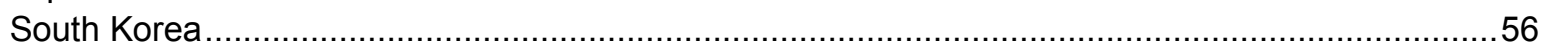

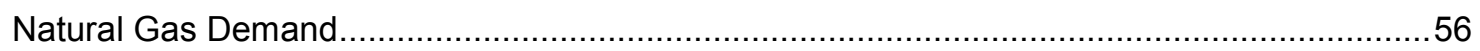

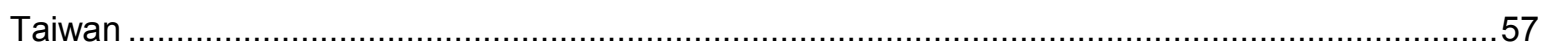

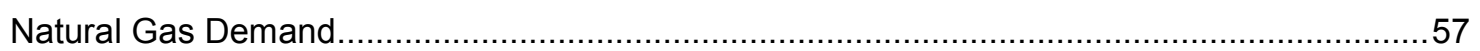

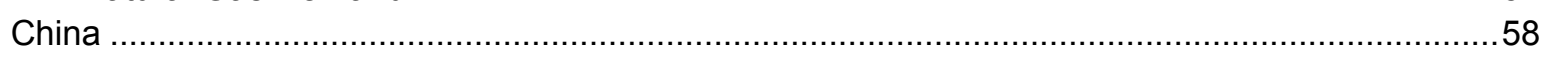

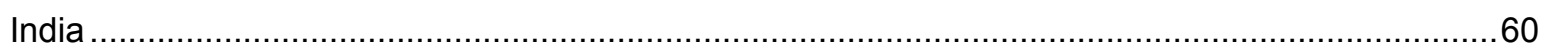

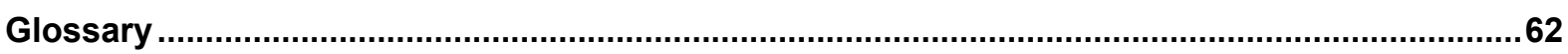

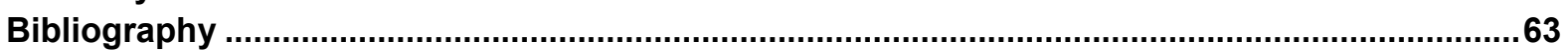




\section{Figures}

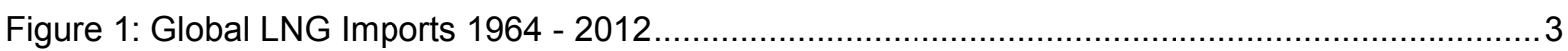

Figure 2: Share of LNG and Inter-Regional Pipeline Gas in Global Gas Supply Flows $1995-2012 \ldots .4$

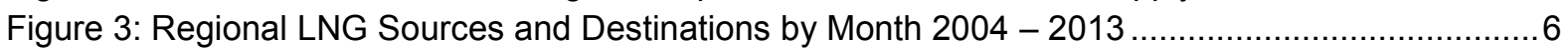

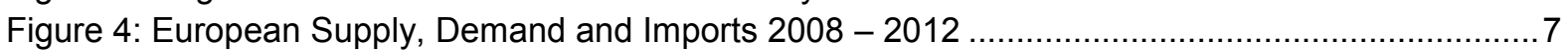

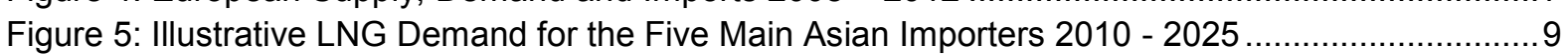

Figure 6: Estimated Japanese Power Generated in 2010 and 2011 (10 EPCOs) .............................10

Figure 7: Annual Net Profit/Loss for the 10 Largest Japanese Electric Power generating Companies.

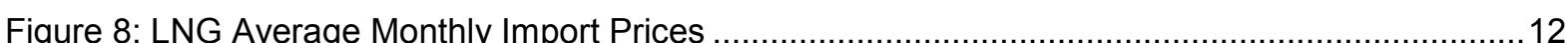

Figure 9: Regional Gas Prices January 2007 - December 2013 (Monthly Averages) ........................13

Figure 10: Total Capital Investment Costs for Selected LNG Projects (capex to first LNG supply) .....19

Figure 11: Nominal New-Built LNG Break-Even Prices of Selected LNG Projects (delivered to Tokyo

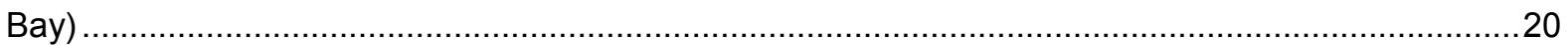

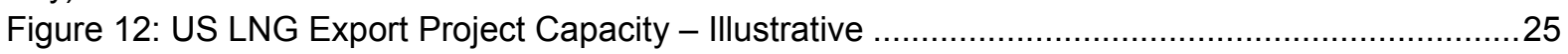

Figure 13: Break-even Destination Market Prices for US LNG to Europe and Asia ............................26

Figure 14: Category of Ownership of Illustrative US LNG Export Project Capacity .............................27

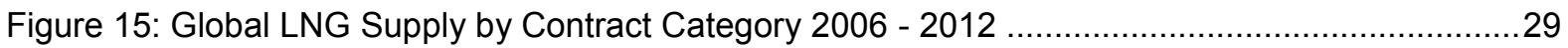

Figure 16: LNG Supplied to Asia by Contract Category 2006 - 2012 .........................................29

Figure 17: LNG Supplied to Japan by Contract Category 2010 - 2012 and Illustrative Contestable

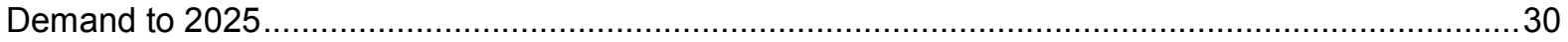

Figure 18: LNG Supplied to South Korea by Contract Category 2010 - 2012 and Illustrative

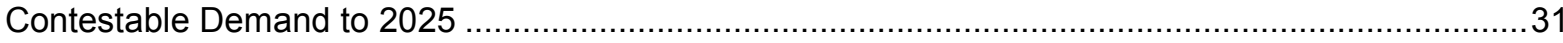

Figure 19: LNG Supplied to Taiwan by Contract Category 2010 - 2012 and Illustrative Contestable

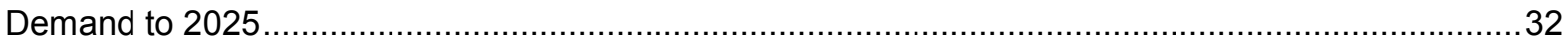

Figure 20: LNG Supplied to India by Contract Category 2010 - 2012 and Illustrative Contestable

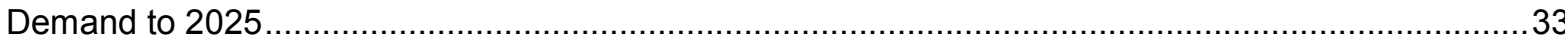

Figure 21: LNG Supplied to China by Contract Category 2010 - 2012 and Illustrative Contestable

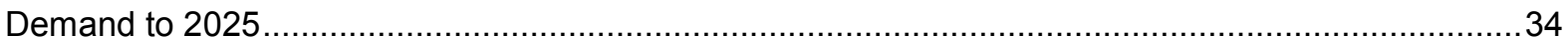

Figure 22: LNG Supplied to Asia by Contract Category 2010 - 2012 and Illustrative Contestable

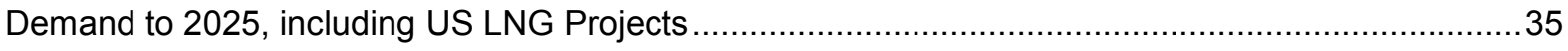

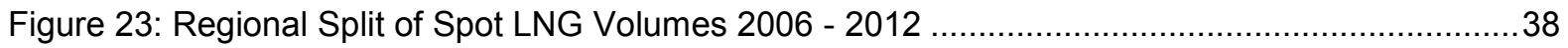

Figure 24: IEA Schematic Representing the Creation of a Competitive Wholesale Gas Market ..........39

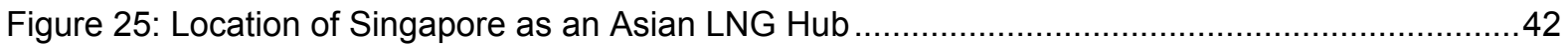

Figure 26: The Consequences of Developing Access to Regasification Terminals in Asian LNG

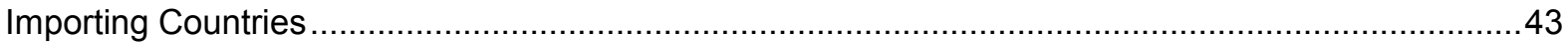

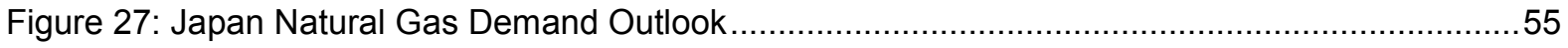

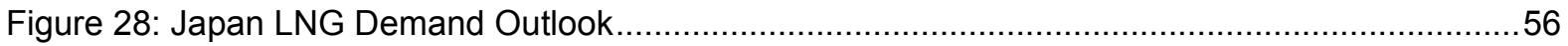

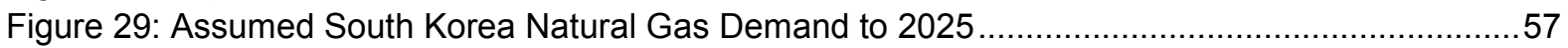

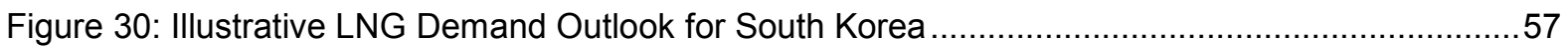

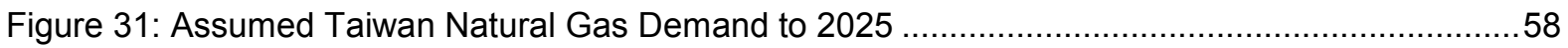

Figure 32: Chinese Natural Gas Demand and Domestic Production Assumptions to 2025 ...............58

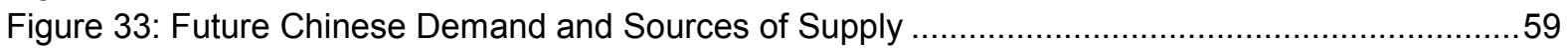

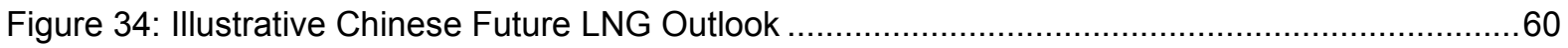

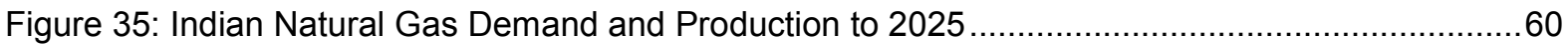

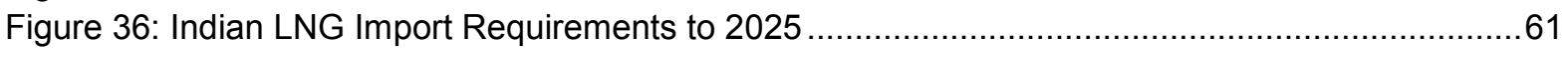




\section{Tables}

Table 1: Asia/Pacific National Natural Gas Consumption (Bcma) and Compound Annual Average Growth \% 8

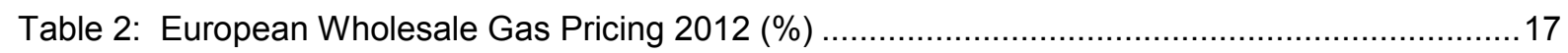

Table 3: Energy Sources Competing with Natural Gas in Asia .....................................................21

Table 4: Net Market Value (NMV) in Asian LNG Importing Countries with JCC at Different Oil Price Levels

Table 5: Status of US LNG Export Projects with Offtake Agreements/Heads of Agreement ..............23

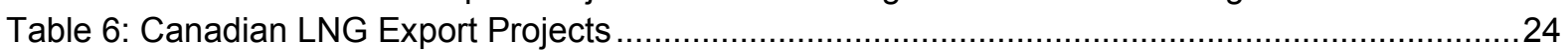




\section{Preface and Acknowledgements}

This is a difficult subject to write about, and it may be wondered why two researchers based in the UK decided to produce a paper on a subject which would more obviously be authored by those based in the Pacific region. The answer is that so controversial has this subject become, that we were unable to find authors who were not conflicted in their ability and willingness to place their views in the public domain. Having said that, there are many with strongly held views on the future of JCC pricing - both for and against - and we hope we have done justice to their opinions, while strongly advancing our own independent conclusions.

We are grateful to all who shared their views with us in the development of this paper and especially to Akira Miyamoto and Anne-Sophie Corbeau for their helpful comments on a previous draft. We alone remain responsible for the conclusions and opinions expressed in this paper.

Howard Rogers and Jonathan Stern

Oxford, February 2014 


\section{Introduction: the LNG price fundamentals challenge in Asia}

Research by the OIES gas programme over the past several years has argued that natural gas pricing is in transition worldwide. In almost every country and every long term international gas contract the commercial status quo - usually established many decades ago when energy and gas markets looked very different - is in the process of change. Our book on gas pricing ${ }^{1}$ reviewed different countries and regions showing that:

- In North America the unravelling of regulatory complexities at a time of supply abundance, and a fragmented and competitive production base, gave rise to a liberalised gas market and the adoption of Henry Hub as the main (but not the only) North American gas trading hub in the late 1980s.

- The UK, after an aggressive privatisation and liberalisation programme, established the NBP as a reference price in the late 1990s.

- In Continental Europe a sustained EU policy drive to create a competitive gas market and establish nascent trading hubs began to succeed in the aftermath of the 2008 financial crisis, when a combination of lower demand and a glut of LNG created the ideal conditions for hubs to develop liquidity and to take over as the reference price for gas in north west European markets.

Since the first Japanese LNG imports in the 1970s, Japan, South Korea, Taiwan, (followed more recently by India, China and Thailand), have in aggregate accounted for the majority of global imports of LNG. For the past 25 years, international LNG trade in Asia has been based on the Japan Crude Cocktail (JCC) price mechanism ${ }^{2}$. Little serious opposition had been raised to this form of pricing prior to the increase of crude oil prices above $\$ 100 / \mathrm{bbl}$ in the early $2010 \mathrm{~s}$. The Fukushima nuclear accident in 2011 placed Japanese LNG buyers in an even more difficult financial situation as they were forced to import increasing quantities of LNG at prices substantially higher than those of Europe and North America, impacting (particularly) Japanese industrial competitiveness and the country's balance of payments.

Since 2011, there has been a rising chorus of complaints about the high price of LNG in the Pacific Basin, but there are divisions between those arguing that prices need to be reduced while retaining the JCC mechanism, and those arguing that the JCC mechanism is no longer appropriate and should be replaced. Asian LNG importers have limited room for manoeuvre: existing long term contracts rarely include provisions for price review ${ }^{3}$ and, driven by real or perceived fears about 'security of supply', buyers signed new contracts in the 2000s which accepted ever-closer indexation of LNG to crude oil prices.

Since 2011, some LNG import contracts have been signed based on a "Henry Hub plus" formula. By December 2013, projects totalling 70 Bcma of US export capacity had gained approval to export LNG to non-Free Trade Agreement countries by the US DOE. (Associated with these projects some 63 Bcma of offtake agreements have been signed). These approvals created an increasing appetite for Henry Hub-related LNG pricing, but this led to uncertainty as to whether this would be a solution to the "fundamentals problem" in Asia. There are also more radical proposals for establishing an Asian

\footnotetext{
1 Stern (2012).

2 JCC is more correctly an acronym for "Japanese Customs-Cleared Crude Oil" a published index of the prices of crude oils imported into Japan.

${ }^{3}$ And even those which do are general, rather than specific, in relation to review criteria (certainly in comparison to their Continental European counterparts).
} 
LNG Hub to provide a regional reference price. This has been the subject of study by the IEA ${ }^{4}$ and has prompted a Japanese government initiative to support the establishment of an LNG futures market.

This paper examines possible alternatives to JCC pricing in Asian LNG markets and critically assesses the possibility and options for creating an LNG hub in the Pacific, and the efforts required on the part of the importing countries to transform that desire into reality.

Chapter 1 shows how the role of LNG in global natural gas fundamentals has changed since 2000 in terms of the development of supply flexibility and market connectivity. Chapter 2 looks at gas demand trends and the drivers for change in Asian LNG markets which have emerged in the post 2008 period, in particular the impact of the Fukushima disaster on the financial position of Japanese utilities. The chapter also looks at the evolution of Asian spot prices during this period. Chapter 3 reviews the evolution of natural gas and LNG pricing mechanisms in North America, Europe and Asia. It then looks at how economic and market fundamentals of LNG projects in Asia have changed and the problems which this is causing for the JCC price mechanism. It reviews the emergence of US LNG export projects based on Henry Hub prices and how this presents opportunities, but also risks, for Asian buyers. Chapter 4 presents an analysis of contractual portfolios for each of the major Asian LNG importers with a scenario of how they might meet anticipated estimates of contestable demand up to 2025. Chapter 5 examines the case for, and the challenges which would need to be overcome in, establishing an Asian LNG trading hub in terms of geographical location and other international experience. Chapter 6 provides a summary and conclusions, and some scenarios for the period up to 2020. 


\section{Chapter 1. LNG trade in the 2000s: the emergence of flexibility and global market connectivity}

Figure 1: Global LNG Imports 1964 - 2012

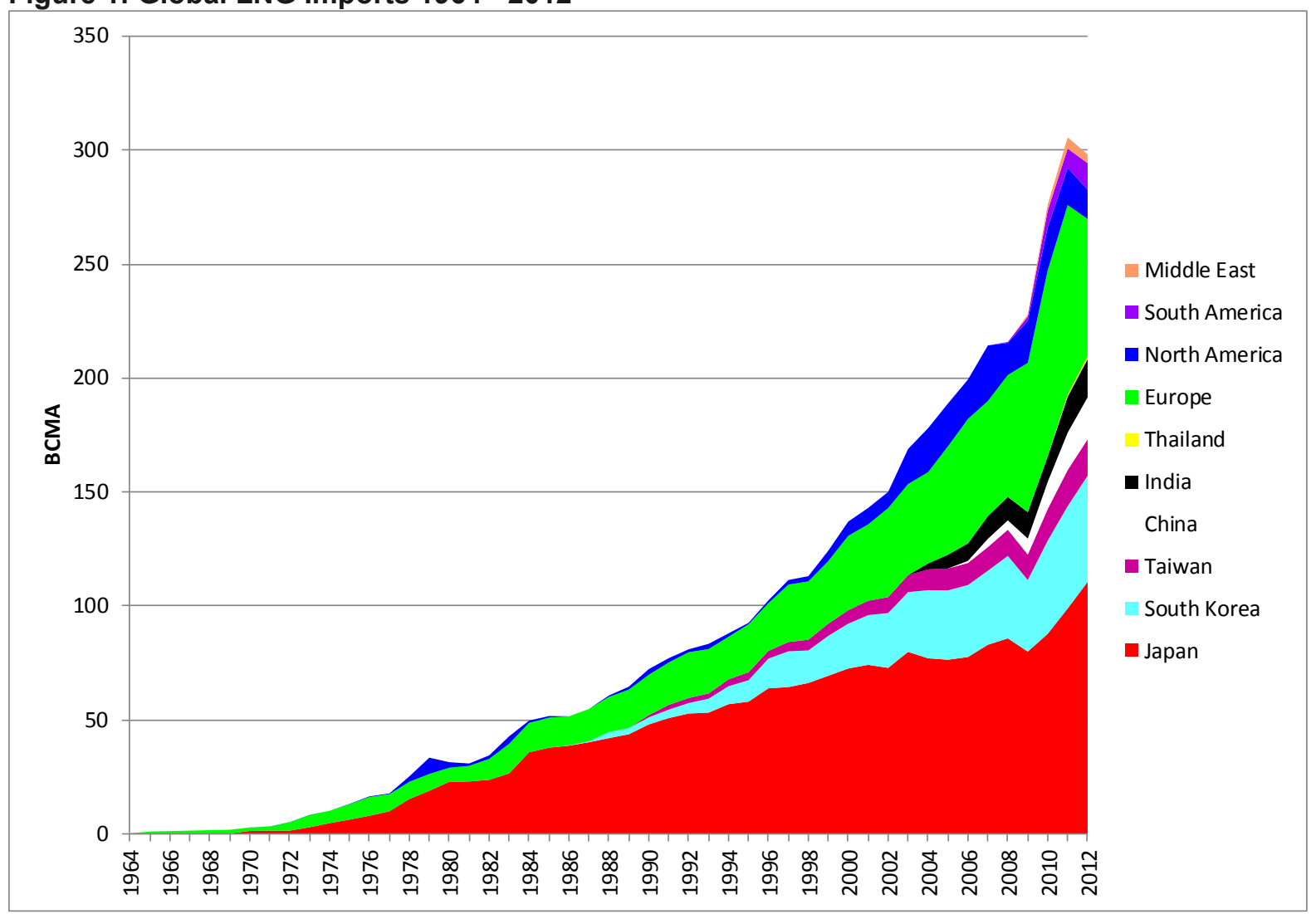

Source: Cedigaz various issues, GIIGNL (2012).

The pattern of global LNG imports from 1964 to 2012 is shown in Figure $1 .{ }^{5}$ While the UK and France were the first importers of LNG in the 1960s, Asia has dominated global LNG trade since the late 1970s. Although Asian LNG imports were reduced in 2009 in the aftermath of the 2008 financial crisis (with LNG surplus to Asia's requirements flowing to Atlantic Basin markets), demand recovery in 2010 was remarkably rapid. As a consequence of the Fukushima disaster, Japanese LNG imports increased significantly in 2011 and 2012. ${ }^{6}$

Figure 2 places LNG trade-flows in the context of global supply. While in excess of $80 \%$ of natural gas production continues to be consumed within national or adjacent markets, 'inter-regional pipeline gas $^{, 7}$ and LNG rose from $11 \%$ of total consumption in 1995 to $17.2 \%$ in 2012 . While inter-regional

\footnotetext{
${ }^{5}$ For a description of the development of the global LNG market in the late 1990 s and early 2000 s see Jensen (2004), Chapter 1.

${ }_{7}^{6}$ Miyamoto et al. (2012).

7 "Inter-regional" is defined as pipeline gas which crosses regional and/or economic trading bloc gas market boundaries (although this is a problematic geographical construct which does not necessarily reflect the distance which the gas travels). Where contiguous markets share the same broad market regulatory framework with a view to encouraging bi-directional gas trade-flows, their cross-border trade is excluded from this segmentation.
} 
pipeline gas as a share of total consumption has declined since 2005, LNG has grown to some $10 \%$ of total consumption.

Figure 2: Share of LNG and Inter-Regional Pipeline Gas in Global Gas Supply Flows 1995 2012

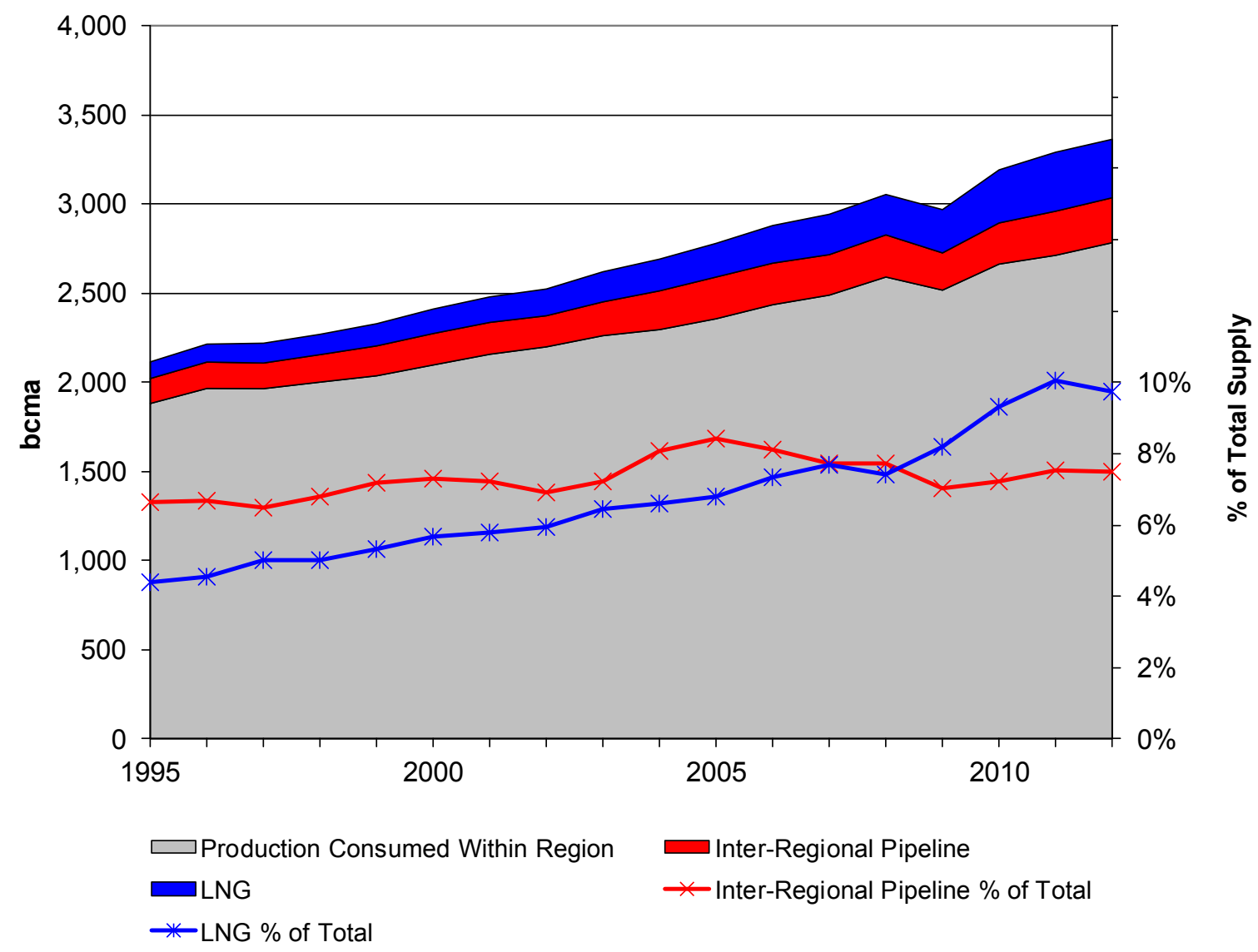

Source: BP (2013).

By the 2000s, LNG was contributing to natural gas supply requirements in an increasing number of regions around the world (Figure 1). But since 2000, different consumption growth trends, and the impact of unforeseen supply and demand side events, have progressively induced flexibility into LNG trade-flows. At the beginning of the 2000s, the prevailing paradigm of LNG project investors was to deliver LNG over the term of the contract to specified destination markets. ${ }^{8}$ The buyer (in the majority of cases an incumbent mid-stream gas and/or power generation utility) would sell the gas (or power produced from it) to its (largely captive) customer base. In the majority of Pacific LNG contracts there was little or no destination flexibility i.e. the LNG had to be delivered to the market specified in the contract.

\footnotetext{
${ }^{8}$ Investment in an LNG project is typically undertaken on the basis of a long-term contract with a buyer (or group of buyers) with a minimum take-or-pay requirement and a pricing formula. While, in common with long-term pipeline gas contracts, LNG contracts have a specified Annual Contract Quantity (ACQ), Take or Pay provisions are not normally expressed as a percentage of ACQ put rather in terms of a 'downward tolerance' of typically $10 \%$ of the $A C Q$.
} 

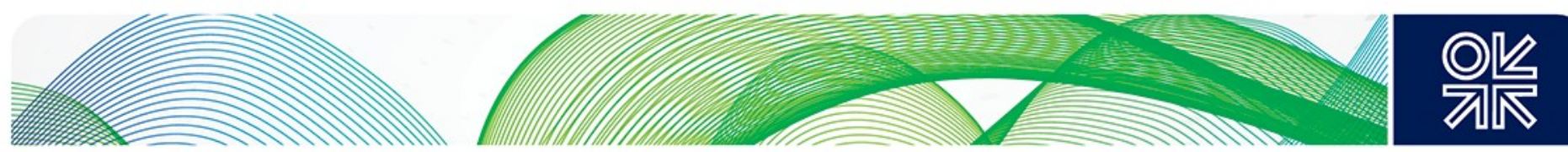

In the early 2000s, US gas production began to decline and LNG imports rose from $6.6 \mathrm{Bcm}$ in 2001 to $17.9 \mathrm{Bcm}$ in $2005^{9}$. In Europe, demand growth in the period up to 2005, particularly in Southern Europe, supported the growth of LNG imports notably into Spain. This period saw some arbitrage activity between Europe and the US, as cargoes were diverted from Europe to the US and 'backfilled' by pipeline imports from Russia, where this was possible within the constraints of long term contracts. In the mid to late 2000s, the development of LNG arbitrage was stimulated by supply-demand imbalances affecting one or more regions. The first was the 'tightening' of the Asian LNG market due to the following factors ${ }^{10}$ :

- The under-performance of Indonesian LNG exports notably from 2003 onwards.

- The continuing rapid growth in Asian natural gas demand.

- The slippage of new LNG supply project start-up dates.

- Recurring Japanese nuclear generation problems requiring increasing usage of gas-fired units $^{11}$.

The resulting high Asian LNG spot prices from 2006 to 2008 attracted flexible cargoes away from the Atlantic Basin, and induced sellers and European buyers of LNG under long term contracts to negotiate additional flexibility into commercial arrangements in order to share the benefits of arbitrage. Figure 3 shows global LNG trade-flows in the period 2004-13. The green area above the axis represents Atlantic Basin-sourced LNG delivered to Atlantic Basin Markets. The blue area represents Pacific Basin LNG delivered to Pacific Basin markets. The yellow area above the axis represents Middle East LNG delivered to Atlantic Basin Markets, and the yellow area below the axis shows Middle East-sourced LNG delivered to Pacific Basin Markets. The green area below the axis represents Atlantic Basin-sourced LNG delivered to Pacific Basin markets. For the 'tight' period for Asian LNG markets from 2006-08, relatively little Middle Eastern LNG reached Atlantic Basin Markets; and significant volumes of Atlantic Basin LNG were drawn into the Pacific Basin reaching a maximum in March 2008.

\footnotetext{
BP (2013).

${ }_{11}^{10}$ For wider context see Rogers (2010), pp. 26 - 33

${ }^{11}$ These include the shutdown of the 8.2GW Kashiwazaki Kariwa plant following earthquake damage in 2007.
} 

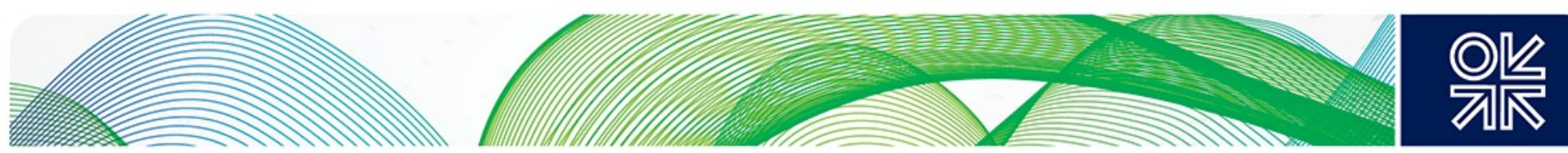

Figure 3: Regional LNG Sources and Destinations by Month $2004-2013$

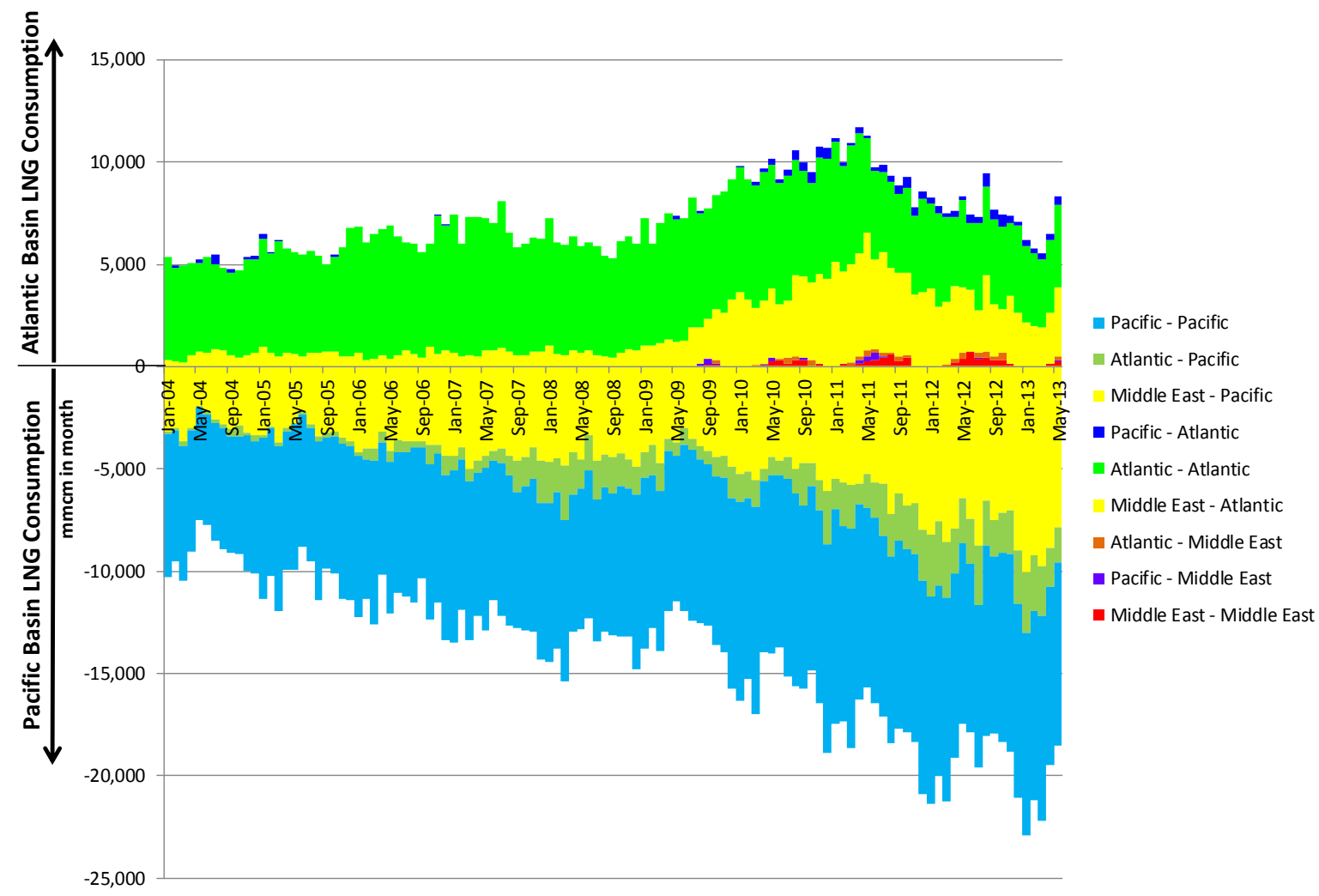

Source: Waterborne LNG Reports

The financial crisis of 2008 , and resulting impact on economic activity in all regions saw a $4.5 \%$ fall in LNG demand in Asia in 2009 (relative to 2008) and the reduced consumption of Atlantic Basin and Middle East-sourced LNG in Asia can be seen in Figure 3. Although Asian LNG demand recovered rapidly, there was a surge of supply as the new Qatari trains came on stream in mid-2009, reaching full capacity in 2011 (in addition to projects in Yemen, Sakhalin and Indonesia). Some of these volumes were originally intended for the US market where, by 2012, some $183 \mathrm{Bcma}{ }^{12}$ of LNG import capacity had been built. The requirement for US LNG imports was undermined from 2006 onwards by the unforeseen growth in shale gas production, such that US LNG imports, which had been expected to reach $70 \mathrm{Bcm}$ by 2010 , were reduced from nearly $18 \mathrm{Bcm}$ in 2005 to $4.2 \mathrm{Bcm}$ in $2012 .^{13}$ The net consequence of these dynamics was a boost in LNG deliveries to Europe during 2009-11. Gas demand was low in both 2009 and 2011, (Figure 4), so that these European LNG imports resulted in a reduction in pipeline imports (mainly from Russia), despite the increase in 2010 demand due to abnormally cold weather.

\footnotetext{
${ }^{12}$ GIIGNL (2012), p.28.

${ }^{13}$ In 2011 and 2012 US LNG net imports reduced to 7.9 and 4.2 Bcm respectively. GIIGNL (2012).
} 
Figure 4: European Supply, Demand and Imports 2008 - 2012

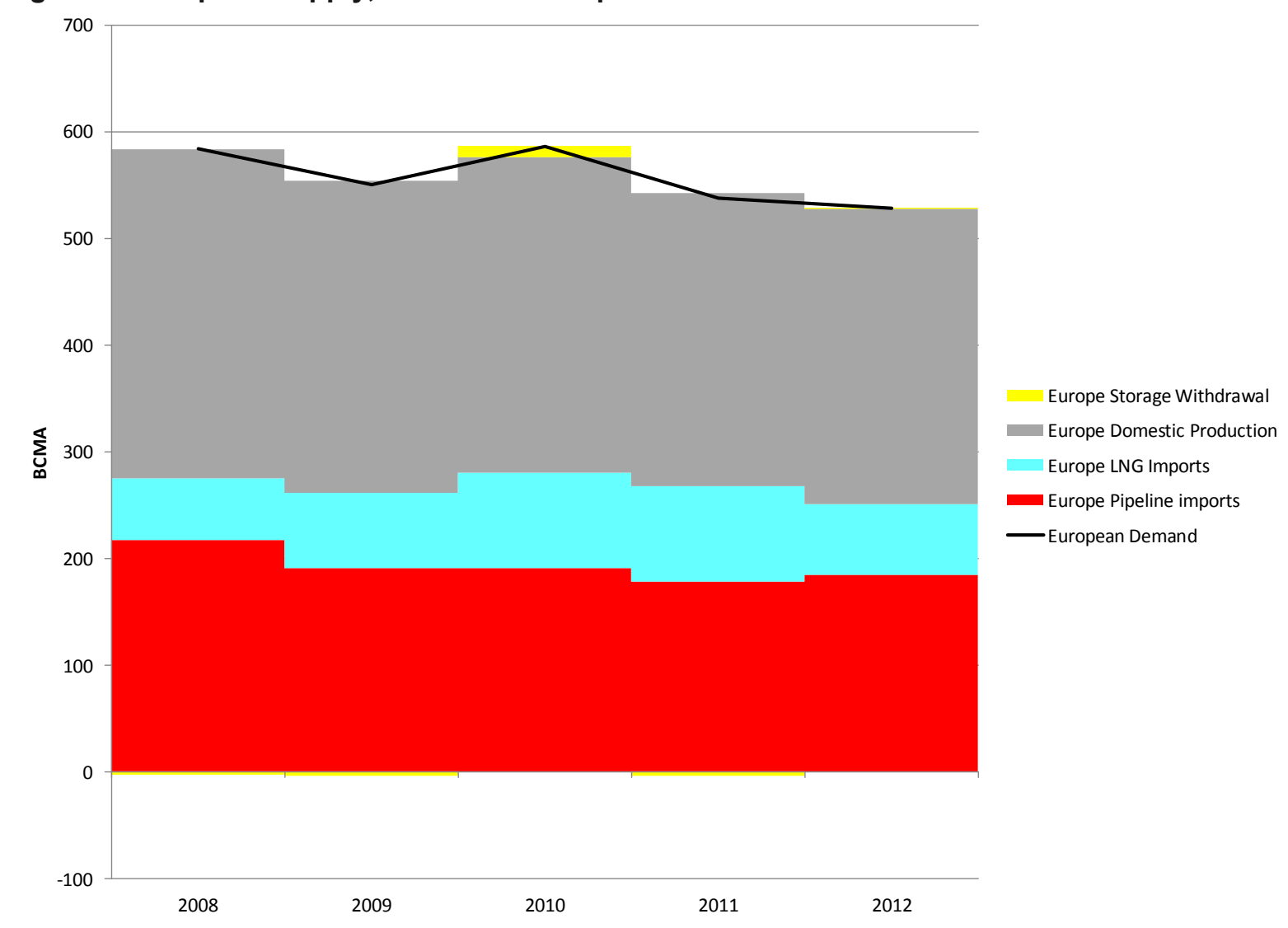

Source: IEA Monthly Gas Survey, IEA Statistics, Waterborne LNG, Author's analysis

From Figures 3 and 4 it is apparent that from 2011 onwards, growth in Asian LNG consumption has resulted in LNG being re-directed away from Europe. The period 2009-12 demonstrated that Russia, with its European supply delivery system geared to responding to buyer-nominated contract quantities (subject to take or pay minima) and growing surplus production capacity, has become the 'shockabsorber' of an increasingly 'globally-connected' system. ${ }^{14}$ Price of course is the prime motivator which provides the incentive for new supply development, and for LNG arbitrage between different markets. 


\section{Chapter 2. Gas demand trends and drivers for change in Asian LNG markets}

\subsection{Asian gas demand and the impact of Fukushima}

Table 1 shows regional natural gas consumption growth in the Asia/Pacific region for the period 200012. Demand growth for gas in the region during this period averaged $6.6 \% / y e a r$ (a rate only exceeded by the Middle East and Africa). ${ }^{15}$ There is a wide range of market sizes and consumption growth rates, as shown in Table 1. Japan, which is almost exclusively supplied by LNG, achieved a consumption level of some $95 \mathrm{Bcma}$ prior to Fukushima, but growth slowed significantly in the late 2000s. From 2010 to 2012, demand increased by $22 \mathrm{Bcm}$ (or 23\%) ${ }^{16}$ which can be attributed to the closure of the nuclear stations post-Fukushima. South Korea and Taiwan, also lacking either significant domestic production or pipeline imports have shown steady consumption growth of $8.4 \% / y e a r$ over the period. Chinese natural gas consumption has grown by a factor of five since 2000, supplied by domestic consumption and by pipeline imports from Turkmenistan (from 2010) and Myanmar (from 2013), and by LNG from a variety of sources since 2006. India, supplied by domestic production and LNG (since 2004) has seen consumption growth of $6.3 \%$ on average since 2000 but this has declined since 2010. During 2010-12, Japan and China accounted for $86 \%$ of natural gas demand growth in Asia.

Table 1: Asia/Pacific National Natural Gas Consumption (Bcma) and Compound Annual Average Growth \%

\begin{tabular}{|c|c|c|c|c|c|c|c|c|c|c|c|c|c|c|}
\hline & 2000 & 2001 & 2002 & 2003 & 2004 & 2005 & 2006 & 2007 & 2008 & 2009 & 2010 & 2011 & 2012 & CAGR \% \\
\hline Japan* & 72 & 74 & 73 & 80 & 77 & 79 & 84 & 90 & 94 & 87 & 95 & 106 & 117 & $4.1 \%$ \\
\hline South Korea* & 19 & 21 & 23 & 24 & 28 & 30 & 32 & 35 & 36 & 34 & 43 & 46 & 50 & $8.4 \%$ \\
\hline Taiwan* & 6 & 7 & 7 & 8 & 9 & 9 & 10 & 11 & 12 & 11 & 14 & 16 & 16 & $8.4 \%$ \\
\hline China* & 28 & 30 & 32 & 36 & 42 & 49 & 59 & 73 & 84 & 93 & 111 & 134 & 147 & $15.0 \%$ \\
\hline India* & 26 & 26 & 28 & 30 & 32 & 36 & 37 & 40 & 41 & 51 & 62 & 61 & 55 & $6.3 \%$ \\
\hline Thailand* & 22 & 25 & 27 & 29 & 30 & 33 & 33 & 35 & 37 & 39 & 45 & 47 & 51 & $7.3 \%$ \\
\hline Australia ** & 21 & 22 & 22 & 22 & 23 & 22 & 24 & 27 & 26 & 25 & 26 & 26 & 25 & $1.8 \%$ \\
\hline Bangladesh & 10 & 11 & 11 & 12 & 13 & 14 & 15 & 16 & 17 & 19 & 20 & 20 & 22 & $6.7 \%$ \\
\hline Indonesia ** & 30 & 31 & 33 & 35 & 32 & 33 & 33 & 31 & 33 & 37 & 40 & 37 & 36 & $1.6 \%$ \\
\hline Malaysia ** & 24 & 25 & 26 & 27 & 25 & 31 & 34 & 33 & 34 & 33 & 34 & 32 & 33 & $2.7 \%$ \\
\hline New Zealand & 6 & 6 & 6 & 4 & 4 & 4 & 4 & 4 & 4 & 4 & 4 & 4 & 4 & $-2.4 \%$ \\
\hline Pakistan & 22 & 23 & 25 & 30 & 34 & 36 & 36 & 37 & 38 & 38 & 40 & 39 & 41 & $5.6 \%$ \\
\hline Philippines & 0 & 0 & 2 & 3 & 2 & 3 & 3 & 3 & 3 & 3 & 3 & 4 & 3 & $60.9 \%$ \\
\hline Singapore* & 0 & 1 & 4 & 4 & 5 & 7 & 7 & 9 & 8 & 8 & 8 & 9 & 8 & $105.1 \%$ \\
\hline Vietnam & 2 & 2 & 2 & 2 & 4 & 6 & 7 & 7 & 7 & 8 & 9 & 8 & 9 & $15.9 \%$ \\
\hline Other Asia Paci & 4 & 4 & 4 & 4 & 5 & 5 & 5 & 6 & 6 & 5 & 6 & 6 & 6 & $4.1 \%$ \\
\hline Total & 290 & 308 & 324 & 351 & 366 & 397 & 424 & 457 & 480 & 497 & 560 & 594 & 625 & $6.6 \%$ \\
\hline
\end{tabular}

Note: *LNG importers in 2012, ** LNG exporters in 2012

Source: BP (2013), Gas Consumption Worksheet

\footnotetext{
${ }^{15}$ BP (2013), Gas Consumption Worksheet, http://www.bp.com/en/global/corporate/about-bp/statistical-review-ofworld-energy-2013/statistical-review-downloads.html

${ }^{16}$ Note that one Japanese source estimates the increase to be $25 \mathrm{Bcma}$ compared to LNG levels just prior to Fukushima: http://eneken.ieej.or.jp/data/4703.pdf, p.3
} 
Figure 5: Illustrative LNG Demand for the Five Main Asian Importers 2010 - 2025

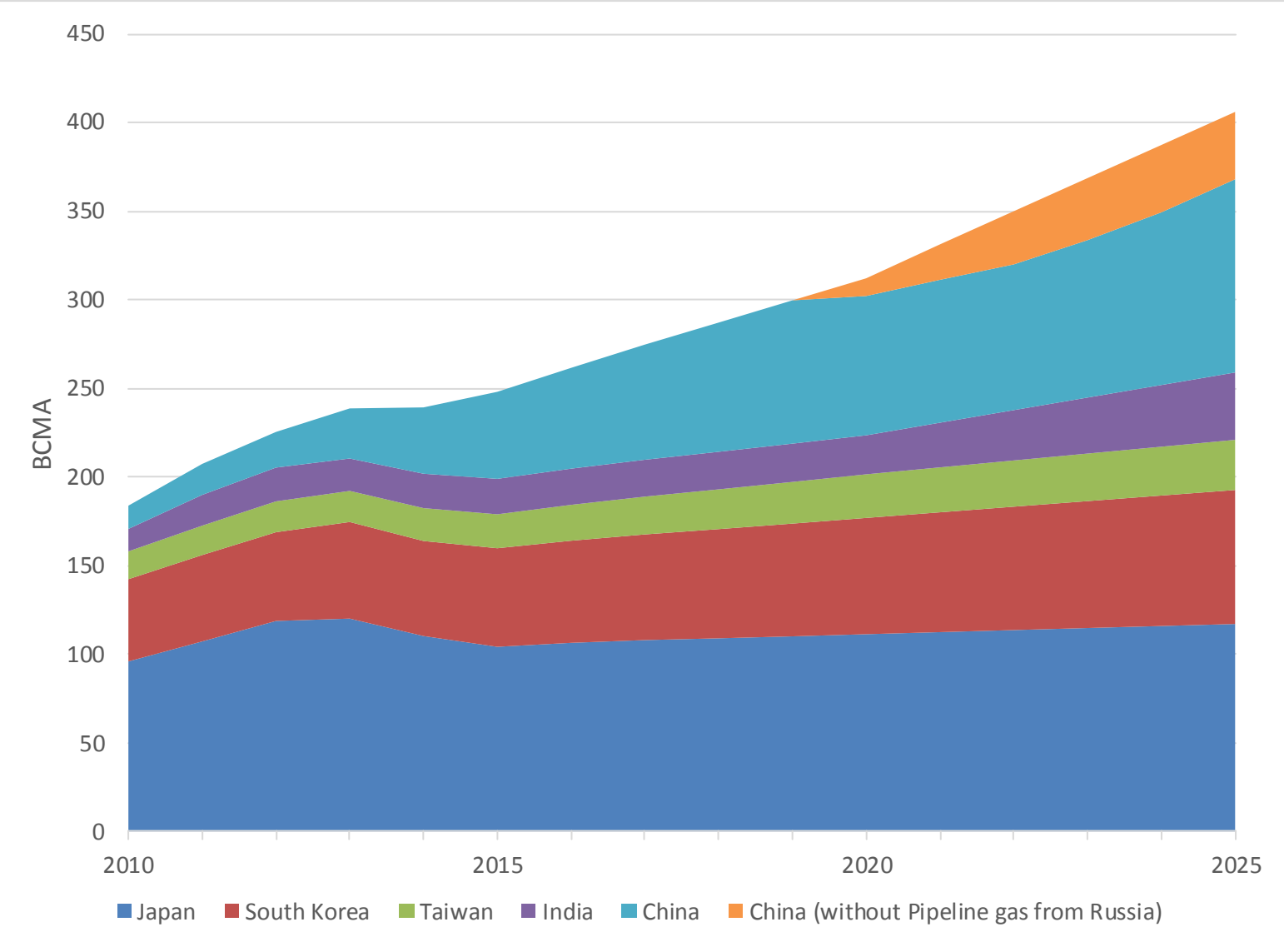

Sources: Waterborne LNG, IEA Monthly Gas Survey, IEA Statistics, IEA (2011) Author's estimates.

Figure 5 shows actual (2010-12) and illustrative future Asian demand for the five main Asian LNG importers to 2025 , based broadly on the IEA's 'Golden Age of Gas' Scenario. ${ }^{17}$ Japan's LNG requirements are assumed to reduce during 2014 and 2015 as nuclear plants are restarted, although the scope and timing of these are at present unclear. The most significant demand growth is that of China. This is subject to wide uncertainties, including natural gas demand overall, the potential for growth in domestic production including coal bed methane and shale gas, the upside in pipeline imports from Central Asia and whether agreement is reached for pipeline imports from Russia.

The impact of the Fukushima disaster and subsequent closure of nuclear power stations on the Japanese power generation fuel mix is shown in Figure $6 .{ }^{18}$

\footnotetext{
${ }^{17}$ The basis for deriving future LNG demand requirements is as set out in Rogers (2012) and (2012a). The domestic natural gas production and demand assumptions, where available, were taken from IEA (2011). The subsequent revised projections in the IEA World Energy Outlook 2013 New Policies Scenario are not significantly different for the purpose of this illustrative analysis. Projections from this later report would, on a 'like for like basis', reduce import requirements of Japan, China and India in aggregate by 9 Bcm in 2020 and 15 Bcm in 2025 compared with the assumption on which this paper's analysis is based, detailed in Appendix 4.

${ }^{18}$ For a comprehensive and incisive review of the impact of the Fukushima on Japanese energy infrastructure, energy rationing/conservation, energy policy and outlook see Miyamoto et al. (2012).
} 


\section{Figure 6: Estimated Japanese Power Generated in 2010 and 2011 (10 EPCOs $\left.{ }^{19}\right)$}
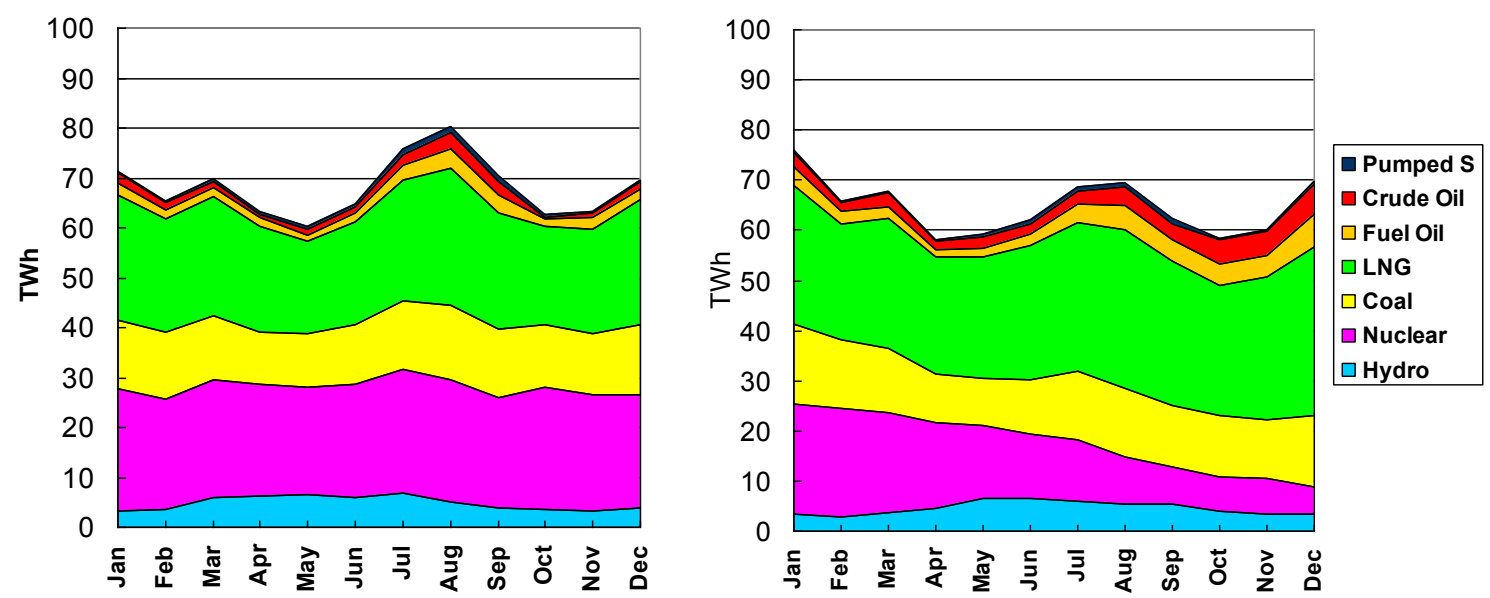

Source: Miyamoto et al. (2012), Figure 9, p.16.

Figure 6 clearly shows the decline of nuclear generation (purple) as all nuclear plants were progressively shut down during 2011-12, and partially compensated by the increase in LNG as power generation fuel (green). ${ }^{20}$ The consequent financial impact of the loss of low cost nuclear, in addition to the additional LNG supplies required (and in turn the impact on spot prices), was severe for the Japanese power generating companies.

Figure 7 highlights the financial impact of the shift from nuclear to LNG-fuelled power generation on the ten largest Japanese power generation companies. From an aggregate 'normal year' profit of $\$ 5$ billion, in FY 2011 and 2012 the companies collectively generated a loss of over $\$ 10$ billion excluding Tokyo Electric (TEPCO) and some $\$ 20$ billion including TEPCO. ${ }^{21}$ In the wake of the closure of nuclear power stations, the regulation of the costs which Japanese power utilities (EPCOs) are allowed to pass through to end-users, has severely impacted their financial position, and notice has been given by government that such limits could become more stringent. ${ }^{22}$

\footnotetext{
${ }^{19}$ Electric Power (Generating) Companies

20 Two reactors subsequently reopened in 2013 but were closed again for maintenance later that year.

${ }^{21}$ The TEPCO financial situation includes the company's expenditure on the Fukushima nuclear disaster and is thus not comparable to that of the other utilities.

${ }^{22}$ Electricity cost pass through is regulated by a combination of two methods: "total cost in service" which is set for a defined period; and "adjustment of fuel costs" which allows for automatic adjustments of costs due to exchange rate and fuel price (such as crude oil price) fluctuations, but which is based on the generation capacity of each EPCO and has an upper limit. The shut-down of nuclear capacity removed low cost generating capacity thereby increasing the generating cost for EPCOs. At the same time the increase in fuel prices exceeded the upper limit of the allowed fuel cost adjustment.
} 
Figure 7: Annual Net Profit/Loss for the 10 Largest Japanese Electric Power generating Companies.

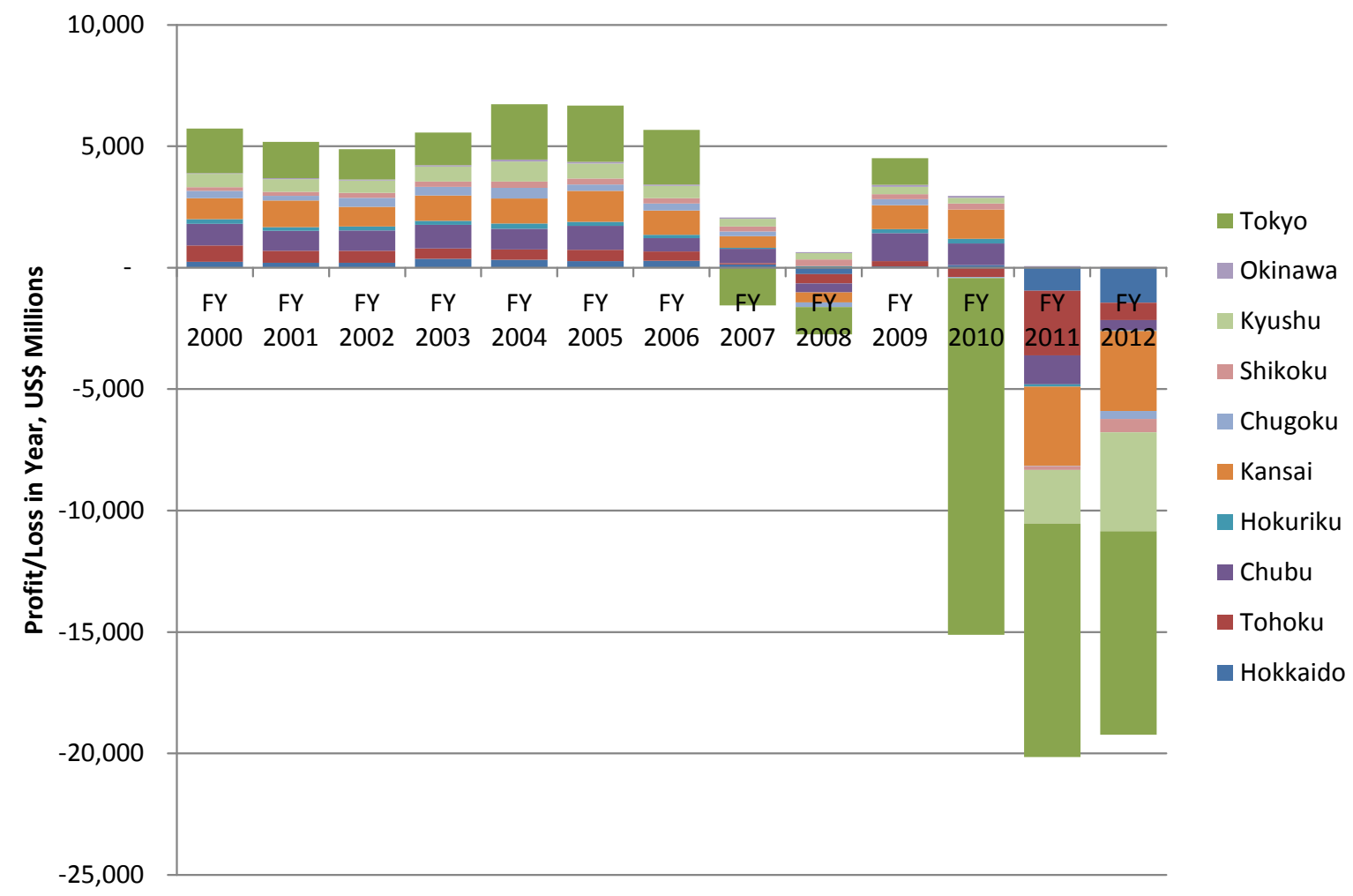

Notes: The names of the companies refer to the electric utilities in the respective regions. Hence Tokyo is Tokyo Electric (TEPCO). The Japanese fiscal year (FY) commences on April 1 and ends on March 31 of the following calendar year.

Source: The Federation of Electric Power Companies of Japan, http://www5.fepc.or.jp/tok-bin-eng/kensaku.cgi

It is generally assumed that, following approval by the new regulatory authority, a significant proportion of Japan's nuclear plant will be re-started in 2014-15, although ongoing problems of radioactive-contaminated water at the Fukushima reactor in 2013 may impact negatively on these prospects. The difference between a complete Japanese nuclear shutdown and reopening of around half of the 54 reactors, which is believed to be acceptable to both regulators and the general population, could equate to $15-20 \mathrm{Bcm} /$ year of gas demand, given that demand increased by some 22 Bcma during $2010-2012 .^{23}$

\subsection{LNG import prices in Japan, South Korea, Taiwan and China}

Figure 8 shows monthly average LNG prices for imports into Japan, South Korea, Taiwan and China $^{24}$. These prices include LNG imported under long term contracts and spot cargoes. The trends for Japan, South Korea and Taiwan are broad similarity although the higher average price paid by Japan post Fukushima (March 2011) perhaps reflects its position of 'distressed buyer' for spot cargoes during this period. China's lower LNG import prices throughout the period reflect advantageous contract terms signed with Australia and Indonesia in the early 2000s which depress

\footnotetext{
${ }^{23}$ But there is a view that restarting nuclear reactors will, initially at least, have little impact on LNG demand as utilities will prioritise shutting down old inefficient oil-fired plant for which prices are higher than for LNG.

${ }^{24}$ Note that a continuous series for Indian import prices was not available from this source.
} 
monthly average prices by some $\$ 3-4 / M M B t u$ compared to the other three importers. Chinese average LNG prices rose above \$10/MMBtu only as recently as mid-2011 and in 2013 were around \$11/MMBtu.

Figure 8: LNG Average Monthly Import Prices

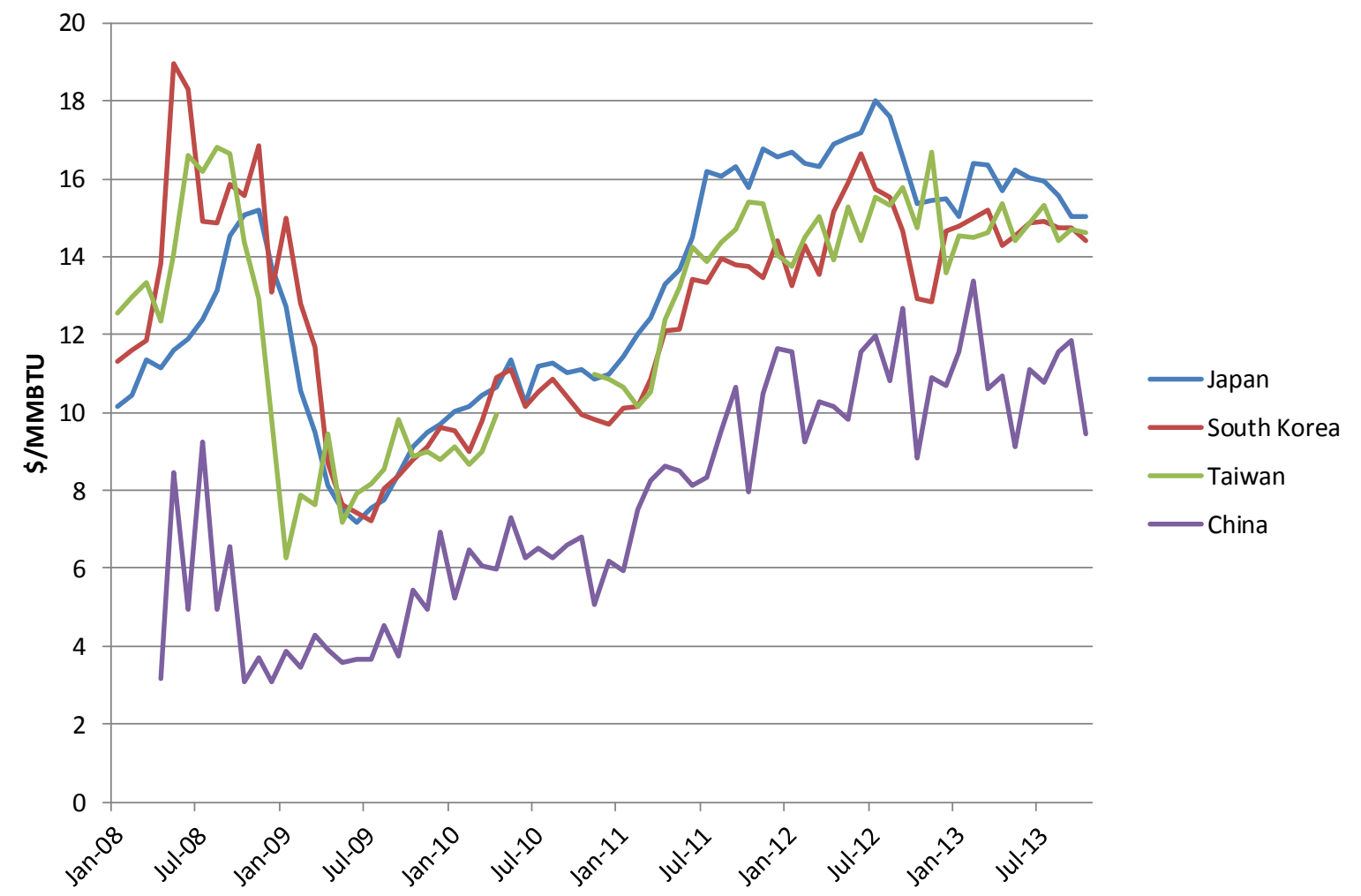

Source: Argus Global LNG

\subsection{Asian spot price development post 2008}

The astonishing rebound in Asian LNG demand which occurred in 2010 was not widely foreseen and the expectation was that LNG which could not be absorbed by Asia and Europe would 'overspill' into the US as the market of last resort. This explains the similar levels of Henry Hub and NBP prices in 2009 (Figure 9). In the event, two abnormally cold periods in Europe at the beginning and end of 2010, together with the Asian LNG demand rebound, ended this situation and prices subsequently diverged. The gap between American and all other prices was particularly striking as the Henry Hub price remained below \$4/MMBtu for most of the two years to September 2013.

In Figure 9, the average Japanese LNG price (blue) is the average of some $60^{25}$ individual JCC-linked contracts, all of which have differing formulaic linkages with crude oil prices and spot cargo deliveries. The direct, lagged, relationship to Brent crude prices is evident. Oil prices recovered to $\$ 100 / \mathrm{bbl}$ plus by 2011 , and subsequently Asian LNG contract prices have remained at historic high levels.

\footnotetext{
${ }^{25}$ Based on analysis of the GIIGNL dataset (for details see Chapter 4).
} 
Figure 9: Regional Gas Prices January 2007 - December 2013 (Monthly Averages)

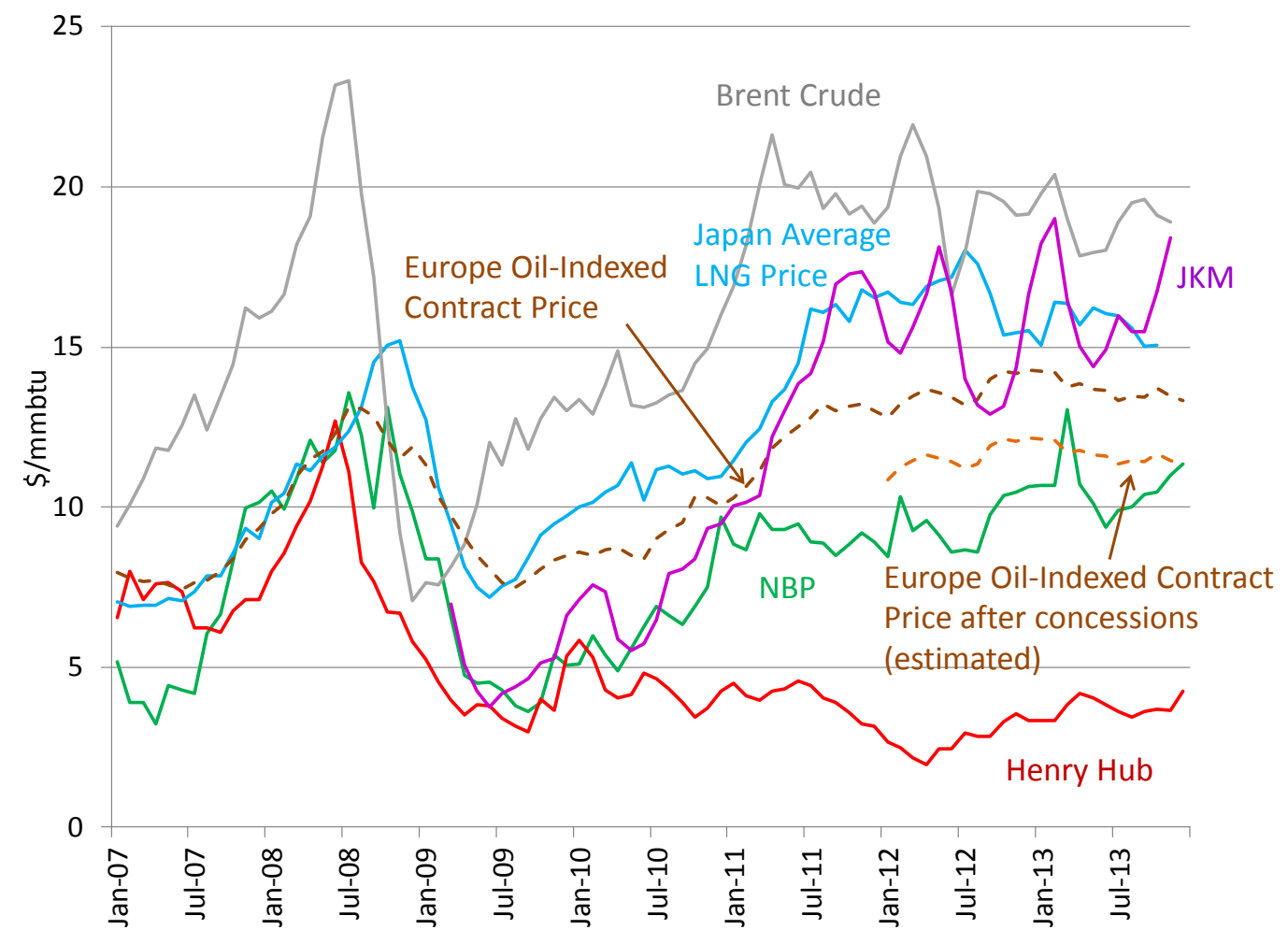

Sources: Rogers: OIES

The purple line in Figure 9 is the Asian LNG spot and short-term contract price - specifically the Platts JKM (Japan Korea Marker) price ${ }^{26}$. Prior to the Fukushima disaster in March 2011, JKM appeared to closely track NBP levels. Although there are differing views on the market dynamics in this timeframe, this price pattern would be consistent with a model where the marginal flexible LNG supplier (be it a Middle East or African LNG exporter) had similar shipping costs to Japan/South Korea and North West Europe. Shortly after Fukushima the additional LNG import requirements of Japan (in addition to continuing LNG demand growth elsewhere in Asia) were reflected in much higher spot price levels. By mid-2013 JKM reached levels similar to the Japan average LNG price, although with considerable volatility. ${ }^{27}$

There are two possible explanations for the escalation and maintenance of the JKM price level significantly above NBP in this period, in contrast to the situation prior to March 2011:

The Discriminating Monopolist Hypothesis ${ }^{28}$ : This economic construct describes the situation where a monopolist (or equally a like-minded oligopoly) has the freedom to distribute its supply between a high price, high price elasticity market (Asia) and a lower priced, lower price elasticity market (Europe). Its optimal solution is to restrict supply to the high price market (Asia) to secure higher margins. Diversion of a greater quantity from the low price market (Europe) would significantly reduce the premium market price (Asia) with little

\footnotetext{
${ }^{26}$ For a discussion of JKM see Chapter 5

${ }^{27}$ For LNG regional supply dynamics see Figure 3; for further discussion of these trends see Flower and Liao (2012) pp.353 - 356.

${ }^{28}$ For details see Allsopp and Stern (2012).
} 
compensating increase in the European market price. This is a plausible explanation. Redirecting LNG volumes from Europe to Asia would invite back-filling with Russian pipeline gas at just a $\$ 2.00-\$ 2.50 /$ MMBtu premium $^{29}$ with the risk of collapsing the NBP - JKM spread from $\$ 5$ to $\$ 6 / \mathrm{MMBtu}$, down to perhaps \$1/MMBtu, over European prices.

The Inertia Hypothesis: It may be however that, given the limitations dictated by contractual commitments and diplomatic/political constraints of European buyers and importing nations, and the logistical challenges involved, the pace of re-direction to Asia from Europe post Fukushima was effectively the most rapid possible.

Whatever the intent of sellers re-directing cargoes from Europe to Asia, it is clear from the levels of JKM relative to NBP that the negotiating position changed from possibly that of 'original market price plus incremental shipping cost plus a modest premium', to that of broad parity with the prevailing average Asian JCC contract prices- i.e. a shift from a buyer's to a seller's market.

Another observation to make about the JKM trend is the pronounced oscillation from mid 2011 onwards, albeit around high price levels relative to NBP. These fluctuations tend to reflect media commentary of high or low spot cargo procurement activity in the Asian market, often driven by forward assessments of winter space heating or summer air conditioning power generation demand for LNG. The extent to which JKM is a problematic indicator because of a 'shallow' Asian LNG spot market and/or low price reporting coverage, will be discussed in Chapter 5 below, but the next chapter looks at the growth of spot and short term LNG trading, particularly in Asia.

\footnotetext{
${ }^{29}$ Based on the difference between NBP and the post-concession European oil-indexed price post 2011.
} 


\section{Chapter 3. The evolution of natural gas price formation: establishing market fundamentals for Asian LNG imports}

\subsection{Natural gas price formation}

North America

In the 1980s, the US was the first country in the world, followed closely by Canada, due to the interlinkage of the two markets, to move to spot pricing at a hub (generally known as "market pricing") by removing regulation of upstream and midstream pricing and liberalising access to pipelines - a process which created the term "deregulation". Once market pricing had been established, on the basis of Henry Hub spot and (after 1990) NYMEX futures prices, it was not commercially feasible for any supplies - domestic or imported - to be delivered on any other price basis. ${ }^{30}$ This meant the end of long term contracts and currently that term applies in North America to any commercial agreement in excess of one year.

North American gas deregulation led to more than a decade of low, market-related prices in the $\$ 2$ $3 /$ MMBtu range which finished at the end of the 1990s. From then until the mid-2000s, US gas prices fluctuated wildly, exceeding $\$ 12 / M M B t u$ in early 2006 and again in early 2008, until the unconventional (principally shale) gas era, ushered in a period of lower prices which during 2012-13 were in the range of $\$ 2-4.20 / \mathrm{MMBtu}^{31}$

North American gas prices are driven primarily by the supply and demand fundamentals of the domestic gas market. Prior to 2006 and for a brief period in 2008 power generation fuel switching introduced a degree of price correlation between natural gas and oil products. From the end of 2011 through 2013 the substitution of coal by gas in the US power sector also provided a 'soft floor' for natural gas prices. At Henry Hub prices above $\$ 4 / \mathrm{MMBtu}$ it is likely that displacement of gas by coal in power generation will slow price recovery although this is expected to be mitigated by the closure of old coal generation plant.

In anticipation of US LNG export projects from 2015 onwards, there has been much discussion of the future impact on domestic US prices due to varying export volumes. Whilst this has generated much debate and analysis it should be recognised that forecasts of the speed and extent of any associated price rise are the subject of many assumptions. ${ }^{32}$ Even with no LNG exports from the US, gas prices would eventually have to rise to the long run marginal cost of dry shale gas production to meet demand requirements, estimated to be in the range $\$ 5-7 / \mathrm{MMBtu}^{33}$.

\footnotetext{
${ }^{30}$ Foss (2012).

${ }^{31}$ Foss (2007), (2011) and (2012). In 2012 prices were mostly in the $\$ 2.00-3.50 /$ MMBtu range; in 2013 the range was $\$ 3.50-4.00 / \mathrm{MMBtu}$ but rising towards $\$ 4.50 / \mathrm{MMBtu}$ at the end of the year.

${ }^{32}$ Including: future development costs, momentum of industry drilling and development, quality and investment economics of shale resources outside play 'sweet-spots' and the relative volumes of 'wet' and dry shale gas production.

See Henderson (2013). For a more detailed analysis of North American LNG exports and their potential impact on global dynamics see Rogers (2012).
} 


\section{Europe $^{34}$}

The UK market liberalised during the 1990s and by the end of that decade had created the National Balancing Point (NBP), a hub with a reference price across the whole country. In the UK, as in North America, traditional long term take or pay contracts disappeared as liberalisation advanced. Centrica has subsequently signed one or two import contracts of up to 10 years, but in general contracts are of much shorter duration and all are priced at the NBP.

Continental Europe began the 2000s with a commercial structure dominated by long-term (15-25 year) oil indexed contracts for pipeline and LNG imports, and also for domestic production. The price of pipeline gas purchased under long term contracts was (largely) based on gasoil and fuel oil prices and indexed to a lagged six to nine month average of those prices. ${ }^{35}$ The buyer committed to purchase the 'Take or Pay' (TOP) quantity within a contract year (usually running from October to September of the following calendar year). The TOP level was typically $85 \%$ of the Annual Contract Quantity (ACQ). A similar approach was taken in long term LNG contracts in Continental Europe.

In the six major Continental European gas markets, the rationale for continued linkage of long-term contract gas prices to those of oil products began to weaken during the 1990s, a process which continued during the 2000s. ${ }^{36}$ Its original rationale - that end-users had a real choice between burning gas and oil products, and would switch to the latter if given a price incentive to do so - was robust when the netback market pricing mechanism (largely) based on oil product-linkage was established in the 1970s (and earlier in some countries). But a combination of:

- the virtual elimination of oil products from the stationary energy sectors in these markets;

- the cost and inconvenience of maintaining oil-burning equipment and substantial stocks of oil products;

- the emergence of modern gas-burning equipment in which the use of oil products means a substantial loss of efficiency;

- tightening environmental standards in relation to emissions, particularly sulphur content and nitrogen oxide;

rendered the original rationale increasingly dubious, particularly in North West Europe. ${ }^{37}$ There is no commercial scenario in which users installing new fuel-burning equipment will choose to use oil products rather than gas in stationary uses, unless they have no access to a gas supply.

The impact on European gas demand of the post 2008 recession, coupled with an increase in renewable energy generation, and the arrival of significant volumes of LNG created severe financial problems for the European mid-stream utilities who were obliged to purchase gas under long term contracts priced on a formula linked to oil products. The development, and increase in liquidity, of

\footnotetext{
${ }^{34}$ As defined for the purpose of modelling in this paper Europe includes: Austria, Belgium, Bulgaria, Croatia, Czech Republic, Denmark, Estonia, Finland, France, Germany, Greece, Hungary, Ireland, Italy, Latvia, Lithuania Luxembourg, Netherlands, Norway, Poland, Portugal, Romania, Serbia, Slovakia, Slovenia, Spain, Sweden, Switzerland, Turkey, UK.

${ }^{35}$ For the history of this mechanism and its logic see Stern (2012), pp.54-59.

${ }^{36}$ Stern (2007) and (2009); the six markets are: Germany, France, Netherlands, Belgium, Italy and Spain.

37 The position of some smaller markets, especially in South Eastern Europe, is different as they are still burning significant quantities of oil in stationary sectors and have retained greater switchable capacity, see Kovacevic (2007) and Giamouridis and Paleoyannis (2011).

${ }^{38}$ However, they may choose to use other alternatives to gas, with the main battleground being in power generation between gas, coal and low carbon (renewable and nuclear) sources. But none of these sources will have prices set in relation to oil products.
} 
trading hubs across the Continent was boosted by the arrival of large volumes of hub-priced LNG imports, the impact of unbundling and third party pipeline access ${ }^{39}$ and court rulings which ended the obligation of end-users to buy gas from midstream utilities on a multi-year, oil-linked pricing basis ${ }^{40}$.

With European hub prices $25-35 \%$ below oil-indexed contract levels during 2011-13, mid-stream utilities were faced with unsustainable financial exposure in their gas trading operations, and a series of price re-negotiations with upstream sellers and international arbitrations ensued. Although in late 2013 this process was still ongoing, Gasterra and Statoil have largely accepted that a move to a hubpriced business model is inevitable. Gazprom has introduced a system of base price reductions and rebates to customers which have brought their prices down to hub levels in competitive markets. ${ }^{41}$ Sonatrach is believed to have made few concessions and is in arbitration with many of its customers.

Table 2: European Wholesale Gas Pricing 2012 (\%)

\begin{tabular}{|l|c|c|c|c|}
\hline $\begin{array}{l}\text { European Region (\% of } \\
\text { total European gas } \\
\text { demand) }\end{array}$ & OIL-LINKED & HUB-BASED & \multicolumn{2}{|c|}{ REGULATED } \\
\cline { 2 - 5 } & \% of Region & $\%$ of Region & $\begin{array}{c}\text { RCS }^{*} \\
\text { of Region }\end{array}$ & $\begin{array}{c}\text { RSP } \\
\% \text { of Region }\end{array}$ \\
\hline North West $(50 \%)$ & 28 & 72 & & 15 \\
\hline Central (10\%) & 48 & 37 & & 12 \\
\hline Mediterranean $(30 \%)$ & 88 & 12 & & 46 \\
\hline South East $(10 \%)$ & 42 & & & 12 \\
\hline
\end{tabular}

*regulated cost of service ** regulated social pricing

Source: IGU (2013), pp.41-44.

Table 2 shows that, in 2012, different regions of Europe had very different price formation mechanisms. In the north west - which represents $50 \%$ of European gas demand, nearly three quarters of gas was priced at hub levels, while Mediterranean and south east Europe remain dominated by oil-linked and regulated pricing. Nevertheless time series analysis of the data suggests that hub pricing is spreading across Europe and, with further development of interconnectors and the new EU network codes, this process will continue. Our research has found no basis for claims that European hub prices are subject to manipulation by downstream market participants. On the contrary, our research demonstrates that, since 2007, price correlations between TTF, PEGs, GPL, NCG and Zeebrugge have been very strong. ${ }^{42}$ Along with the more established NBP, TTF in 2012 achieved a churn ratio in excess of 14 and its forward curve is actively used for portfolio risk management ${ }^{43}$. While other European hubs may not achieve high liquidity ratios and operate more as 'balancing hubs', they maintain close price correlation with TTF and NBP.

\section{Asian LNG importing countries}

International gas pricing in LNG-importing Asia reflects some of the European features described above. However, there are significant differences: crude oil price linkage was introduced into Japanese LNG import contracts in the 1970s when crude oil was the main competing fuel to gas in power generation. The cost pass-through mechanisms allowed Japanese utilities to adjust their gas

\footnotetext{
${ }^{39}$ Stern and Rogers (2012).

40 Heather (2012).

${ }^{41}$ Societe Generale (2013) shows Gazprom prices within 5\% of NBP levels in the first half of 2013.

42 Petrovich (2013). The hubs and their locations are: TTF - Netherlands, PEGs - France, GPL and NCG -

Germany, and Zeebrugge - Belgium. More recent data from 2012-13 suggests that the correlation increased for most north western hubs, but worsened significantly for PEG Sud.

${ }^{43}$ Heather (2012), Table 3, p.33.
} 
and power tariffs to end users by company-specific percentages (regulated by government) based on a combination of their generation portfolio, and fuel purchase cost and exchange rate movements (but with an upper limit). ${ }^{44}$ By the time that Japan was joined by other LNG importers in the Pacific Basin (South Korea in 1986 and Taiwan in 1990), the pricing principle of the "Japan Crude Cocktail" (or $\mathrm{JCC})^{45}$, or the average price of crude oils imported into Japan, was well established and exporters were unwilling to countenance any other mechanism. ${ }^{46}$ The main focus of commercial negotiations was the index - known in Pacific LNG contracts as "the slope" - or the extent to which the LNG price changes in response to a change in crude oil prices.

Over the decades, Japanese electric power utilities moved away from crude oil-fired generation with the exception of peaking and emergency situations (for city gas companies crude oil was never a competing fuel). It was clearly always a strange assumption that South Korean and Taiwanese (later followed by Chinese and Indian) LNG buyers should price their imports relative to crude oils imported into Japan. Despite these problems, the JCC pricing and contractual framework worked well for many decades. Partly this was due to the cost pass-through mechanism (described above); partly because in all countries gas was replacing oil products (of various kinds) in stationary energy balances; partly because although Japan and South Korea flirted with liberalising their gas and power markets in the 1990s and 2000s, this never progressed to exposing incumbents to (what in North American and European markets would be considered) serious competition. Also because from 2008 until the Fukushima accident LNG import prices for Japan, South Korea and Taiwan were broadly similar; since 2011 Japanese prices have been noticeably higher (see Figure 8).

\subsection{Economic and market fundamentals of Asian LNG projects and contracts}

The original price principles behind long term gas contracts were (or should have been) that the seller needed to cover its economic fundamentals i.e. its costs of production and delivery (plus a margin). Buyers needed to price gas at a level which would secure their market fundamentals, i.e. a price which would persuade their customers to convert from their current fuels to gas, and maintain the competitiveness of gas against those fuels (otherwise customers would switch back to them) which would threaten the marketability of the gas, and therefore their ability to take their minimum annual quantities, for which they would be contractually required to pay. In both cases, the traditional fundamentals in Asian LNG projects were oil-related and have remained so. In this section, we briefly review the main economic and market fundamentals which are causing the current problems.

\section{Economic fundamentals}

While LNG projects could never have been described as "cheap", costs fell significantly during the 1990 s and early 2000s. ${ }^{47}$ However from the mid-2000s, there was a very substantial cost escalation which greatly exceeded the overall increase in oil and gas production and development costs. In general, LNG liquefaction costs increased by a factor of 3 to 4 compared with around 2 in the upstream sector overall. Some LNG projects - particularly those in Australia - have experienced cost overruns of up to $30 \%$. Figure 10 shows that capital costs of existing projects are in the range of $\$ 1,000-1,500 /$ million tonnes of LNG per annum (mtpa), while newer projects are in the range of $\$ 2,500-3,600 / \mathrm{mtpa}$.

\footnotetext{
${ }^{44}$ See note 22.

${ }^{45}$ Official name: the "Japan customs-cleared crude oil price".

${ }^{46}$ For details of the history see Stern (2012), pp.68-73, and for the more recent period Flower and Liao (2012).

47 See Songhurst (Forthcoming 2014).
} 

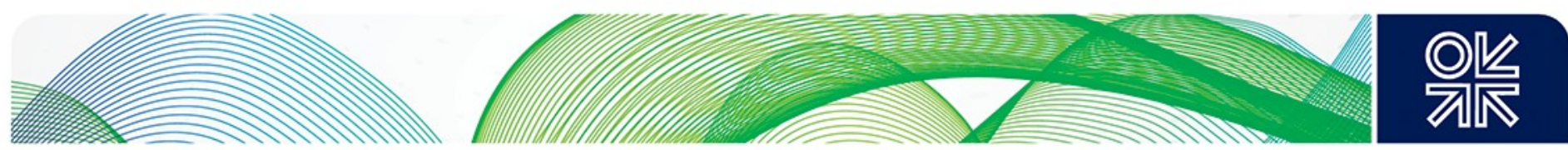

Figure 10: Total Capital Investment Costs for Selected LNG Projects (capex to first LNG supply)

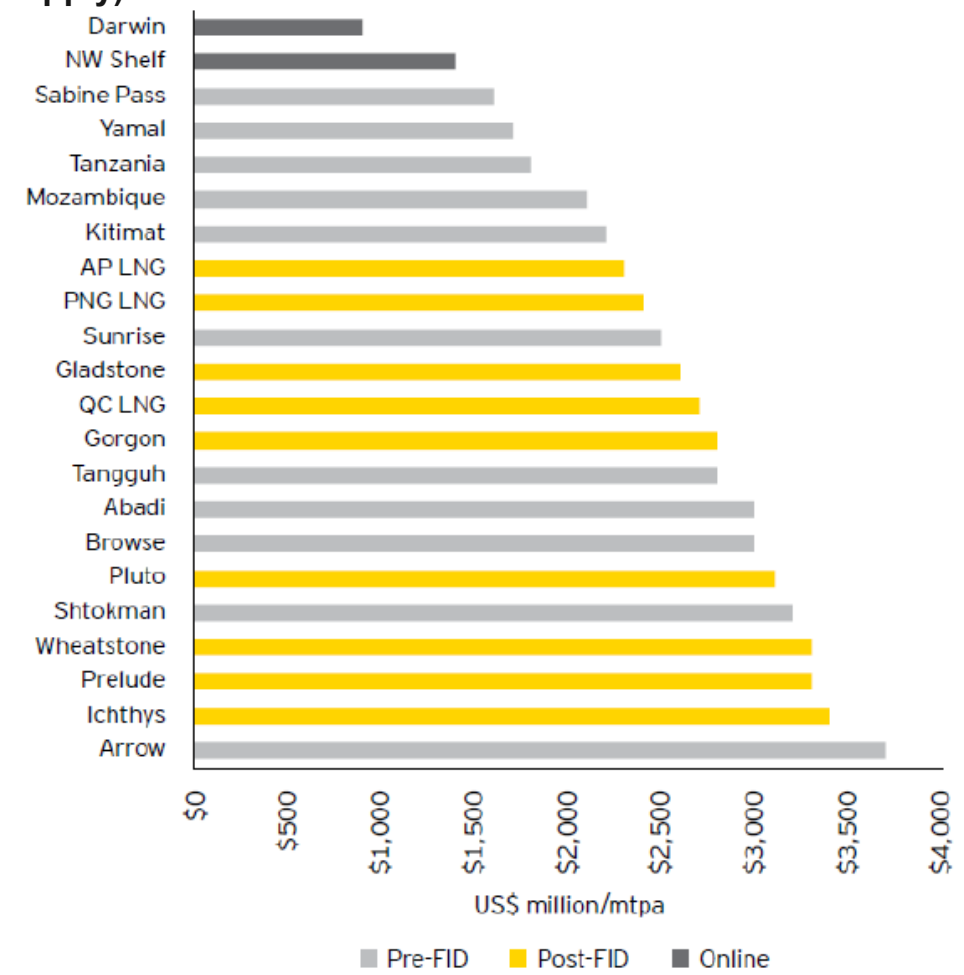

Source: Credit Suisse Global Equity Research, Global LNG Sector Update, 7 June 2012.

Figure 11 provides an illustration of the costs of delivering LNG from a range of new projects to Japan and shows that the new projects have a delivered cost of $\$ 12-14 / \mathrm{MMBtu}$. With many of these projects coming on stream in the mid to late 2010s at capital investment expenditures of $\$ 30-50$ billion, it is clear that their commercial room for compromise on prices is very limited. This has an impact on the potential for price renegotiation of existing contracts should this be necessary (see Chapter 5) 
Figure 11: Nominal New-Built LNG Break-Even Prices of Selected LNG Projects (delivered to Tokyo Bay)

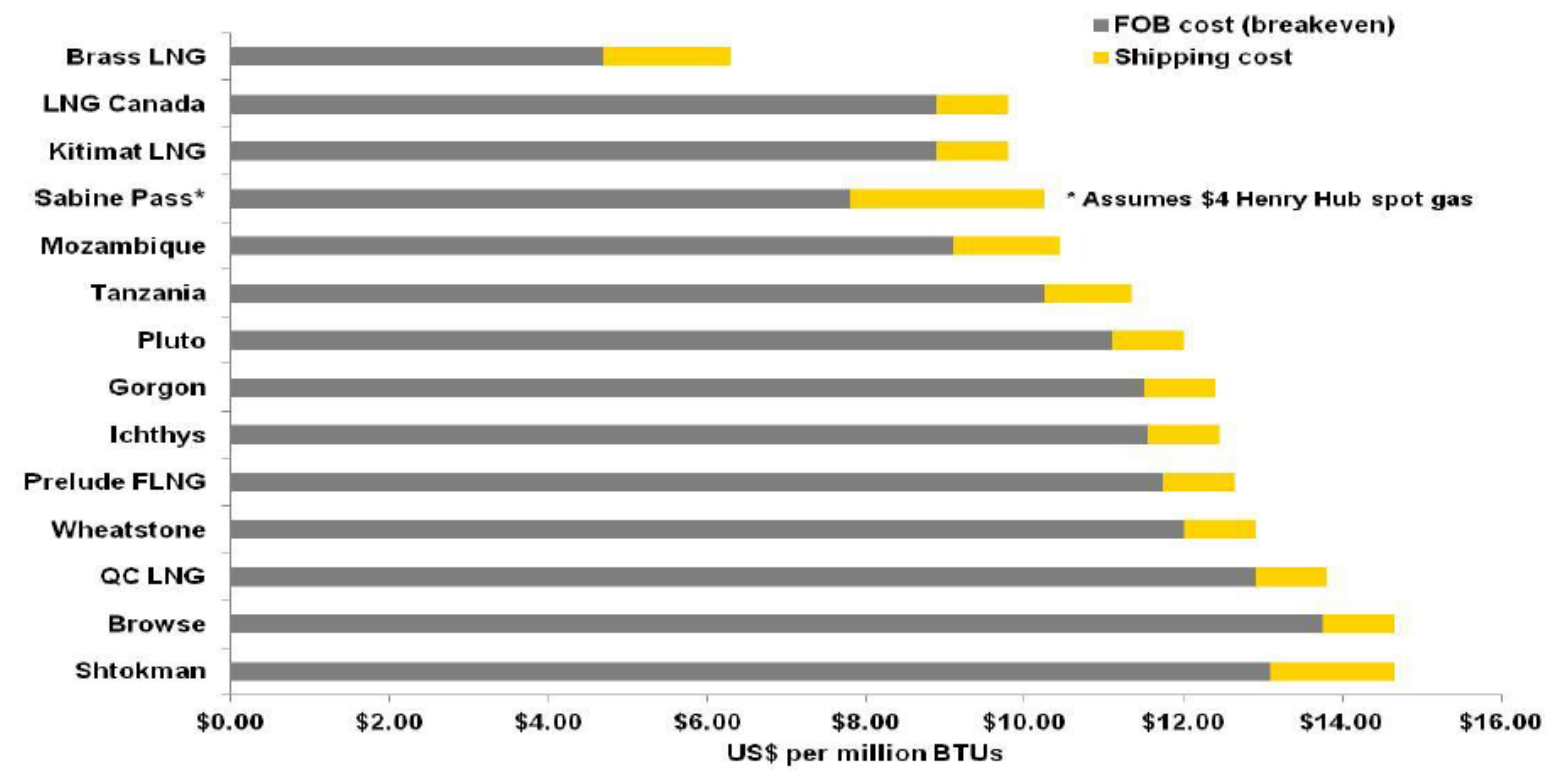

Source: Deutsche Bank Markets Research, Global LNG, 17 September, 2012.

Note: In addition to capital cost levels, the presence of condensate co-production in the fields supplying

liquefaction feed gas will serve to lower the break-even LNG price. This will vary between projects. It should also be noted that, given the decision to defer the Shtokman project indefinitely, its inclusion here should be regarded as illustrative only. Some observers would expect its break-even price to be higher than that shown here.

\section{Market fundamentals}

A 2009 study by Miyamoto and Ishiguro developed a 'netback market value' (NMV) methodology for LNG pricing in the five major Asian importing markets. The aim of this research was to examine the weighted average cost of fuels competing with gas in the relevant importing country and to compare this NMV price with JCC import prices at various oil price levels. In the 1970s and 1980s, crude oil and oil products were clearly the main competing fuels for LNG in Japan (the major importer) and hence the formulaic linkage of the LNG contract price to JCC crude price had some validity. The authors note however that, notwithstanding the later introduction of 'S-curves' to dampen the impact of wide fluctuations in oil price on LNG prices, the validity of this approach became much more questionable for most countries at oil price levels above $\$ 40 / \mathrm{bbl}^{48}$

Table 3 shows the relative shares of energy sources competing with gas in the five main Asian LNG importing countries in the period 1979-2006. For Japan the change in this period is stark: from 1979 where oil constituted $91 \%$ of fuel competition with gas, by 2006 coal and oil were comparable competitors. South Korea in 2006 had a similar profile to that of Japan in 2006; but had the highest level of competition from oil of all countries. India's level of oil competition with gas in 2005 was comparable to that of Japan, however its situation was complicated by the low and regulated price of domestic gas sold to the fertiliser sector. ${ }^{49}$ In Taiwan, coal was the dominant competitor to gas, primarily driven by the power sector. In China, gas was competing with coal in the power generation

\footnotetext{
${ }^{48}$ Miyamoto and Ishiguro (2009), P. 25. The S curve refers to a pricing formula in which the relationship between the LNG price and the oil price (ie the slope) varies over different oil price ranges. For more details on this and the applicable ranges of oil prices, see Flower and Liao, especially pp.340-1.

${ }^{49}$ For an account of Indian gas pricing see Sen (2012).
} 
sector and with naphtha in the fertiliser sector, but overall gas represented a small share of the energy balance.

Table 3: Energy Sources Competing with Natural Gas in Asia

\begin{tabular}{|c|r|r|r|r|c|r|r|}
\hline \multirow{2}{*}{$\begin{array}{c}\text { Competing } \\
\text { Energies }\end{array}$} & \multicolumn{2}{|c|}{ Japan } & Korea & Taiwan & India & China & \multicolumn{1}{c|}{ Asia } \\
\cline { 2 - 8 } & FY1979 & FY2006 & 2006 & 2006 & 2005 & 2005 & \multicolumn{2}{c|}{$2005 / 6$} \\
\hline Coal & $5.7 \%$ & $49.6 \%$ & $44.7 \%$ & $73.2 \%$ & $55.2 \%$ & $57.0 \%$ & $50.6 \%$ \\
\hline Oil & $90.9 \%$ & $40.7 \%$ & $45.8 \%$ & $20.2 \%$ & $40.8 \%$ & $28.4 \%$ & $40.3 \%$ \\
\hline Electric Power & $3.4 \%$ & $9.7 \%$ & $9.7 \%$ & $6.6 \%$ & $4.0 \%$ & $14.6 \%$ & $9.1 \%$ \\
\hline Total & $100.0 \%$ & $100.0 \%$ & $100.2 \%$ & $100.0 \%$ & $100.0 \%$ & $100.0 \%$ & $100.0 \%$ \\
\hline
\end{tabular}

Note: $\mathrm{FY}$ is the Japanese Fiscal Year which runs from April 1-March 31 of the respective year Source: Miyamoto and Ishiguro (2009), Table 2, p.14.

Table 4: Net Market Value (NMV) in Asian LNG Importing Countries with JCC at Different Oil Price Levels

\begin{tabular}{|c|c|c|c|c|c|c|c|}
\hline \multicolumn{2}{|c|}{ JCC } & \multicolumn{6}{|c|}{ NMV } \\
\cline { 3 - 8 } \$/bbI & \$/MMBtu & JAPAN & KOREA & TAIWAN & INDIA & CHINA & ASIA \\
\hline 20 & 3.5 & 5.7 & 5.3 & 2.3 & 2.9 & 4.8 & 5.3 \\
\hline 30 & 5.2 & 6.4 & 6.8 & 2.7 & 4.4 & 5.6 & 6.2 \\
\hline 40 & 7.0 & 7.0 & 8.4 & 3.2 & 5.9 & 6.5 & 7.1 \\
\hline 50 & 8.7 & 7.7 & 9.9 & 3.7 & 7.4 & 7.3 & 8.0 \\
\hline 60 & 10.5 & 8.4 & 11.5 & 4.1 & 8.9 & 8.1 & 8.9 \\
\hline 70 & 12.2 & 9.1 & 13.0 & 4.6 & 10.4 & 8.9 & 9.8 \\
\hline 80 & 14.0 & 9.8 & 14.6 & 5.1 & 11.9 & 9.8 & 10.7 \\
\hline 90 & 15.7 & 10.4 & 16.1 & 5.6 & 13.4 & 10.6 & 11.5 \\
\hline
\end{tabular}

Source: Miyamoto and Ishiguro (2009), Table 4, p.26

Net Market Value at different JCC prices is shown in Figure 4 for the five Asian LNG importers. For each country, the research compared the NMV with the average price of imported LNG, up to a $\$ 90 / \mathrm{bbl}$ crude oil price. At above $\$ 40 / \mathrm{bbl}$, JCC price exceeds the average Asian NMV for LNG and at $\$ 90 / \mathrm{bbl}$ the difference is very substantial for most countries. Only for South Korea did NMV exceed the JCC price up to a $\$ 90 / \mathrm{bbl}$ crude oil price; in all other countries (with the exception of India where, as noted above, there are special circumstances) NMV was significantly below JCC with the gap between the two values growing wider at oil prices above $\$ 60 / \mathrm{bbl}$.

The data set used by Miyamoto and Ishiguro covered the period 2000-07, but the authors projected their results to 2015 , which showed very little difference from the data in Table $3{ }^{50}$ When contacted in connection with this study, the authors confirmed that although the absolute market value of gas had increased (due to the increase in oil prices) they believed there had been little change in the relationship between gas and competing fuels since they completed their research. ${ }^{51}$

\footnotetext{
${ }^{50}$ Miyamoto and Ishiguro (2009), Table 3, p.14.

${ }^{51}$ Personal communication with Akira Miyamoto, November 2013.
} 

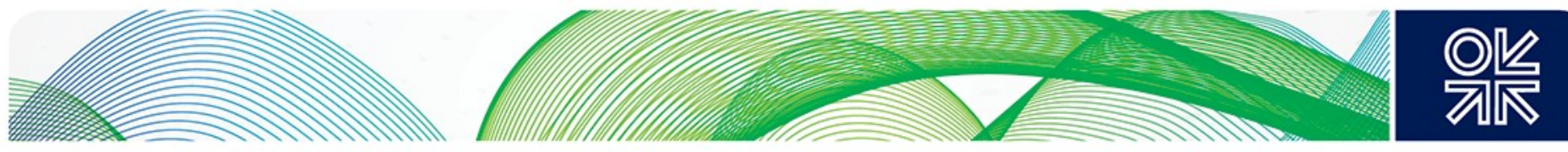

Clearly, market fundamentals differ between the Asian LNG importing countries, with oil products remaining important in countries such as South Korea, India and China. But even in these countries, market fundamentals do not indicate that $100 \%$ linkage to oil (let alone Japanese crude oil import) prices is an appropriate way to price LNG. In Japan, there appear to be no convincing arguments to base the price of gas on that of any other fuel, and therefore a hub price reflecting gas supply/demand, rather than alternative fuel, fundamentals is the logical solution. We return to these issues in Chapter 5 .

\subsection{North American LNG exports at Henry Hub-related prices - hopes and risks}

We now examine possible US LNG export volumes and their potential impact on Asian LNG imports and prices. For US producers, the prospect of exporting production to Asian markets currently paying 3 to 4 times the US price for LNG appeared compelling. In October 2013 there were 34 US LNG export projects at the planning/seeking approval or implementation stage. In aggregate their capacities are $350 \mathrm{Bcma}$, although it is unlikely that the majority will be implemented. Details of these projects are shown in Appendix 3.

Following approval of the coveted Non-FTA status ${ }^{52}$, the first two trains of the Sabine Pass LNG export project gained FID during 2011 (and $12.4 \mathrm{Bcma}$ is expected to commence production in late 2015/early 2016); trains 3 and 4 took FID in 2013 and are expected to be in production from 2017.

A hiatus followed the initial Sabine Pass FID as the US Administration sought assurance regarding the impact of LNG exports on domestic wholesale gas prices and the overall impact on the economy. A two-part study for the US Department of Energy ${ }^{53}$ concluded that LNG exports would on balance confer economic benefits to the US and that the domestic price impact would be minimal. During 2013, three further export projects were granted non-FTA approval (Freeport LNG, Lake Charles and Dominion Cove Point).

Table 5 shows the status of the six US projects for which contracts or MOUs are in place; $112 \mathrm{Bcma}$ of capacity is covered by such agreements. ${ }^{54}$ Of this some $63 \mathrm{Bcma}$ are covered by non-FTA approvals $^{55}$, in projects which have either already taken FID or are expected to do so by mid-2014. Two points need to be made with regard to these US Projects.

Firstly while the number of projects receiving non-FTA approval has grown rapidly during 2013 it is unclear whether this pace will continue into 2014 and beyond. Nevertheless it should be recognised that the situation represented on Table 5 is a rapidly changing one which could see project additions through 2014.

\footnotetext{
${ }^{52}$ FTA status is relatively straightforward and allows US LNG exports to 20 countries with which the US has a Free Trade Agreement (FTA) (listed in Appendix 2). Of these only South Korea and Mexico represent LNG markets with the scale to absorb significant new LNG volumes (in excess of existing contracted supplies). In order to export LNG to China, India, Japan and Taiwan and European markets, and hence provide a more readily financeable proposition, projects need to gain non-FTA approval. ${ }^{53}$ EIA (2012) and NERA (2012).

${ }^{54}$ Note that at present some of these are conditional on obtaining non-FTA approval and project FID.

${ }^{55}$ Note that only $63 \mathrm{Bcm}$ of the $70 \mathrm{Bcma}$ of non-FTA approved volumes can be matched to an offtake agreement or MOU.
} 
Table 5: Status of US LNG Export Projects with Offtake Agreements/Heads of Agreement

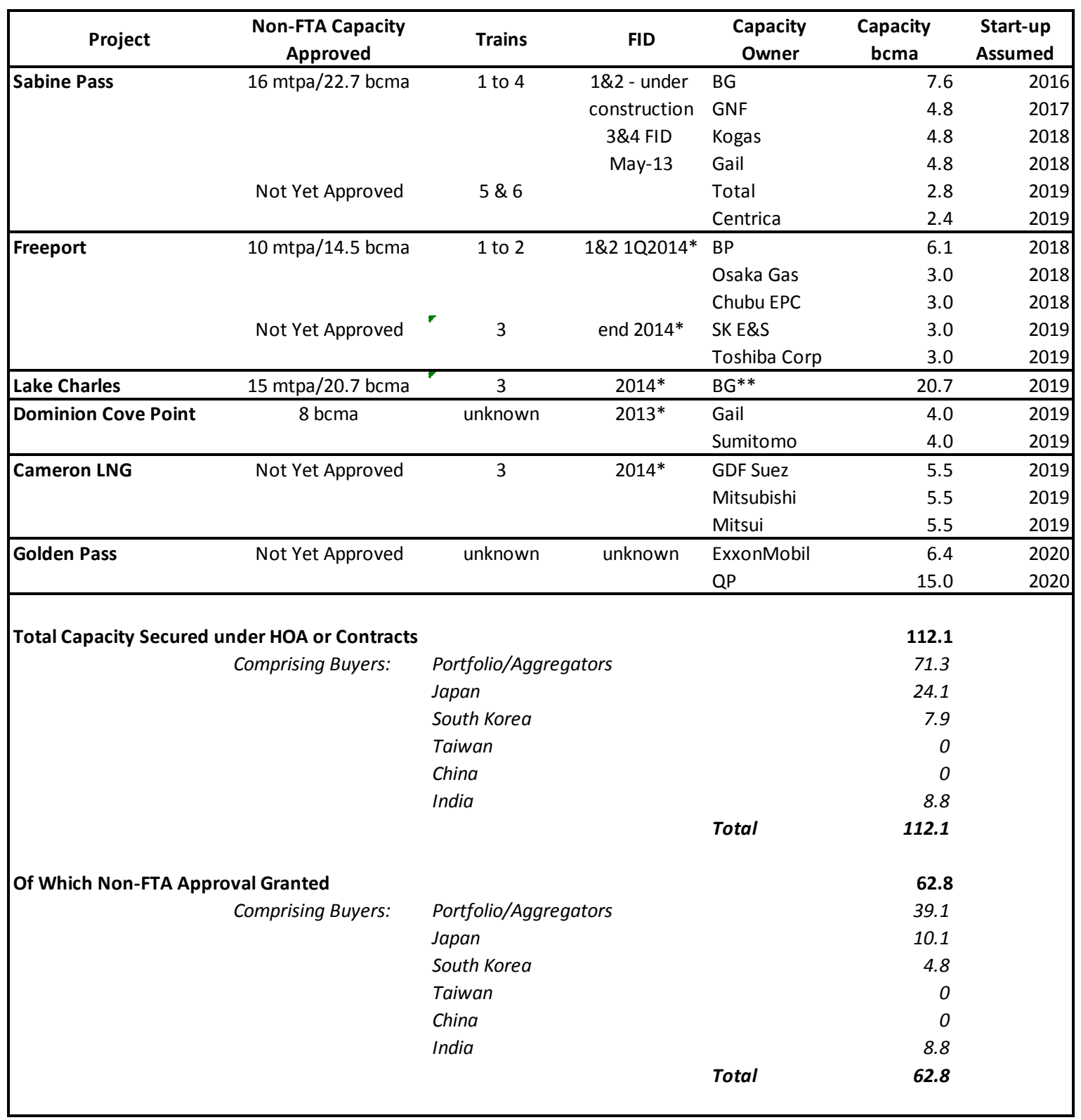

* Timings assumed by the authors, may be later than those stated by the respective project sponsors because of the risk of delays in the approval process.

${ }^{* *}$ It is assumed for illustrative purposes that BG retains all capacity, it states it intends to retain the majority. Source: Company Reports

Secondly it is important to appreciate the full sequence of approval requirements. The Natural Gas Act (NGA) requires companies to obtain permission from the Department of Energy (DOE) which must approve the application unless this is against the public interest. Exports to FTA countries are automatically approved. For applications to export to non-FTA countries, DOE announces the application to the Federal Register and invites comments, protests and motions to intervene. After this 

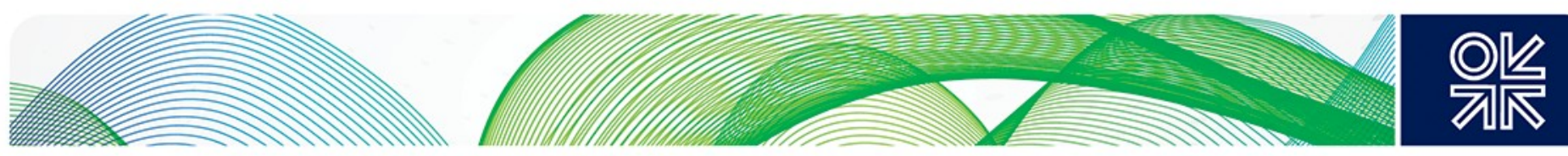

comment period the DOE approves the application unless it finds the project to clash with the public good. DOE approval is conditional upon an environmental assessment of the project by FERC.

FERC is responsible for approving the siting and construction of LNG export facilities on and near the shore. It regulates facilities under its jurisdiction over their operational lifespan. FERC also conducts environmental assessments. The National Environmental Policy Act requires full environmental impact statements (EIS) for new and converted terminals ${ }^{56}$. The EIS must also identify any other acts that apply to the project, such as the Clean Water Act and the Endangered Species Act ${ }^{57}$.

To date only the Sabine Pass project has obtained both DOE and FERC approval and is under construction. For its first four trains, Sabine Pass commenced the approval process in July 2010 and gained final FERC authorisation in April 2012. Construction of trains 1 and 2 commenced in Q3 2012 and start-up is anticipated in Q4 $2015{ }^{58}$ In summary the complete approval process took around 2 years and construction is expected to take 3 years.

The illustrative start-up dates shown on Table 5, used for the basis of subsequent analysis, are later than those stated by the respective project sponsors. There is a risk that the approval process could be extended due to the need to evaluate several projects in parallel.

With Canada's exports of pipeline gas to the US in decline since the advent of large scale shale gas production growth a number of Canadian LNG export projects are currently being evaluated but as at the time of writing, none had reached FID.

\section{Table 6: Canadian LNG Export Projects}

Project
KM LNG Operating General Partnership
BC LNG Export Cooperative
LNG Canada Development Inc
Pacific Northwest LNG
WCC LNG
Prince Rupert LNG Exports Limited
Woodfibre LNG Export

Key Sponsors
Chevron, Apache
LNG Partners (Texas) and Haisla Nation
Shell, Petrochina, Mitsubishi, KOGAS
Petronas
ExxonMobil, Imperial Oil
BG Group
Woodfibre Natural Gas Ltd

\section{Location}

Kitimat, BC

Douglas island, $B C$

Kitimat, BC

Prince Rupert Island, BC

Prince Rupert Island, BC

Prince Rupert Island, BC

Squamish, BC

Total
Capacity, bcma

7.2

2.6

33.4

25.8

39.3

43.4

2.8

154.5

Source: https://www.ferc.gov/industries/gas/indus-act/lng/lng-proposed-potential.pdf, http://www.nebone.gc.ca/clf-nsi/rthnb/pplctnsbfrthnb/lngxprtlcncpplctns/lngxprtlcncpplctns-eng.html

In December 2013 the Canadian National Energy Board approved export licences for four additional LNG export projects, bringing the total to seven. The projects are shown in Table 6. On the basis of project descriptions current in September 2013, in aggregate these sum to $155 \mathrm{Bcma}$.

\footnotetext{
${ }^{56}$ Note that in the case of Sabine Pass it was contended that an EIS was not required. FERC reasoned that the liquefaction facility does not pose a significant environmental threat, given it is sited on an already existing LNG import terminal.

57 US Liquefied Natural Gas Exports, A Primer on the Process and the Debate, Center for American Progress, http://www.americanprogress.org/issues/green/report/2013/11/05/78610/u-s-liquefied-natural-gas-exports/

${ }^{58}$ Cheniere Sabine Pass website: http://www.cheniere.com/sabine liquefaction/project schedule.shtml
} 
The Canadian projects are 'greenfield', i.e. they will not benefit from pre-existing jetties and storage facilities as is the case for the US regas project conversions. While the general expectation of the Canadian projects is to secure sales contracts with pricing mechanisms based on oil-indexation, it remains to be seen whether this will be realised given the evolving future preferences of Asian LNG buyers. ${ }^{59}$ This mismatch of expectation casts additional uncertainty over the future volumes of LNG exports from Canada. Given the expected lead time for greenfield plant construction, it is unlikely that Canadian LNG plant would commence operations significantly before 2020.

Figure 12 shows the potential export volumes of the six US projects detailed in Table 5.

Figure 12: US LNG Export Project Capacity - Illustrative

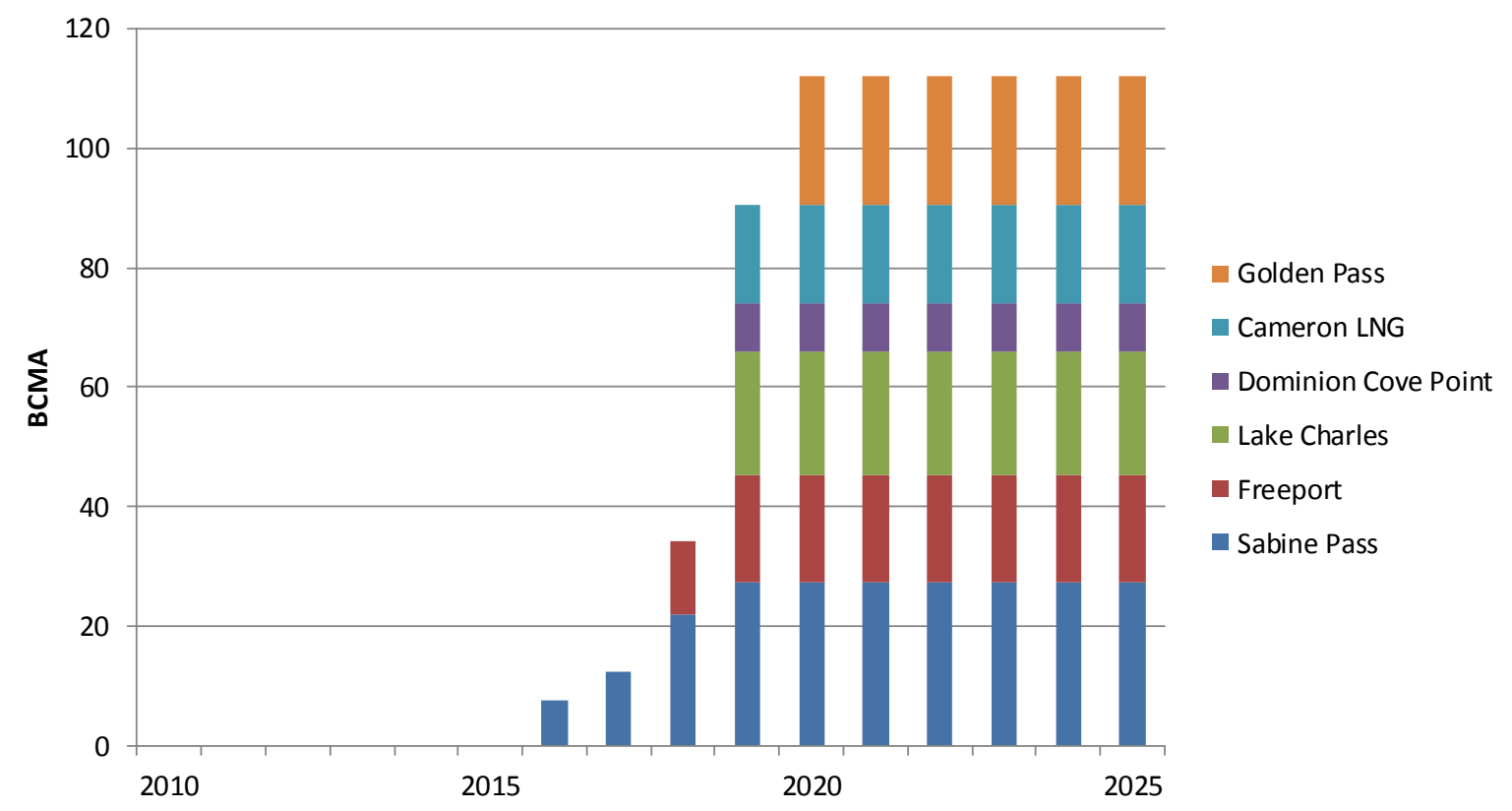

Source: Company Websites, Author's assumptions

The Sabine Pass business model is to sell LNG to buyers on an FOB basis using the following price formula: $\mathrm{P}(\mathrm{LNG})=1.15{ }^{*} \mathrm{HH}+\mathrm{B}$. Where $\mathrm{HH}$ is the Henry Hub futures price on the New York Mercantile Exchange (NYMEX) for the month of lifting and $B$ is a constant agreed between Cheniere and each buyer. ${ }^{60}$

The constant B in the price formula in Cheniere's first agreement with BG was set at $\$ 2.25 / \mathrm{MMBtu}$ to reflect the cost of liquefaction. In subsequent deals this rose to $\$ 2.50$ and $\$ 3.00 / \mathrm{MMBtu}$ which perhaps reflected differing risk sharing arrangements and a 'scarcity premium' as US authorities delayed decisions on approving subsequent LNG export projects. The multiplier factor of 1.15 applied to the Henry Hub price is presumably intended to cover the cost of gas consumed as fuel in the liquefaction process (typically between 8 and 11\%) and transport costs to the liquefaction facility. At present no other details are known of liquefaction fee/price formulae for the other project offtake arrangements. With several US export projects proceeding on the basis of incremental liquefaction

\footnotetext{
${ }^{59}$ An exception is Goldboro on the Canadian east coast where E.ON has an MOU to purchase 5 mtpa at European market prices. 'E.ON to take 5 million mt/yr of LNG from Canada', Platts European Gas Daily, June 4, 2013, p.2.

${ }^{60}$ Flower and Liao (2012).
} 
investment, one might expect competition to favour future offtakers in the form of lower regas tolling fees. While some observers might expect the opposite effect i.e. greater competition for construction resources and therefore project cost inflation, this might be countered by the application of more efficient project execution ${ }^{61}$.

A counter to fears of an 'overbuild' of US liquefaction capacity is that export volumes will ultimately be limited by the dynamics of the price spread between Henry Hub and destination markets. If this reduces such that the liquefaction, shipping and regas costs can no longer be covered, exports would be constrained. However given that liquefaction fees are a contractual commitment (and hence in effect a sunk cost) exports could still proceed at the margin where the Henry Hub to destination market price spread only covered shipping (and in the case of Europe regasification) $\operatorname{costs}^{62}$.

Although US (and potentially also Canadian) LNG exports provide great hopes for Asian LNG importers in relation to both supply and price diversity, they also raise risks in relation to Henry Hub pricing. Figure 13 shows an illustration of delivered costs of US LNG to Japan; Henry Hub prices of \$5-7/MMBtu produce a cost range of \$10-14/MMBtu delivered to Japan. As mentioned in Chapter 1, the LRMC of dry shale gas in the US is believed to be 5-7/MMBtu and therefore Asian LNG importers need to recognise that although Henry Hub prices have been in the range of $\$ 2-4 / \mathrm{MMBtu}$ during 2010-13, there is a serious possibility that they may rise to the point where, at crude oil prices below $\$ 100 / \mathrm{bbl}$, they could produce delivered prices higher than JCC formulae.

\section{Figure 13: Break-even Destination Market Prices for US LNG to Europe and Asia}

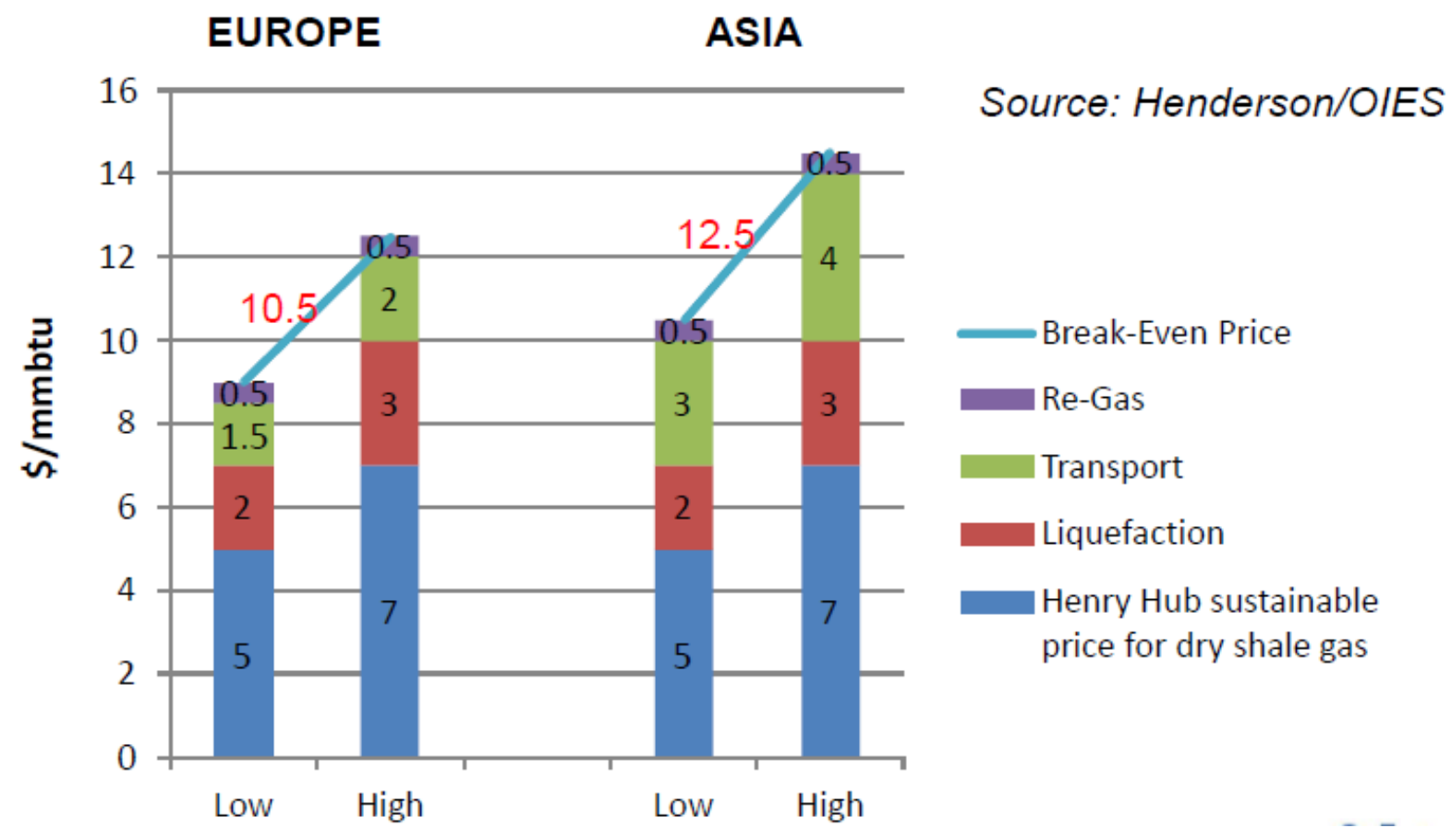

Source: Henderson (2013).

\footnotetext{
${ }^{61}$ See Songhurst, (Forthcoming 2014).

62 The Asian LNG pricing basis being prior to unloading at regas terminals. European hub prices are based on an inland location, i.e. post regasification.
} 
Asian enthusiasm for Henry Hub-related pricing, while understandable in relation to the refusal of sellers to countenance any alternative to JCC over the past several decades, may therefore be making two potentially serious mistakes:

- $\quad$ first, confusing price formation with price level i.e. embracing a price formation mechanism because in 2011-13 it gave a lower purchase price than existing long term contracts;

- $\quad$ second, failing to recognise that Henry Hub represents the fundamentals of the North American, rather than the Asian, market and that these fundamentals can and will change independently of changes in Asian market fundamentals.

Thus although North American LNG exports are likely to have a substantial impact on Asian LNG supplies and prices, the risks for Asian buyers of formal contractual linkage to Henry Hub pricing need to be carefully analysed.

Table 5 identified the offtakers for the six US projects considered and these are shown by category in time series form in Figure 14. While Japanese, South Korean and Indian buyers have been active in securing US export capacity, the majority has been taken by portfolio players/aggregators such as BG, BP, Centrica, Gas Natural Fenosa, GDF-Suez, Total, Exxon Mobil and Qatar Petroleum. These companies will likely use these volumes within their existing portfolios to supply existing contractual commitments, new long term contracts and also some spot sales. The next chapter deals with the growth of spot and short term LNG sales to Asian markets.

Figure 14: Category of Ownership of Illustrative US LNG Export Project Capacity

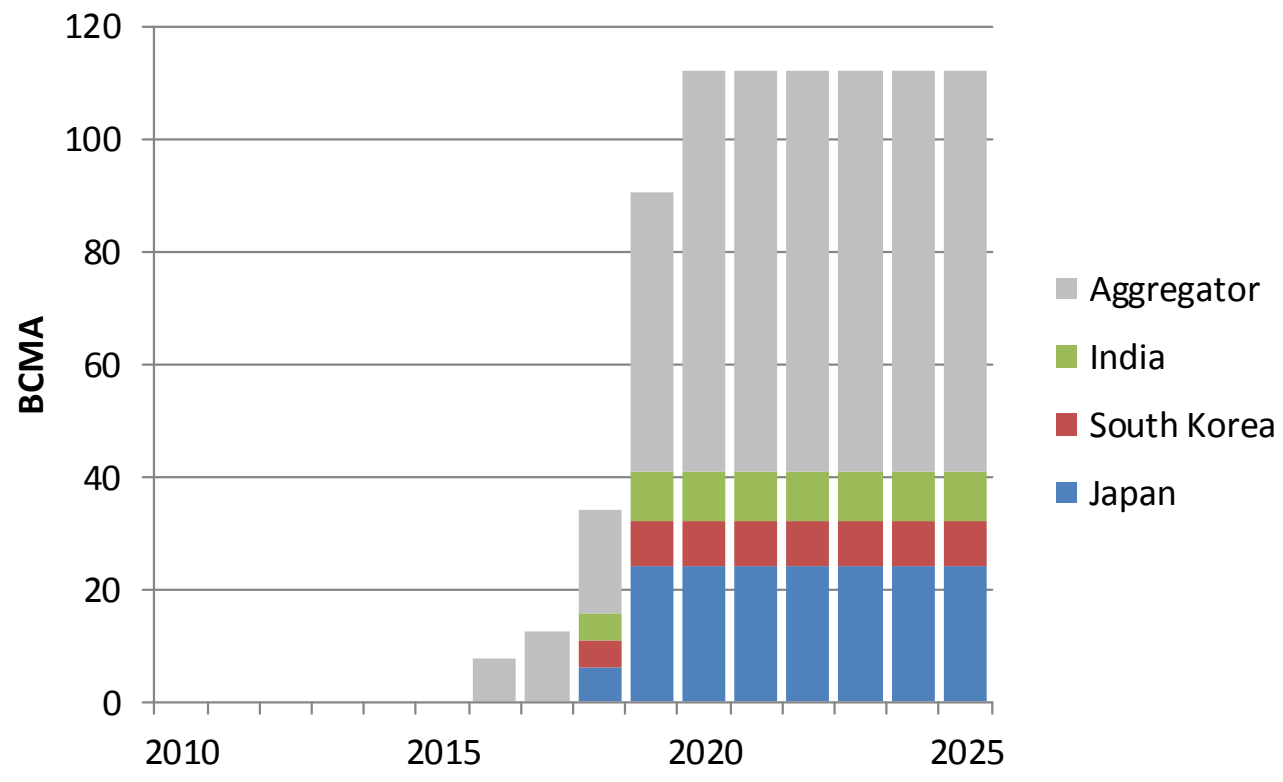

Source: Company Websites, Author's assumptions 


\section{Chapter 4: The growth of spot and short term LNG trading in Asia 2006-12}

The percentage of global LNG sold as 'spot cargoes' has been a key focus of those industry participants and observers keen to see the evolution of a liquid market for gas as a traded global commodity, and perceiving LNG as the key enabler of such a transition.

The only source of comprehensive data in the public domain on how supply divides between long, medium term contract volumes and more flexible short term trades is provided by the organisation GIIGNL ${ }^{63}$. This is a semi-anonymised data set assembled from data provided by LNG industry participants. ${ }^{64}$ GIIGNL data highlight the distinction between 'spot' and 'short-term' contract sales and total LNG trade volumes at the global level. In the course of research for this paper the authors have constructed a database of these trades from the GIIGNL data-set for the period 2006-12 and are therefore able to distinguish, within the LNG supply flows, between true spot LNG trades, shorter term contracts (up to 4 years in duration), and medium and long term contracts (greater than 4 years duration) ${ }^{65}$. The database was constructed to enable this data (where possible) to be analysed by region, supply source and destination.

This allows us to place the stated desires of (in particular) Asian LNG importing countries for a different LNG contractual pricing basis in the context of their already contracted supply, and contrast this with potential LNG demand in these markets.

Figure 15 shows global LNG supply delivered under medium and long term contracts (blue), short and medium term contracts (green) and in the form of spot cargoes (yellow). In 2011 and 2012, spot cargos represented 65 and $58 \mathrm{Bcm}(21 \%$ and $19.5 \%$ of total volumes) respectively.

63 GIIGNL (The International Group of Liquefied Natural Gas Importers) was founded to share information to facilitate the development of LNG imports and support the growth of the LNG industry, providing its members with overviews of the general economic condition of the LNG industry and current, state-of-the art LNG technology, operations and best practices. GIIGNL has more than 70 Full and Associate members from 19 different countries around the world (Asia, Europe and Americas), representing virtually every LNG import terminal as well as other aspects of the LNG trade.

${ }^{64} \mathrm{~A}$ list of GIIGNL member organisations is at Appendix 1.

${ }^{65}$ Note that GIIGNL does not distinguish between 'medium' and 'long term' contracts. 
Figure 15: Global LNG Supply by Contract Category 2006 - 2012

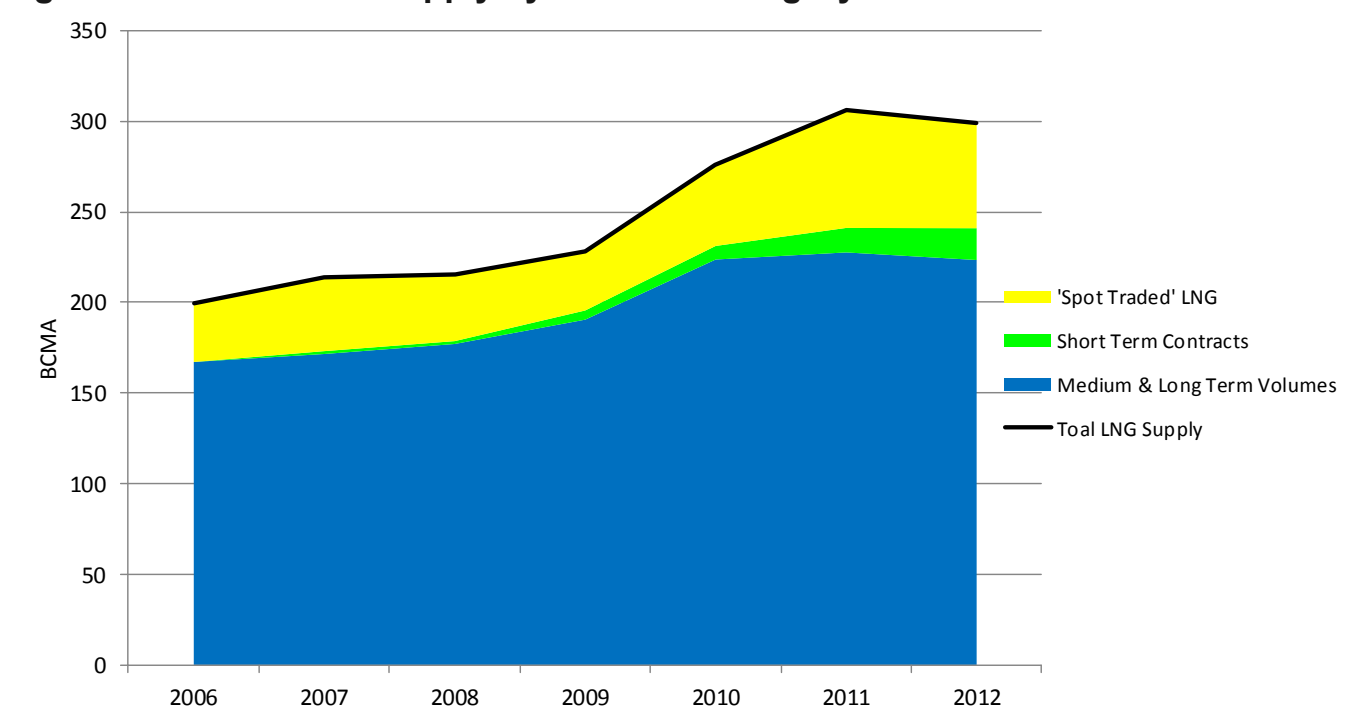

Source: GIIGNL data $2006-2012$

Figure 16 presents data in the same categories for Asian LNG importing countries:

Figure 16: LNG Supplied to Asia by Contract Category 2006 - 2012

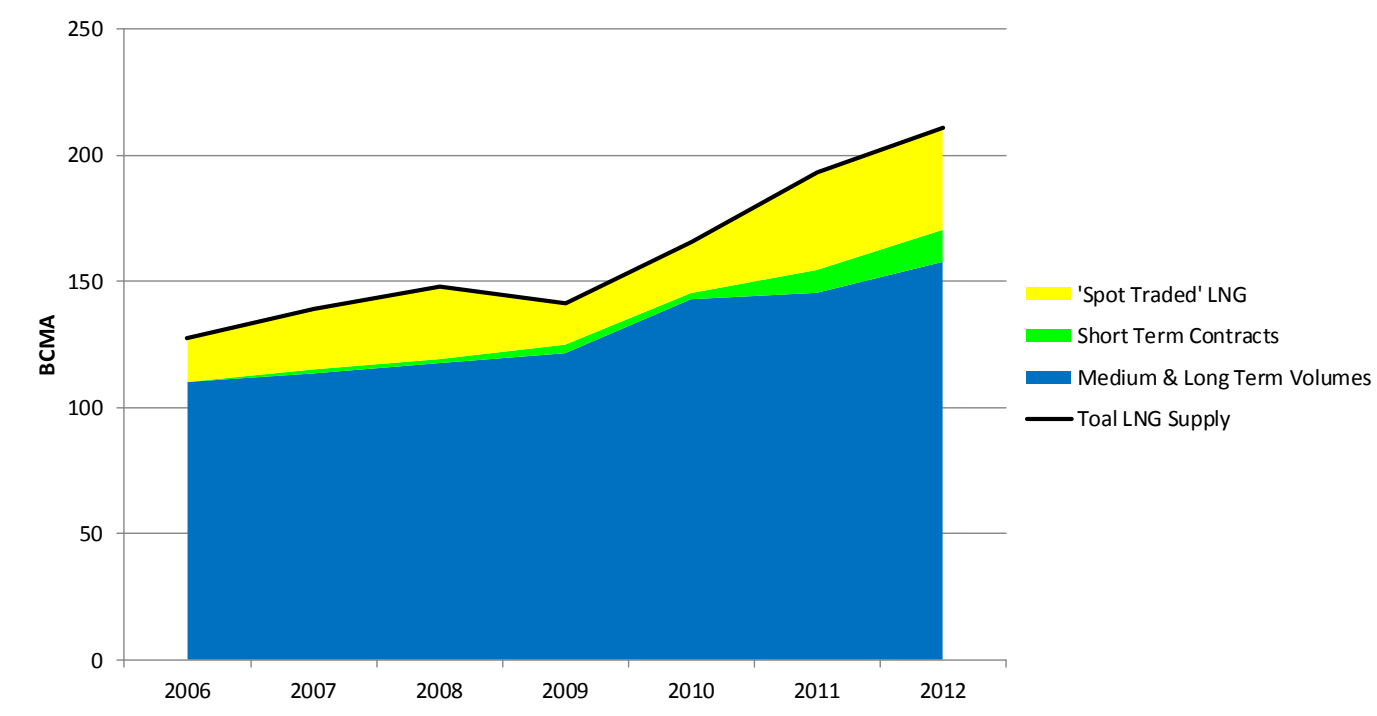

Source: GIIGNL data $2006-2012$

In Figure 15, there is no significant break in global or spot LNG supply, from 2008 to 2009. But in Figure 16 it is clear that the reduction in LNG demand caused by the financial crisis, appears to have been absorbed by a reduction in spot cargoes. The conclusion to be drawn is that 2009 saw a redirection of spot LNG from Asia to the Atlantic LNG markets, but after 2009, and especially after 2011, that trend reversed. By 2012, spot LNG deliveries to Asia were $40 \mathrm{Bcm}$, representing $19 \%$ of total Asian LNG supply. There has been an assumption that suppliers who had, since 2011 redirected LNG supplies away from Europe towards the 'premium' Asian markets were 'terming up' spot supplies - i.e. converting spot supplies into short or medium term contracts on a JCC price basis. Figure 16 certainly confirms this, but not to the degree often assumed. 

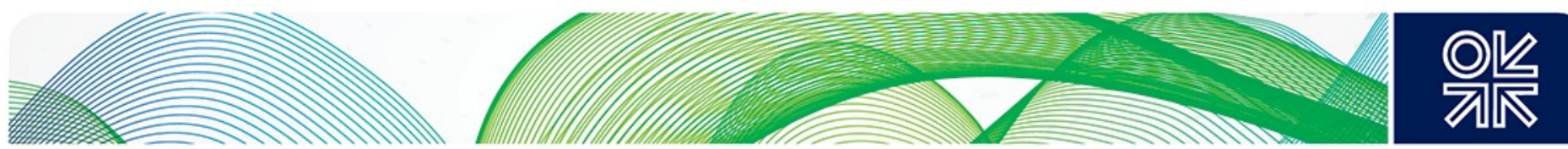

\subsection{Individual positions of the five major Asian LNG importers}

We now turn to the individual positions of the five major Asian LNG importers. The intention of this analysis is to examine the trends as depicted in Figures 15 and 16 at the importing country level and to use illustrative projections of future LNG demand ${ }^{66}$ and contractual commitments (identified as of 2012 by $\mathrm{GIGNL}^{67}$ ) in order to examine the 'contestable' demand for new LNG supplies.

\section{Japan}

Figure 17: LNG Supplied to Japan by Contract Category 2010 - 2012 and Illustrative

\section{Contestable Demand to 2025}

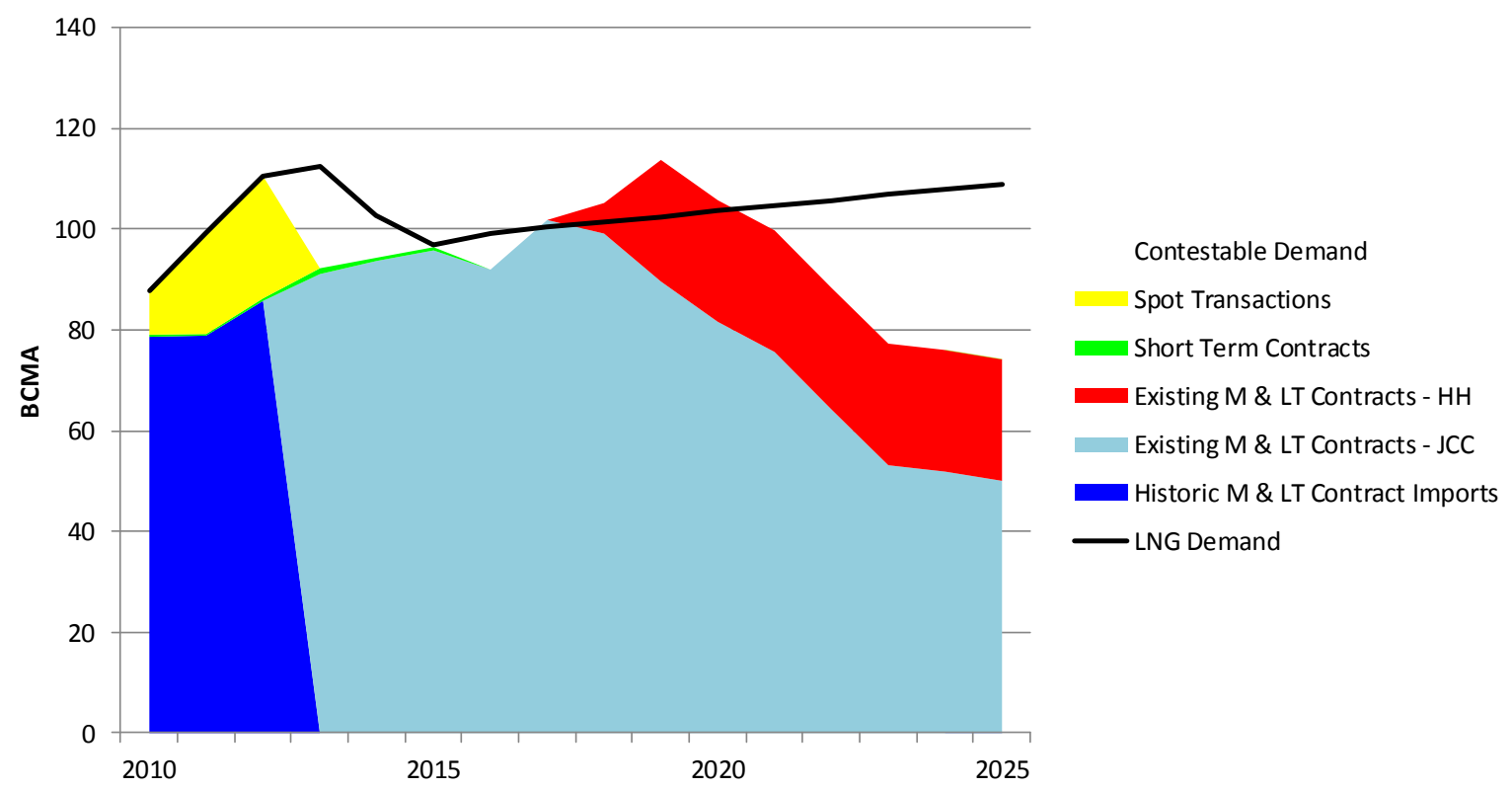

Source: GIIGNL, Rogers (2012)

Figure 17 shows the increase in spot LNG supplementing long term contracts in the period 2010-12 (following the March 2011 Fukushima accident). Interestingly, short term contract volumes (green) are relatively small. Beyond 2012, Japan will continue to rely on spot cargoes prior to the restart of nuclear generating plant. A significant resumption of nuclear generation would see Japan well covered by existing long term JCC priced contracts to $2018 .{ }^{68}$ The US LNG export position taken by Japanese buyers (as detailed in Table 5) adds significant volumes beyond 2017. By 2021 however, contestable demand increases, requiring additional supplies. The conclusion here is that unless Japan is able to renegotiate the price formation terms of existing contracts, it will not be able to effect a material shift away from JCC-indexed LNG prices until the end of this decade.

\footnotetext{
${ }^{66}$ See Appendix 4.

${ }^{67}$ Note Additional data on Chinese contracts was provided by D. Ledesma, OIES

${ }^{68}$ For scenarios of nuclear power plant resumption and their impact on LNG imports see Miyamoto et al., (2012).
} 


\section{South Korea}

Figure 18: LNG Supplied to South Korea by Contract Category 2010 - 2012 and Illustrative Contestable Demand to 2025

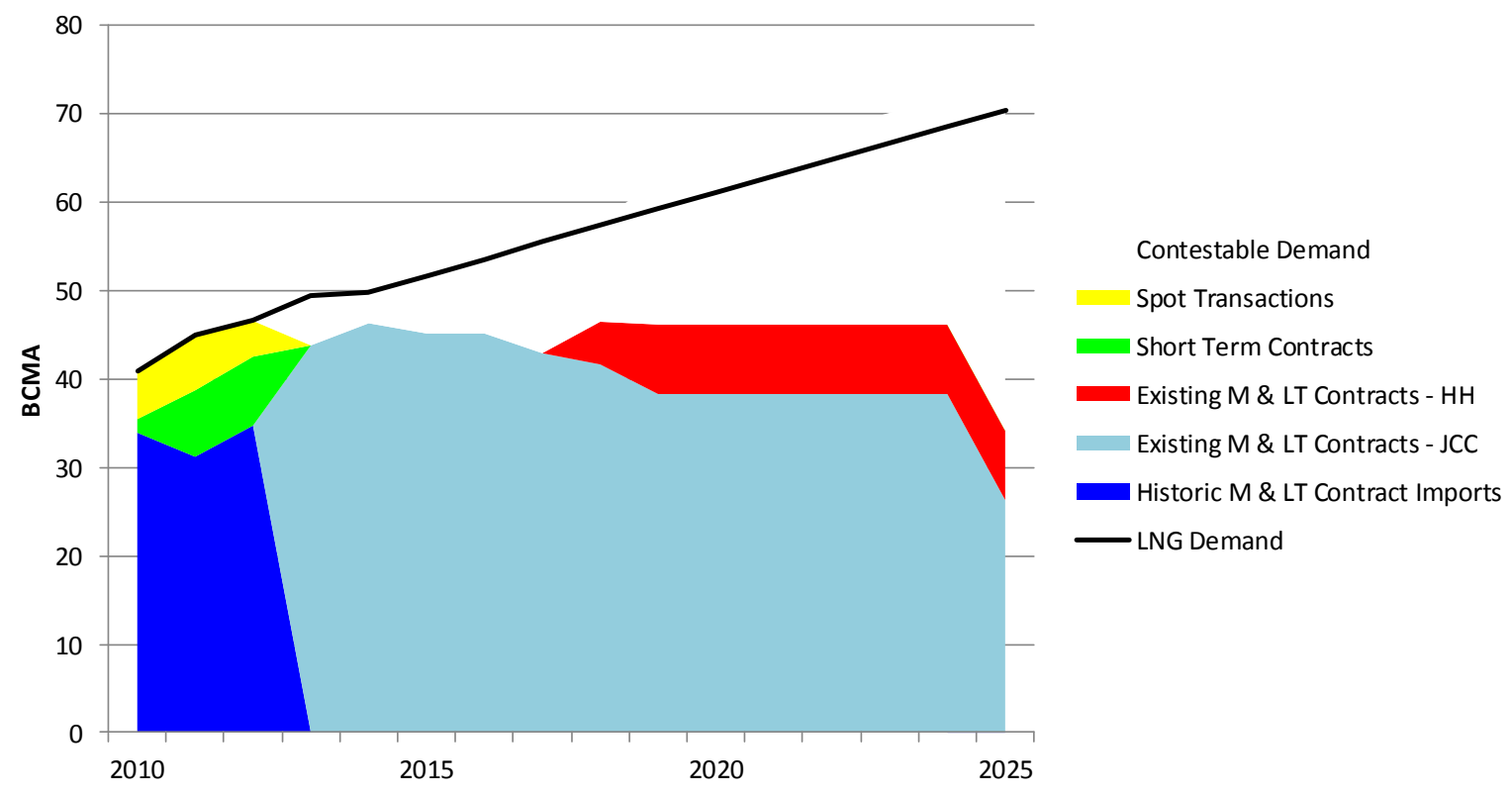

Source: GIIGNL, Rogers (2012)

Compared with Japan, South Korea has made greater use of short term contracts in the period 2010 to 2012, supplementing these with spot volumes. The continued use of similar levels of spot LNG and medium term contracts, in addition to its existing medium and long term contracts, should be sufficient to meet demand to 2017. Despite the addition of US LNG volumes post 2017, JCC-related contracts will still represent a significant portion of South Korea's LNG supply to the end of this decade at least.

\section{Taiwan}

Taiwan has relied to a considerable degree on spot LNG supply in the 2010 - 2012 period (Figure 19). Its medium and long term JCC contracts continue at similar levels to 2025. Taiwan has considerable scope to meet its future contestable demand through supplies on a different price formation mechanism to JCC, however JCC-linked LNG will continue to provide a significant core supply base. 

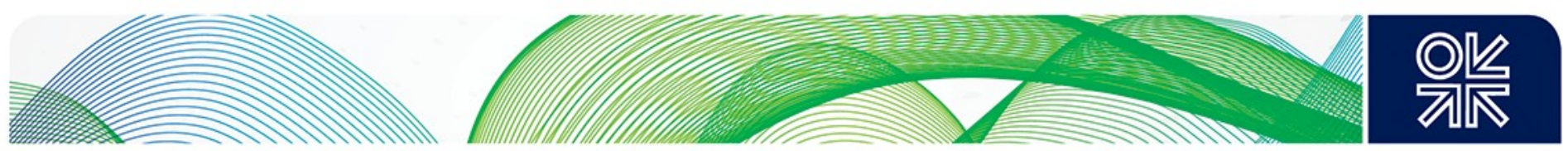

Figure 19: LNG Supplied to Taiwan by Contract Category 2010 - 2012 and Illustrative Contestable Demand to 2025

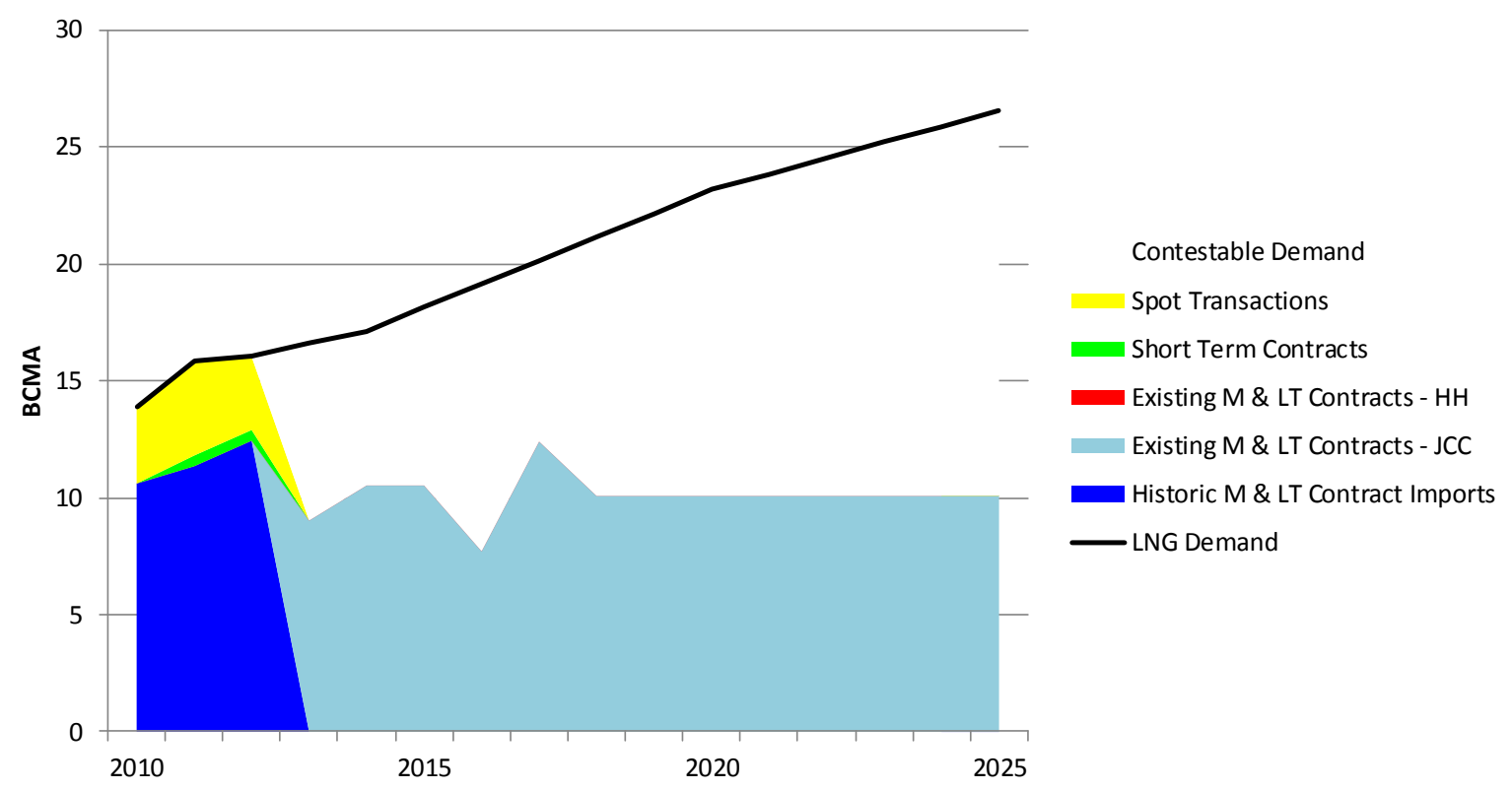

Source: GIIGNL, Rogers (2012)

\section{India}

The outlook for India's LNG requirements is heavily influenced by uncertainties about levels of future domestic production on the one hand, and the consequent price impact on natural gas demand on the other. The response of future exploration and development activity to the 2013 price reform which will significantly increase prices paid to domestic producers will be of great significance, but the extent to which these prices are passed through to customers (in particular power and fertiliser customers which are heavily subsidised) is uncertain. Future competition from coal and renewables in the power sector is an additional threat to gas demand growth. Possibly as a consequence of such uncertainties, India has relied to a significant extent on spot and short term contract volumes in the $2010-2012$ period as shown in Figure 20. The impact of US LNG capacity secured by GAIL is significant. Given its existing JCC contract portfolio, India would probably need to establish a clearer view on future LNG requirements before committing to further US volumes, unless it combines this with a trading strategy in which it is able to redirect volumes to other markets. 
Figure 20: LNG Supplied to India by Contract Category 2010 - 2012 and Illustrative Contestable Demand to 2025

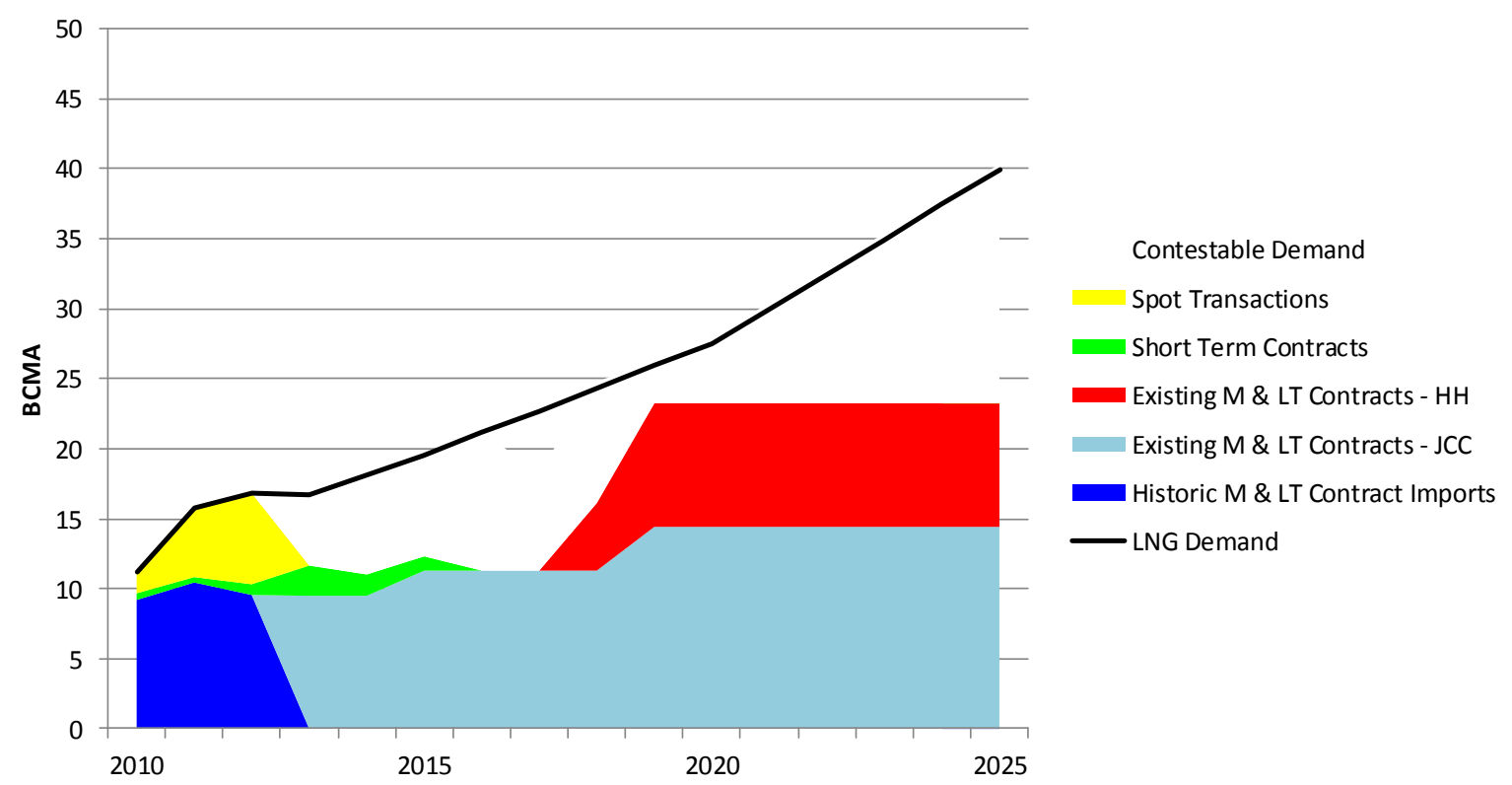

Source: GIIGNL, Rogers (2012)

\section{China}

While China has been and is expected to remain the major Asian growth market for natural gas, any projection of its future LNG requirements is subject to a number of interacting assumptions. These include: future natural gas demand, future domestic natural gas production (including considerable uncertainty about the extent and timing of coal bed methane volumes and shale gas production), the extent of future pipeline imports from Central Asia and Myanmar, and whether and when the long discussed pipeline import projects from Russia come to pass. In Figure $21^{69}$ from the modest LNG import levels of 10 to $20 \mathrm{Bcma}$ in the 2010 to 2012 period, by 2025 China reaches LNG import levels comparable to those of Japan in recent years. The slowdown in imports shown around 2020 is due to an assumed Russian pipeline gas project commencing ${ }^{70}$, however unless a contract between Gazprom and CNPC is signed early in 2014, it will be difficult for substantial flows to be on stream prior to 2020. The dashed line represents the LNG import requirement with no Russian pipeline import project.

\footnotetext{
${ }^{69}$ Figure 21 is based on a combination of assumptions discussed in more detail in Rogers (2012) and in Appendix 4.

70 If successful this is assumed to reach 38 Bcma by 2025.
} 

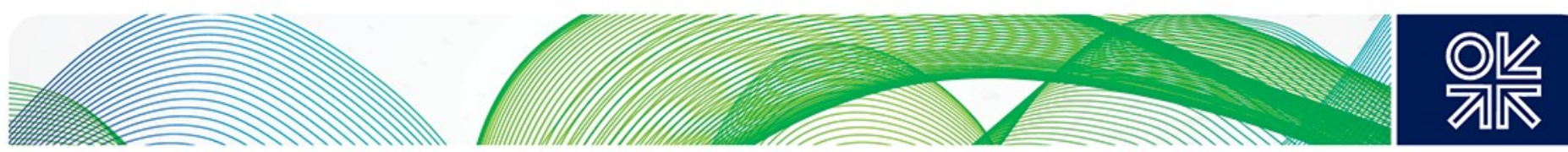

Figure 21: LNG Supplied to China by Contract Category 2010 - 2012 and Illustrative Contestable Demand to 2025

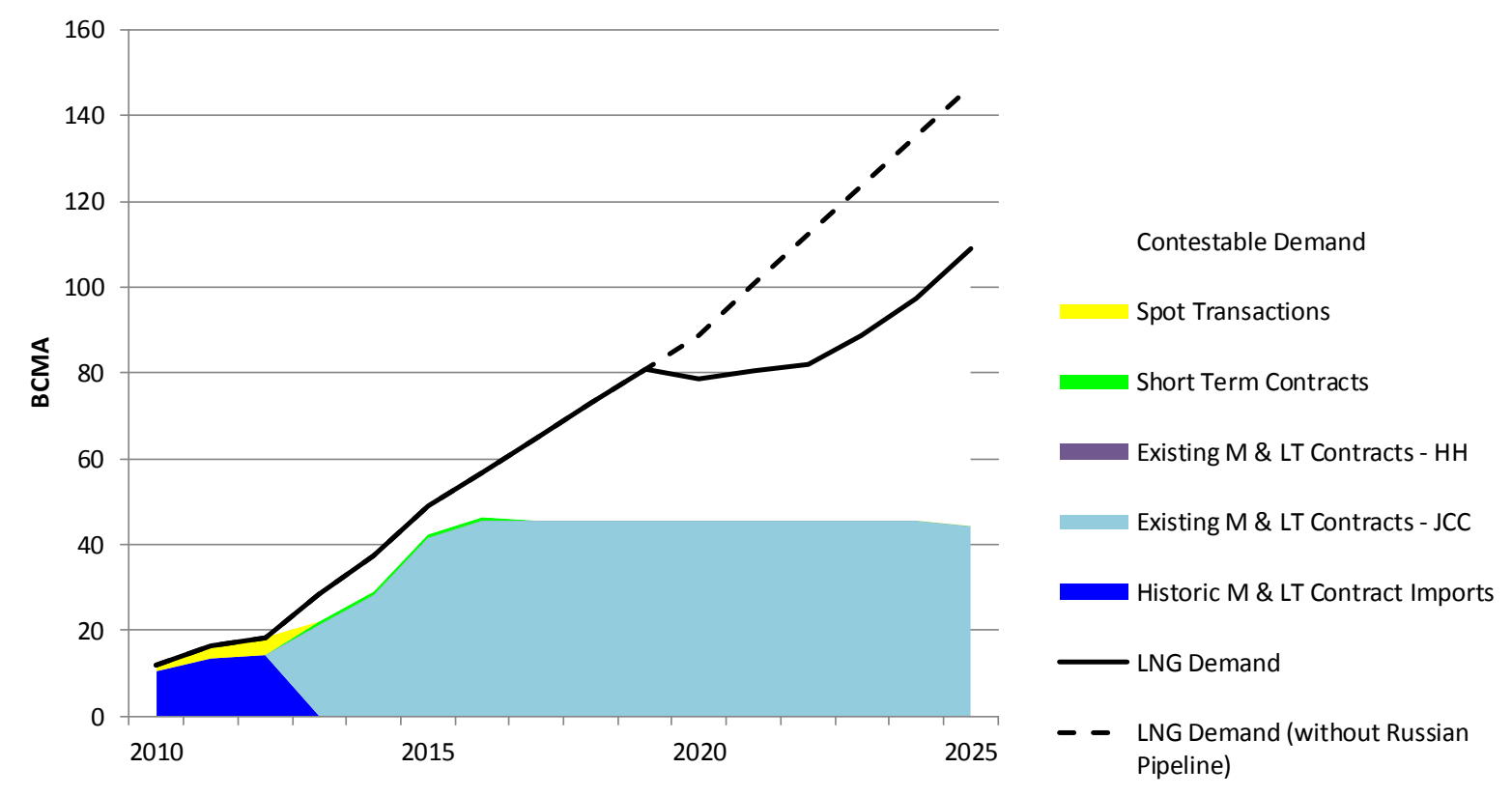

Source: GIIGNL, D. Ledesma OIES, Rogers (2012)

China has relied mainly on medium and long term contracts during 2010-12 with spot volumes supplying $23 \%$ of its needs by 2012 . On the basis of assumptions used to create Figure 21 , it has a portfolio of (medium and long term and to a lesser degree short term contracts) which keep it reasonably supplied (assuming spot volumes to bridge any shortfall) to 2015 or 2016 . Clearly if the illustrative LNG demand projection from 2015/2016 onwards is realised, China would need to rely increasingly and significantly on spot volumes. Given lead times for liquefaction projects, it is unlikely that additional medium and long term contracts could be signed with deliveries starting prior to 201718.

An explanation for this picture might be an internal Chinese view of future LNG imports which is more modest than that shown above. However, by 2015 China is expected to have $55 \mathrm{Bcma}$ of LNG import capacity ${ }^{71}$ of which $30 \mathrm{Bcma}$ is already operational. The full $55 \mathrm{Bcma}$ capacity could be used if more LNG could be purchased by means of additional short/medium or long term contracts with portfolio aggregators such as BG, Total, GDF Suez, Shell or BP on the basis of price formation yet to be negotiated.

In addition to the many uncertainties which will determine China's future LNG requirements, the proposed pipeline gas agreement with Russia could reduce LNG volumes by $38 \mathrm{Bcma}$ by 2025.

\footnotetext{
${ }^{71}$ See Chen (forthcoming 2014).
} 
In Figure 22, the aggregated view of contestable demand for the five main Asian LNG importers is shown combined with the US LNG export outlook discussed in chapter 3 . This graph excludes LNG consumption in the Atlantic Basin and other nascent Asian markets. It also excludes future spot and short term volumes and supply from non-US LNG supply projects which have not yet achieved FID.

Figure 22: LNG Supplied to Asia by Contract Category 2010 - 2012 and Illustrative Contestable Demand to 2025, including US LNG Projects

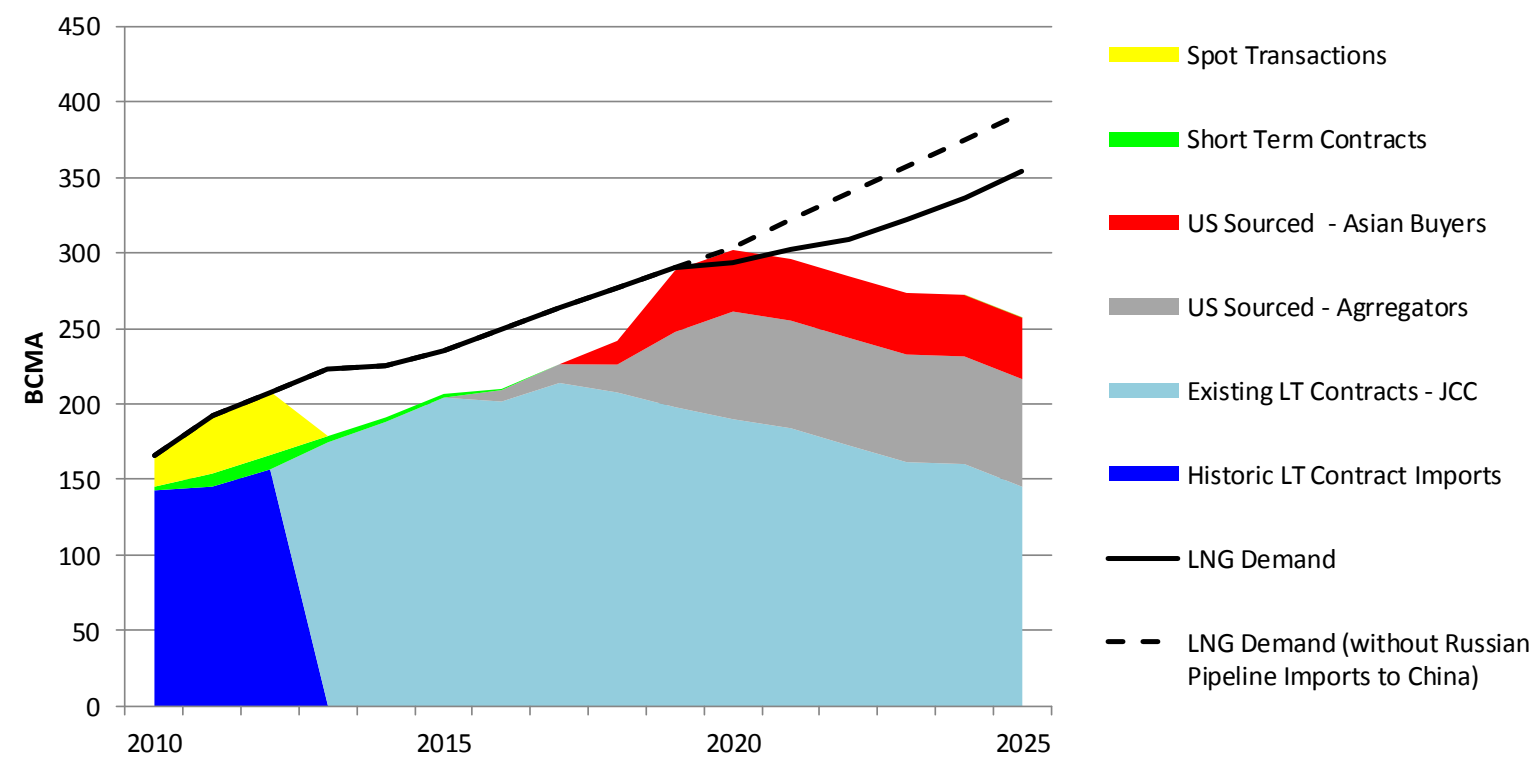

Source: GIIGNL, Rogers (2012), Company Websites, Author's Assumptions

The implications of this outlook are:

- If Asian buyers had hoped to substantially lower their average LNG purchase price by including substantial volumes of Henry-Hub price related LNG, they have been slow to seize this opportunity. Judging by statements made in company presentations and on conference platforms in 2012-13, the aggregators owning US export capacity individually believe that a 'tight' LNG market is likely to persist for many years and as a consequence they hoped to offer US-sourced LNG (through spot transactions, short, medium and long-term contracts), priced in line with current Asian prices i.e. at JCC levels.

- The potential additional US capacity as yet not committed to, still represents a prize, however this occurs in a post-2020 timescale and will not benefit buyers in the nearer term. It also entails considerable risk that if, over the duration of these contracts, Henry Hub prices rise to around or above $\$ 7 / \mathrm{MMBtu}$, buyers could find themselves paying prices in excess of JCC levels, depending in part on oil price trends.

- The remaining contestable demand for LNG from sources such as Australian projects not yet included in GIIGNL's 2012 contract database, and projects expected later in this decade from Mozambique, Tanzania, Canada and Russia will face significant competition in the Asian market both in terms of the size of the remaining contestable demand, and the price formation mechanism. This competition is the best hope for Asian LNG buyers to break with the JCC system because the alternative option of competing with Russian pipeline gas to Europe at hub prices is currently a less attractive option to LNG sellers. 
While stressing again the significant uncertainties underlying such illustrative projections, the picture of the late 2010s and early 2020s (conveyed in Figure 22), taking into account other competing nonUS projects, is one of a potentially well supplied global LNG market bringing with it the potential for deferral of high cost projects and possibly downward pressure on liquefaction capital costs ${ }^{72}$.

The conclusion of this analysis is that Asian Buyers, in their negotiations with aggregators and upstream sellers, will need to insist on a move away from JCC to a price mechanism which reflects anticipated market fundamentals in their countries. In the first instance this would be manifested in a refusal to pay JCC-related prices for aggregator volumes sourced from the US. This appears to be happening according to a report in early $2014^{73}$ implying a refusal on the part of Asian buyers to pay a premium of more than $\$ 1 / \mathrm{MMBtu}$ over contract price for US re-sales.

This however still leaves open the question of what, in the longer term, would be an appropriate pricing mechanism which reflects the fundamentals of the Asian LNG importing markets. One approach, adopted by India in setting the price paid for domestic production, combines an assessment of competing fuel netback in the Indian market with benchmark global gas prices such as Henry Hub and $\mathrm{NBP}^{74}$. Another approach is that of China with its netback from competing fuel (including gas) prices at the Shanghai city gate. These approaches are unlikely to be applicable more widely in the case of Asian LNG. Netback calculations tend to be country-specific, and can become rapidly outdated in fast growing markets where sectoral demand emphasis shifts over time. Other complexities include subsidy regimes such as for fertilizer manufacture. Also, in the case of competition with coal, government policy to reduce particulate and $\mathrm{CO}_{2}$ emissions introduces additional considerations which arguably render the netback approach impracticable. Nevertheless netback market gas pricing can work in a specific market as long as: there is sufficient flexibility to change the price as energy market conditions change and there is genuine and demonstrable switching capability between gas and the fuels against which its prices are being benchmarked.

The imperative for buyers, whether adopting a netback or any other price formation mechanism, will be to avoid locking themselves into long term inflexible price arrangements during a period when market dynamics will be changing rapidly.

If it is not possible to reach agreement on a new or transitional regime for LNG pricing, Asian buyers may simply be unable to sign new long term contracts. This would result in higher physical volumes sold on Asian spot and short term markets. If it transpires that the post 2015 period is one of LNG 'supply plenty' then US LNG export volumes would be limited to those which reduced the Henry Hub - Asian spot price spread to the level where liquefaction fees ${ }^{75}$ and shipping costs were no longer recovered.

For existing contracts, a renegotiation of price terms will be very difficult because Asian LNG contracts contain little in the way of enforceable price reopener provisions, and sellers which have made huge investments (particularly in new projects which have yet to start production) will be extremely resistant to any change in pricing. If prices in existing contracts cannot be changed, the only course of action for buyers will be to await with hope a sustained slump in crude oil prices which will reduce the immediate financial pain, but not the basic problem of economic and market

\footnotetext{
${ }^{72}$ See Songhurst, (forthcoming 2013).

73 ICIS Global LNG Markets, $2^{\text {nd }}$ January 2014, p.17

${ }^{74}$ http://articles.economictimes.indiatimes.com/2013-06-30/news/40287022 1 gas-price-hike-oil-gas-city-gasdistributors

${ }^{75}$ Note if liquefaction fee commitments are regarded as a fixed cost, then the Henry Hub - Asian LNG Spot price spread could reduce to that of just shipping costs.
} 
fundamentals. Oil prices substantially below $\$ 100 /$ bbl levels would bring relief to buyers but given the costs of new LNG projects (Figures 10 and 11) destabilising problems for exporters ${ }^{76}$.

We believe that, given the lead times for LNG projects, Asian LNG stakeholders should be anticipating a move towards pricing at an Asian hub. The challenges of creating such a hub are discussed in the following chapter.

\footnotetext{
${ }^{76}$ The exception would be LNG projects reaching the end of an existing contract where, with little or no new investment required and adequate remaining production potential, a new contract could be signed on a different price formation basis.
} 


\section{Chapter 5. The case for, and challenges facing, an Asian LNG trading hub}

As shown in Figure 23, the Asian LNG importing countries accounted for some $60 \%$ of all spot traded volumes in the period 2006 to 2012 . Given the increasing problem of defining market fundamentals and hence the difficulty of justifying a price mechanism - based on alternative fuels (described in Chapter 3), plus the growth trend in spot LNG trading over this period an obvious question is: why not base Asian LNG contract prices on a regional LNG spot price index? This is particularly germane against a background of Europe steadily moving away from oil-indexed to hub-based gas pricing.

Figure 23: Regional Split of Spot LNG Volumes 2006 - 2012

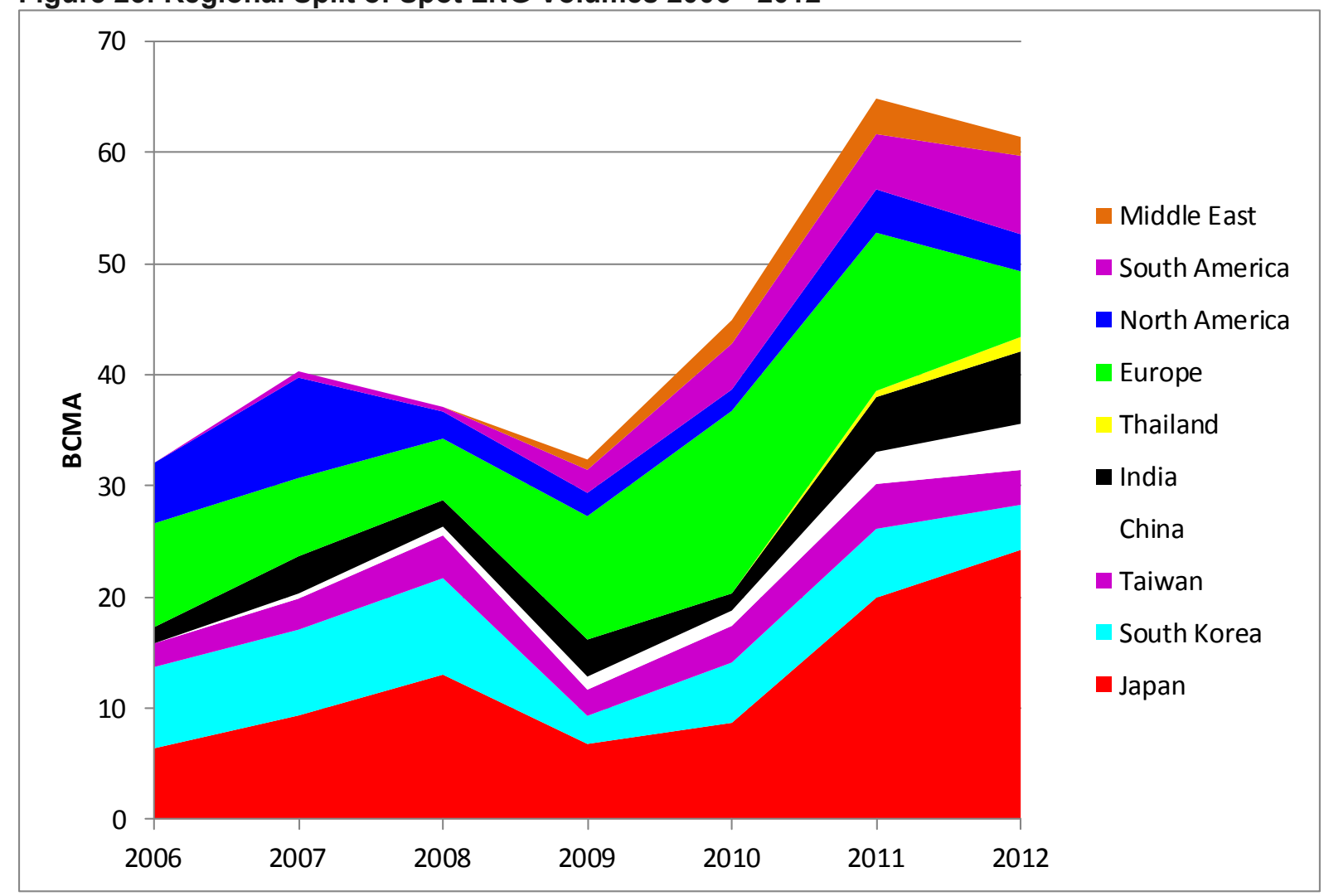

Source: GIIGNL

In 2013 the IEA published a report examining the obstacles and opportunities for developing a natural gas trading hub in Asia, the conclusions of which were summarised in its subsequent 2013 Medium Term Market Report. ${ }^{77}$ The key conclusions are that a competitive national/regional market would need to be developed in order to set a reliable gas price for the region. The market would need to meet a set of institutional and structural requirements to create the confidence for market parties to use a trading hub for constructing portfolios and to draw in new, especially financial, participants. Importantly it was concluded that this would require a 'hands-off' approach by governments, third party access to transport and LNG regasifaction facilities, and price deregulation at a wholesale level. Figure 24 is a schematic from the report which depicts the sequence of steps required to create a competitive wholesale gas market.

\footnotetext{
${ }^{77}$ IEA (2013a) and (2013b) pp.173 - 176.
} 
Figure 24: IEA Schematic Representing the Creation of a Competitive Wholesale Gas Market

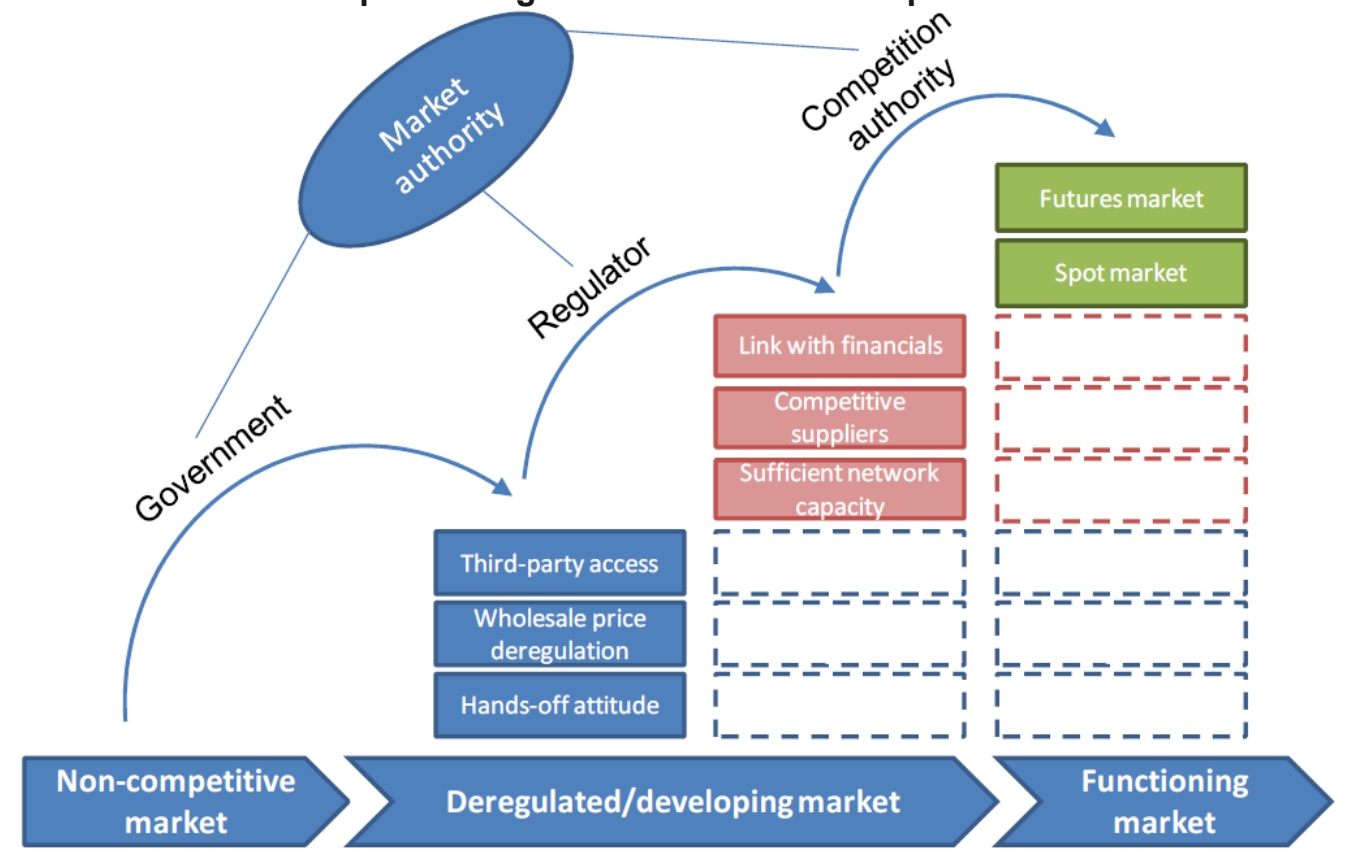

Source: IEA (2013a), Figure 18, p.33.

\subsection{Differences between North American, European, and LNG importing Asian markets}

There are a number of major differences between the current position of Asian markets and the experiences of North America and Europe in relation to hub development. The most important is that both the latter were mature pipeline gas markets with (aside from particular regions such as New England and individual countries such as Spain) limited reliance on LNG. Secondly both North America and Europe created hubs as part of deregulation (North America) and liberalisation (Europe) reforms which required several years (decades in Continental Europe) to develop. Only when these reforms had liberalised the market and allowed the entry of players other than the established utility companies could competition and hubs develop.

Another important aspect of hub development in North America and Europe was that initial resistance to liberalisation and competition was eventually overcome. Particularly in Continental Europe, major stakeholders resisted these developments. For around a decade up to 2007 hubs existed in north west Europe but they traded little gas and did not provide a reliable price reference. Eventually, following the events described in Chapter 3 , the former monopoly companies actively pressed for a transition to hub-based pricing, principally because the financial position in which they found themselves with their long term contractual commitments, became commercially untenable. In Continental Europe this situation is still ongoing and that is why - as mentioned above (see Table 2) there is still some way to go before the southern part of the Continent moves to hub prices. In addition, it is perfectly possible for a single country to operate a different market model if it is sufficiently isolated from the rest of the region - hence Britain had a liberalised gas market and a hub (NBP) price for a decade before similar developments began to transform Continental European markets. 
However, the major lesson from North American and European gas markets is that financial distress of major utilities is transformative. Therefore, for as long as Asian LNG importers are willing and able to continue paying high prices under long term contracts and pass these through to customers, oillinked pricing may continue (although we would argue that the traditional JCC price formation mechanism is unlikely to do so). But if the current system begins to impose multi-billion dollar losses on utilities, and the latter realise that future losses have become unpredictable and unquantifiable which appears to be the case currently in Japan (see Chapter 2) - then pricing and contractual mechanisms will have to change.

\subsection{Possible locations for an Asian LNG hub}

Japan

Japan has a tradition of commodities futures trading extending over 300 years. What is lacking for the formation of an energy futures trading system is a hands-off government approach and effective unbundling of transport activities. Onshore gas infrastructure is regionally segmented (although there are some connections) and is not counterbalanced by flexible LNG, as third party access (TPA) to LNG import terminals remains limited. ${ }^{78}$ The initiative of the Ministry of Economy, Trade and Industry (METI) to set up a gas futures market is an encouraging sign, but this would require liberalisation of the wholesale gas market, specifically TPA to LNG terminals and pipelines. This could provide the basis for a strong underling physical spot market on which a futures market could eventually be based.

From late 2012, Japanese politicians - increasingly supported by utility buyers - have been increasingly vocal in challenging the continuation of JCC-priced long term LNG contracts. In September 2012, Japanese Trade Minister Yukio Edano commented that Japan was experiencing an 'outflow of national wealth' as a result of high priced, oil-indexed LNG import contracts. Edano, at a conference in Tokyo called upon countries to 'brainstorm new measures as an alternative to the crude oil-linked pricing system, ${ }^{, 79}$.

As the largest Asian gas market China has domestic production, pipeline imports from both Turkmenistan and Myanmar (and potentially from Russia by the end of this decade) and LNG. The IEA sees formidable obstacles to establishing a liquid spot market, despite the fact that small quantities of LNG are already being traded in Shanghai. There is no TPA to pipeline or LNG infrastructure and the gas industry is dominated by three NOCs. ${ }^{80}$ Positive signs include an attempt to move from a heavily regulated pricing structure towards one that is more market-based, although this is still based on a netback to oil-indexed supplies. The major price reform which started at the end of 2011, introduced the concept of a "hub" to be established in Shanghai. ${ }^{81}$ However, although some trading is already taking place, the price is more akin to a city gate benchmark than a hub price. Although the Chinese price reform looks more like a classic Continental European netback price based on alternative fuels, this is the first step towards a price which reflects market fundamentals.

\footnotetext{
${ }^{78}$ Miyamoto (2008)

79 .Aussie LNG at risk as Japan shakes up Asian pricing model', Interfax Natural Gas Daily, 2 ${ }^{\text {nd }}$ October 2012, p. 1.

${ }^{80}$ However in early 2014 there were indications that the Chinese government was considering separating transmission networks from supply. Interfax Gas Daily, January 2, 2014, pp. 5-6.

${ }^{81}$ For an account of the Chinese price reform see Chen (2012) and Chen (forthcoming 2014).
} 
South Korea's KOGAS is the world's largest LNG importer and given the country's winter demand needs and lack of underground gas storage, South Korea is a large purchaser of spot LNG and has been pro-active in securing US LNG export volumes. However the South Korean market is dominated by KOGAS, although more recently other players have begun to enter the market and the most recent regasification terminal to be built is owned by Posco. While third party access exists legally, in practise market participants have to negotiate with KOGAS. Wholesale market gas prices are regulated based on an import cost pass-through basis, limiting incentives for spot trade.

Singapore has begun to develop a competitive natural gas market and a trading hub. Singapore has pipeline connections with Malaysia and Indonesia and Asia's first open-access LNG terminal (SLNG) which started operating in 2013. In the IEA's view, the government is pursuing a free market approach to both gas and power markets with unbundling of gas transport activities and deregulation of the wholesale market already in place; and is also supportive of establishing a gas trading hub. However, the Singapore gas market is less than $10 \mathrm{Bcma}$, and its expansion potential in terms of LNG receiving terminal and storage capacity is uncertain. It is also unclear whether and how gas imports will be allowed to evolve (as presumably there will be no wish to allow LNG to undercut contracted pipeline supplies).

Due to the simple fact of geography Japan, Korea, Taiwan, China and India will never achieve pipeline interconnections ${ }^{82}$ and so even if these countries were to liberalise their gas markets, it is unlikely that their individual reference prices would be well correlated. The movement of flexible LNG cargoes could in time provide something of a levelling force through arbitrage but, due to the timelags in LNG logistics, there are limits to how far such a process can develop.

Rather than waiting for one or more of the large Asian markets to act as the 'host' liberalised pipeline gas market to provide the regional price reference for LNG spot cargoes, it may be more pragmatic to focus on the Asian LNG market itself and assess its scope to become a liquid traded market in its own right, which in time could provide a reference price for longer term contracts, if these were still deemed necessary. The dynamics of the demand side would be driven by the quantities of LNG (in excess of other long term LNG contract supplies and in the case of China and India domestic and pipeline supplies) required to meet demand at the Asian hub price. Supply side dynamics would be driven by LNG availability (at the Asian hub price) in competition with other LNG consuming regions.

\subsection{An Asian LNG hub - practical considerations and challenges}

What follows are some practical considerations as to how such an Asian LNG hub could develop. The challenges to this are addressed later in this section. The key requirements for a hub are: a defined physical location (from which shipping costs to importing centres could be assessed by buyers considering trades); and a trading code would need to be developed (and impartially enforced) which would apply to all participants whether conducting bilateral, OTC or (later) exchange based trades. The risk of a cargo missing its trading delivery time window (and suffering the cost of delay and other missed opportunities) primarily due to adverse weather and possibly technical problems at cargo loading points, becomes important. In the context of the North American and North West European markets such delays can be hedged on the forward curve (and physical delivery met by other supplies). In Asia it would be necessary to either compensate the counterparty for delay or bridge the late (or early arrival) by using LNG storage facilities. Two further questions are the additional cost and

\footnotetext{
${ }^{82}$ Pipeline links would be physically possible - and at times have been proposed - between Japan and Korea, and China and Taiwan.
} 

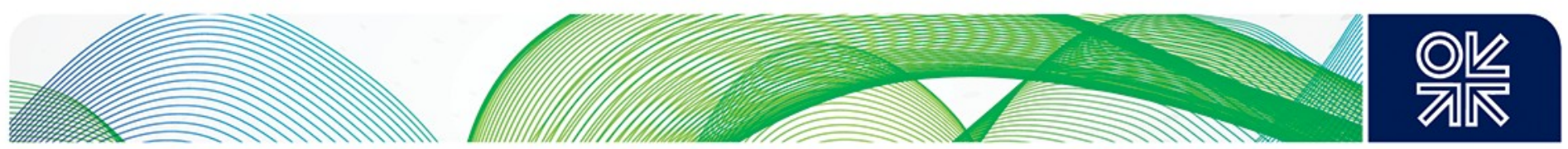

the size of storage facility required for a given level of market activity. On both these points Singapore currently appears to be a viable option (see Figure 25). Note however that this has nothing to do with Singapore's domestic gas market or its pipeline interconnections with Indonesia and Malaysia. It is unlikely that these could play a sizeable and responsive role in the task of time-balancing LNG cargo deliveries.

The key challenges to creating an Asian LNG trading hub in Singapore (or any alternative location established to serve the main Asian importers) relate to liquidity development. In 2011 and 2012 Asia imported some $40 \mathrm{Bcma}$ of spot LNG. Assuming an average vessel size of $150,000 \mathrm{~m}^{3}$ of liquid LNG this would translate to 465 cargoes/year (assuming all spot trade flowed through the hub) or on average 1.3 cargoes/day. If the minimum trade was one whole cargo this is likely to be a barrier to developing liquidity ${ }^{83}$. The second consideration in this regard is the restricted number of participants on the buying side of the trades. In the model where buyers purchase a spot cargo in Singapore and subsequently import it to their home country, the absence of access to regasification terminals, severely restricts the number of potential participants.

\section{Figure 25: Location of Singapore as an Asian LNG Hub}

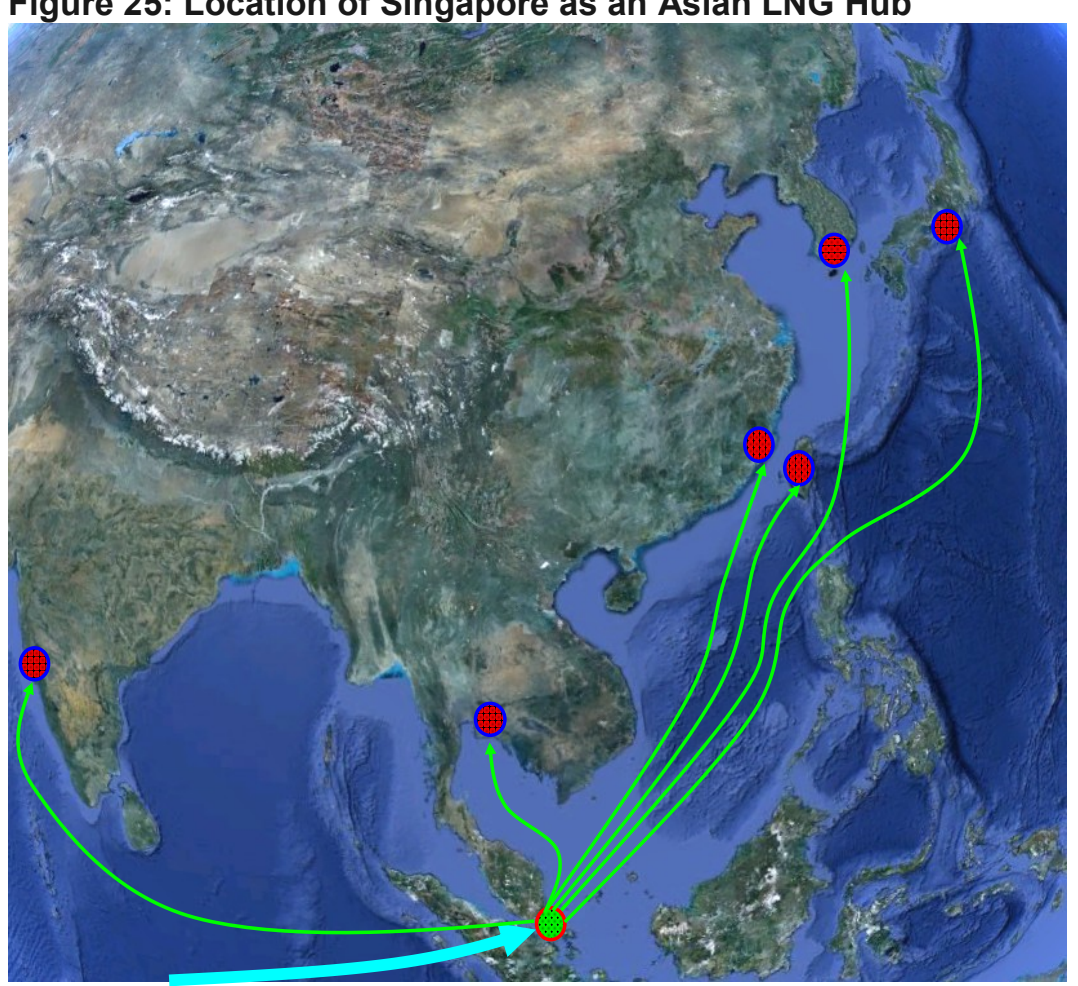

Source: GoogleEarth, Author

Figure 26 portrays stages of progress towards, and the potential consequences of, importing countries granting TPA to large end-users. In the final phase, where LNG hub prices were below those of JCC contracts, there is the real possibility of incumbent midstream utilities losing endconsumer market share to the extent that they could become unable to meet their Take or Pay obligations under existing contracts. In some ways this is comparable to developments in the North

\footnotetext{
${ }^{83}$ Part-cargoes could be traded but the additional cost of transporting them to the ultimate consuming country would be high in Singapore's case. This situation might be different if the hub was located in Japan or China, subject to terminal TPA considerations.
} 
West European market in the 2008-11 period which catalysed the transition to hub pricing, but involved great financial pain for the mid-stream incumbents. It is questionable whether Asian LNG importing governments would be prepared to expose their national LNG 'champions' to such financial burdens in the cause of reduced end-user prices. In the case of Japan however this already seems to be happening, with METI restricting the pass through of power generation costs by utilities to customers.

Clearly if an Asian LNG trading hub were to develop from the current position of bilateral trading, the next step would be the formation of a Singapore OTC market with brokers acting as intermediaries within an established and enforced trading code. Price reporting directly by an association of brokers $^{84}$ or via price reporting agencies (and ultimately exchanges when the hub acquires significant maturity) would constitute a considerable improvement on the current situation where transparency is limited ${ }^{85}$. Whether and when liquidity could develop to the point where such a reference price could provide the basis for long term LNG contracts is difficult to judge at this juncture.

Figure 26: The Consequences of Developing Access to Regasification Terminals in Asian LNG Importing Countries

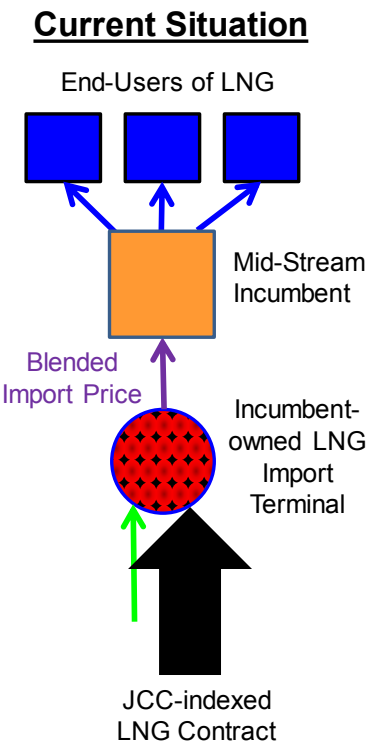

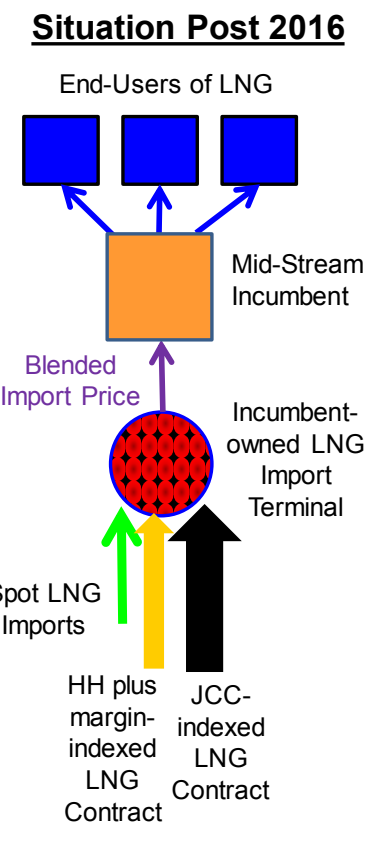

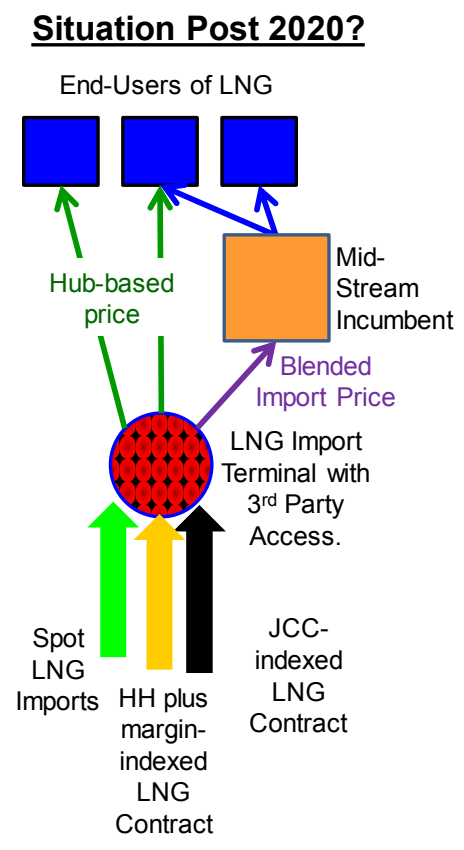

Source: Author

The Platts JKM price (shown in Figure 9) is the result of anonymous price disclosure by an unknown sample of counterparties to trades destined for Japan and Korea. For the first half of 2013, we examined the lists of Asian trades disclosed by Waterborne LNG and ICIS Heren. Combining these records (and excluding duplicate entries) 78 spot cargoes were identified for which price was reported for only 57 . The cargoes for which price was disclosed equate to some $4.8 \mathrm{Bcm}$ for the first half of 2013 (9.6 Bcm scaled-up to 12 months). The $9.6 \mathrm{Bcm}$ compares with the GIIGNL total Asian spot

\footnotetext{
${ }^{84}$ Such as the Tankard Index in European traded gas markets.

${ }^{85}$ For an account of the development of traded gas markets in the UK and Continental Europe see Heather (2010) and (2012).
} 

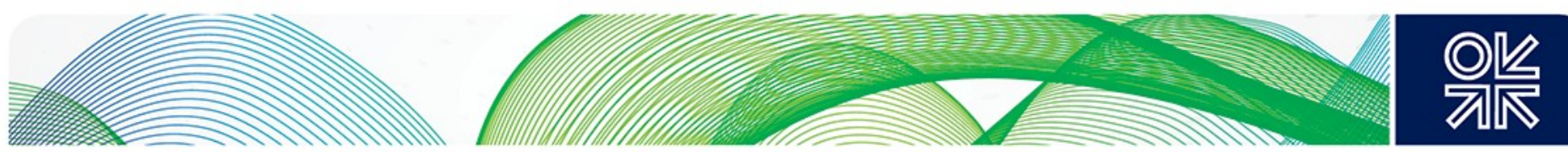

cargoes for 2012 of $40 \mathrm{Bcm}$ - i.e. a crude coverage ratio of $24 \%^{86}$. Whether Platts' coverage is more complete is not known.

The government-expressed intention to establish a gas futures market in Japan is something of a puzzle. In North America and Europe the experience has been that futures markets developed after confidence in a liquid prompt physical market had been established. Absent a liberalised and interconnected gas market within Japan, a futures price would be based on a view of future Japanese LNG import prices driven by the forward curve for JCC. Given their territorial control of the import and transmission network it would be highly unlikely that Japanese midstream LNG importers would allow a glut of physical supply on a wholesale market to depress prices. This could become more likely if the share of spot and short term trade - priced on a hub basis - continued to grow relative to long term oil-indexed volumes.

The challenges in establishing a hub reference price for LNG in Asia are significant. The prospect of any of the major LNG importing markets liberalising and establishing a hub with sufficient liquidity to act as a price reference for LNG trades appears remote until at least the late 2010s. Basing a hub reference price purely on LNG spot trading at a location such as Singapore seems feasible from a physical and practical viewpoint. But the likelihood of it developing the required level of liquidity to serve as a reference price for long term contracts seems overly optimistic, unless volumes can expand sufficiently to become a credible indicator of regional LNG supply and demand fundamentals. While approvals of new US LNG export projects, and the implicit challenge (in volumetric terms) to other suppliers, will help to create change in this direction towards the end of this decade, this is probably the earliest date we are likely to see a liquid traded market for Asian LNG.

${ }^{86}$ Assuming 2013 Asian spot cargo volumes are broadly in line with 2012. 


\section{Chapter 6. Summary and Conclusions: scenarios for future Asian LNG pricing and contracting}

Since 2000, diverging regional gas demand and production trends have induced a wider and more flexible network of trade-flows in an increasingly interconnected gas world. This progress was accelerated by unforeseen shocks in both supply and demand. Flexibility was negotiated into European contracts to enable arbitrage with Asian markets when price spreads were favourable and post 2005 some new trains, particularly in Qatar, were developed with deliberate destination flexibility. North America and the UK entered the 2000s with liberalised markets and hub prices driven by supply and demand for gas. After many years of pro-competition EU regulatory initiatives, the dominance of oil-indexation in continental Europe began to wane in the aftermath of the 2008 financial crisis as increased LNG imports, flagging demand and the increased liquidity of continental European trading hubs provided end users with a lower price alternative to oil-indexed supply. The consequent financial exposure experienced by the midstream buyers catalysed a series of arbitration proceedings and price renegotiations, after which the majority of Norwegian and Dutch contracts are now operating at hub prices. In 2013 a combination of base price reductions and rebates brought Russian long term contract prices in competitive markets close to hub levels. But Algerian long term contract prices remain oil indexed and many arbitrations are ongoing. Hub pricing in Europe is expected to continue to spread from the north west, east and south across the European geography over the rest of this decade and beyond.

Since the 1980s, prices in Asian long term LNG contracts have been based on linkage to crude oil prices through the JCC mechanism. For nearly 30 years this relatively simple mechanism (with its details shrouded in commercial confidentiality) worked well. But with the rapid increase in oil prices post 2008, Asian LNG contract prices became significantly higher than European, and multiples of North American, levels. This situation was further exacerbated by the impact of the Fukushima disaster in March 2011, and consequent additional Japanese LNG demand to compensate for the progressive shut down of Japan's nuclear power generating facilities. While Asian spot LNG prices prior to Fukushima generally appear to reflect differential transport costs to alternative markets (i.e. arbitrage on the part of flexible LNG suppliers), since March 2011 these prices appear to be based on sellers seeking parity with JCC long term contract prices with flexible LNG suppliers perhaps exercising 'discriminating monopoly' power. The impact of the replacement of nuclear power by LNG at historically high prices, caused a dramatic deterioration in the financial position of Japan's ten largest power generation companies which, in Japanese FY 2011 and FY 2012, made an aggregate loss of $\$ 19-20$ billion (\$10-11 billion excluding TEPCO). Since 2012, increasing outflows of national wealth due to a rapidly increasing LNG import bill, and the deterioration of domestic industrial competitiveness, have led the Japanese government to propose a number of alternatives to crude oilindexed pricing, including a futures market and a market hub. In other gas markets which have liberalised, financial distress of major stakeholders has been transformative, and this is likely to be the case in Japan.

Low gas prices in the US, caused by the rush of upstream players to establish positions on the numerous shale gas plays, and the consequent growth in gas production outstripping domestic demand, prompted some of the owners of the numerous US regas import terminals to develop liquefaction facilities which would allow them to become LNG exporters. At the end of September 2013, four export projects had received non-FTA approval totalling some 70 Bcma of export capacity with further project approvals potentially to follow. When projects with agreed off-take arrangements are included, (subject to future approval and FIDs), this total rises to $112 \mathrm{Bcma}$ ). The majority of US export capacity secured to date has been by LNG aggregators, with Asian LNG buyers slow to seize 
the opportunity. It is likely that the aggregators intended to sell these volumes to Asian buyers in the form of short, medium or long term JCC-linked contracts, however this seems at present to be resisted by Asian buyers. The pace of build-up of US export volumes will be driven by:

- the time taken for FERC to approve the 70 Bcma of capacity for which non-FTA approval has been granted and the subsequent construction time and

- the rate at which the US DOE awards non-FTA approval to the balance of the 112Bcma of export projects which have in-place offtake agreements (or Heads of Agreement). At present it appears highly likely that at least 80 Bcma of export capacity will be onstream in the 2019 to 2022 window, but perhaps only around 30 Bcma prior to 2019 .

Spot LNG volumes grew from $16.1 \%$ of global LNG trade in 2006 to $19.5 \%$ in 2012; in Asia the corresponding figures were $13.6 \%$ to $19.1 \%$. Having examined the future gas requirements and trading patterns of individual major Asian LNG importing countries we concluded that:

Japan is likely to continue to rely on spot volumes to supply its additional requirements prior to the re-start of substantial nuclear generation. In addition to its long term JCC contracts, it must find additional volumes post 2020 as its long term contractual portfolio volumes begin to expire.

Beyond 2017, South Korea needs to identify additional volumes beyond existing medium and long term contracted volumes and current levels of spot LNG. This could be from a combination of US-sourced portfolio volumes, and new Australian, Russian and East African LNG projects.

Up to 2020, Taiwan could probably meet the gap between its existing medium and long term contract volumes and demand by further recourse to spot volumes.

India's future LNG requirements are subject to significant uncertainty, however to 2020 it could probably supplement its existing $\mathrm{JCC}$ and $\mathrm{HH}$-linked medium and long term contract portfolio with spot volumes.

Of all the Asian LNG importers, China appears to have the lowest degree of coverage of its potential future LNG requirements in the form of medium and long term contracted volumes, despite its ongoing construction of import terminals. Its future requirements will likely be met by Canadian, Russian, Australian and East African new project volumes in addition to USsourced aggregator volumes.

If this is correct, it means that Korea, Japan and China will need to sign new LNG contracts for delivery in the early 2020s. The question then is what price and contractual conditions should those buyers be seeking? The conclusion of this analysis is that Asian buyers, in their negotiations with aggregators and upstream sellers, will need to insist on a move away from JCC to a price mechanism which reflects anticipated market fundamentals in their countries. These fundamentals will be some combination of:

- the price-volume relationship of competing fuels in their domestic energy markets;

- the volume of LNG available, including that which can be attracted to Asia (as a function of price):

$\circ \quad$ from the US (where Asian prices remunerate gas sourcing, liquefaction and transportation costs),

- from Europe (i.e. in excess of pipeline gas prices)

- from new LNG projects able to achieve FID at the anticipated Asian LNG price. 
As we state above, the imperative for buyers will be not to lock themselves into long term inflexible price arrangements during a period when market dynamics will be changing rapidly. At present those arrangements relate to oil- and specifically JCC-related contracts, but should Henry Hub prices increase and oil prices fall, there is a risk that Henry Hub-related prices could exceed prices in existing JCC contracts. Overall there is a major analytical problem of assuming that spot gas or hub prices will always be "cheaper" than oil-related prices (although at oil prices in excess of $\$ 100 / \mathrm{bbl}$ this is likely to be the case). We stress again that the main task is to focus on the current and future gas supply/demand fundamentals of the market where the gas is being imported.

If it is not possible to reach agreement on a new or transitional regime for LNG pricing. Asian buyers may simply be unable to sign new long term contracts. This would initially result in higher physical volumes sold on Asian spot and short term markets. If it transpires that the post 2015 period is one of LNG 'supply plenty' then US LNG export volumes would be limited to those which reduced the Henry Hub - Asian spot price spread to the level where liquefaction fees, ${ }^{87}$ and shipping costs were no longer recovered.

For existing contracts, a renegotiation of price terms will be very difficult because Asian LNG contracts contain little in the way of enforceable price reopener provisions, and sellers which have made huge investments (particularly in new projects which have yet to start production) will be extremely resistant to any change in pricing. If prices in existing contracts cannot be changed, the only course of action for buyers is to await with hope a sustained slump in crude oil prices which would reduce the immediate financial pain, but not the basic problem of economic and market fundamentals. Oil prices substantially below $\$ 100 / \mathrm{bbl}$ levels would bring relief to buyers but, given the costs of new LNG projects (Figures 10 and 11), financial problems for exporters.

Unlike North America and increasingly Europe, where liquid trading hubs for natural gas provide a readily accessible market for spot LNG cargoes and a reliable and 'hedgeable' price, none of the Asian LNG markets have liberalised wholesale gas markets and have not demonstrated any determination at the policy level to achieve this over the next five years. Due to geographic separation, the Asian LNG importers do not have any prospect of establishing regional connectivity through cross-border interconnecting pipeline infrastructure.

This directs the focus towards the establishment of an Asian hub purely on the basis of spot LNG trading. The hub would have to be at a fixed physical location (to assess onward shipping costs) and have LNG storage capacity to allow for cargoes arriving earlier or later than their trade settlement date. Subject to sufficient storage capacity being available, Singapore appears to represent the best initial location for such a hub, and got under way as a trading location at the end of 2013.

The biggest current challenge is that of achieving liquidity at such a hub. In 2011 and 2012 Asian LNG spot volumes averaged $40 \mathrm{Bcma}$. This translates to 465 cargoes/year (1.3/day on average). As it is difficult to envisage the trading of less than a whole cargo in this model, liquidity remains an open question. If Asian buyers are successful in resisting the aggregators' aims to "term-up" US exports into JCC priced contracts, the number of cargoes could increase by a factor of two or more.

Another challenge is the likely restriction of buy-side trading participants to the existing Asian incumbents owning regasification facilities and onward grid transmission systems. Unless importing

\footnotetext{
${ }^{87}$ Note that if liquefaction fee commitments are regarded as a fixed cost, then the Henry Hub - Asian LNG Spot price spread could reduce to that of just shipping costs in this situation.
} 
nation governments require Third Party Access (TPA) to be made available at these facilities it is unlikely that large end-users (industrial customers for example) could engage in LNG spot trading. A consequence of such a move to establishing TPA could be that the midstream incumbents lose end user market share, to the point where they are unable to meet their long term take or pay commitments and suffer the consequent financial exposure seen in Europe during its transition to hub pricing

The participation of OTC brokers at a nascent Singapore hub, (with Price Reporting Agency disclosure or broker association indices), would be a positive move in providing a transparent price index. At present indices such as Platts JKM (Japan Korea Marker), cover bilateral trades where the buyer or seller is willing to disclose price. The level of coverage is unknown and the significant swings in JKM during 2010-2013 suggest a shallow market.

Whilst it is expected that LNG spot volumes will continue at least at 2011-12 levels in the future, the contractual conditions in existing JCC contracts for all the Asian countries (with the notable exception of China) suggest limited scope for radically changing national average LNG import prices away from JCC-linkage. Changing this situation lies wholly in the hands of the Asian LNG importers. To bring about a material change in their circumstances they would need to: support the establishment of an LNG trading hub and refuse any suggestions that they should pay JCC-related price for new supplies even if this should result in the deferral of projects. Gas buyers need to create a price formula which is based on demonstrable gas supply and demand fundamentals in their respective countries. This need not necessarily be the same price formation mechanism for all countries. Some countries - in particular China and India - could operate a netback market pricing system similar to Continental European countries prior to the transition to hub-based pricing. But we believe that the long term LNG pricing solution in Asia is market pricing at a hub.

There will be many problems in developing an LNG hub as a reference price for Asian LNG. This may require a significantly different attitude to security of supply - particularly in Japan - where security concerns have created a culture of early contracting of long term LNG supplies in order to cover possible future demand requirements. How quickly spot cargo liquidity will be sufficient to allow for a reliable reference price is also uncertain, both in extent and timeframe. Whether the determination of LNG buyers to promote a market-based solution to their pricing problems will be sufficient for success is uncertain but, as we have mentioned above, financial distress of major utilities may be transformative. The example of price formation evolution in Europe, and the analysis in this paper, suggests that the Asian LNG market is at the very beginning of such a transition which is likely to be ongoing throughout the 2010 s and into the 2020s.

\section{Scenarios for Asian LNG pricing and contracting in the 2010s and beyond}

We conclude this paper with three scenarios for the development of LNG pricing in Asia over the next decade:

Contractual Impasse: buyers continue to complain about JCC pricing but there is little change in the status quo. No changes can be agreed in existing contracts. Buyers refuse to sign new long term contracts at prices linked to crude oil even with lower slopes; producers refuse to go ahead with new projects on any other price basis, and no new long term LNG contracts are signed. Spot trade increases with US LNG export growth, but the problems identified in this paper in relation to price competitiveness (of average LNG import prices) mean that Asian LNG trade stagnates.

Smooth Contractual Transition: new contracts start to be signed with a mix of oil, hub and spot prices (perhaps from various regions of the world), with price review clauses which mandate renegotiation of prices after a number of years, anticipating the creation of an Asian hub or hubs. There are challenges to existing contract prices, but renegotiations result in adjustments which are tolerable for 

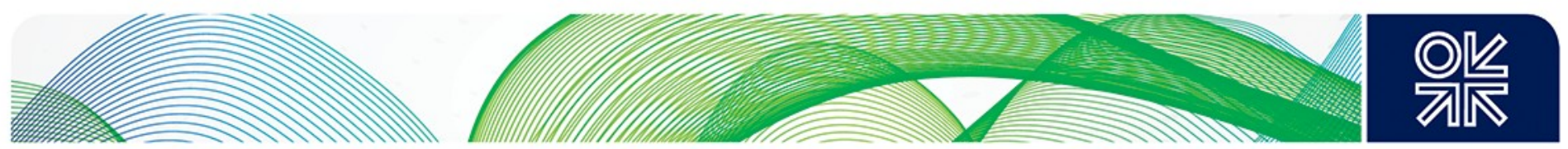

both buyers and sellers with no fundamental changes or litigation. Despite suffering substantial financial losses, Japanese buyers "hang on" until their existing long term contracts begin to expire. Spot trading increases significantly and a hub price begins to emerge during the late 2010s, initially in Singapore. By the 2020s, larger and more liquid hubs emerge in Tokyo and Shanghai and new contracts with buyers in those countries are priced on this basis. This scenario is most likely in a context of an oil price decline to significantly below $\$ 100 / \mathrm{bbl}$.

Contractual Train Wreck: Japanese LNG buyers find that their losses from existing contracts become financially untenable and demand price renegotiations; these are resisted by suppliers with new, high cost projects coming on stream which need to pay back substantial investments and are unable to compromise on the JCC-related prices in their contracts. Litigation ensues with unpredictable results (and large financial sums at stake), but the process highlights the need for a "reset" in the commercial framework. A several year period of commercial upheaval ensues during which no new contracts are signed other than with North American sellers, but spot and short term trading continues to increase and, as in the 'Smooth Commercial Transition' scenario, a hub price emerges in Singapore, followed by larger and more liquid hubs in Tokyo and Shanghai and new contracts with buyers in those countries are priced on this basis. This scenario becomes more likely in a context of an oil price increase significantly above $\$ 120 / \mathrm{bbl}$.

In all three scenarios, new contracts are signed with North American sellers on a Henry Hub or other North American hub price basis, but this introduces another risk for buyers that such prices do not reflect evolving market fundamentals in the Pacific region.

We believe that 'Contractual Impasse' may describe the Asian LNG market in 2013-14. It is not a likely scenario beyond those years but remains a possible outcome, at least for a few years, if parties are unable to reach agreement. The 'Smooth Contractual Transition' scenario is clearly the most desirable outcome to move from the JCC status quo to hub-based pricing. However, it depends on maintaining a controllable financial situation for buyers and sellers. The 'Contractual Train Wreck' scenario results from the financial position of buyers (and/or sellers) becoming untenable. All Asian LNG stakeholders must clearly be hoping this does not occur, but every other market where prices have liberalised and hubs have been created - North America, UK and Continental Europe - has been characterised by "contractual train wrecks" of varying magnitude (Continental Europe is the best example of smooth contractual transition albeit with several major 'bumps'). It must be hoped that Asian LNG markets can avoid such a scenario, but it is by no means guaranteed. 
Appendix 1 - Membership of GIIGNL in 2014

\section{Americas - 10 Members}

BG Group PIc.

Cheniere Energy, Inc.

Chevron Global Gas

Freeport LNG Development, L.P.

GDF SUEZ GAS NA

GNL Quintero S.A.

Repsol Energy Canada

Sempra LNG

Southern LNG Company, LLC

YPF S.A.

\section{Europe - 32 Members}

\section{Botas}

BP Global LNG

Centrica LNG Company

DEPADistrigas S.A.

DONG NATURGAS A/S

Dragon LNG Limited

Dunkerque LNG

EDF Trading Limited

Edison S.p.A.

EDP Energias de Portugal, S.A.

Elengy S.A.

Enagas

Enel Trade

Eni S.p.A

E.ON Global Commodities SEFluxys LNG S.A.

Gas Natural Fenosa

Gate Terminal B.V.

GDF SUEZ

GNL Italia S.p.A.

Iberdrola Generacion S.A.U.

National Grid Grain LNG, Ltd.

N.V. Nederlandse Gasunie

O.M.V. Gas and Power GmbH

POLSKIE LNG S.A.

Ren Atlantico, S.A.

Shell Western LNG B.V.

Sonatrach Gas Marketing UK Limited

South Hook LNG Terminal Company, Ltd.

Statoil ASA

Total S.A.

Vopak LNG Holding B.V.

Asia - 32 Members

Chubu Electric Power Company, Inc. 
CNOOC Gas \& Power Group

CPC Corporation, Taiwan

Gail India Limited

Guandong Dapeng LNG Company, Ltd.

Gujurat State Petroleum Corp. Ltd. (G.S.P.C.)

Hiroshima Gas Company, Ltd.

HOKKAIDO GAS

INPEX CORPORATION

Itochu Corporation

JX Nippon Oil \& Energy Corp

Korea Gas Corporation

Kyushu Electric Power Company, Inc.

LNG Japan Corporation

Marubeni Corporation

Mitsubishi Corporation

Mitsui \& Company, Ltd.

Nippon Gas Company, Ltd

Osaka Gas Company, Ltd

Petronet LNG Limited

Posco (PTT)

Saibu Gas Company, Ltd.

Shikoku Electric Power Company

Shizuoku Gas Company, Ltd.

SK E\&S Compant Ltd.

Sumitomo Corporation

The Chugoku Electric Power Company, Inc.

The Kansai Electric Power Company, Inc.

The Tokyo Electric Power Company, Inc.

Toho Gas Company, Ltd.

Tohoku Electric Power Company, Inc

Tokyo Gas Company, Ltd. 


\section{Appendix 2 - List of US LNG export Free Trade Agreement countries}

The United States has free trade agreements in force with 20 countries. These are:

Australia

Bahrain

Canada

Chile

Colombia

Costa Rica

Dominican Republic

El Salvador

Guatemala

Honduras

Israel

Jordan

Korea

Mexico

Morocco

Nicaragua

Oman

Panama

Peru

Singapore

Source: Office of the United States Trade Representative, http://www.ustr.gov/trade-agreements/free-tradeagreements 


\title{
Appendix 3 - US LNG Project Application Status, $5^{\text {th }}$ October 2013
}

\author{
Applications Received by DOE/FE to Export Domestically Produced LNG \\ from the Lower-48 States (as of October 15, 2013) \\ All Changes Since September 19, 2013 Update Are In Red
}

\begin{tabular}{|c|c|c|c|}
\hline Company & Quantity ${ }^{(a)}$ & $\begin{array}{l}\text { FTA Applications }{ }^{(b)} \\
\text { (Docket Number) }\end{array}$ & $\begin{array}{l}\text { Non-FTA Applications } \\
\text { (Docket Number) }\end{array}$ \\
\hline Sabine Pass Liquefaction, LLC & $\begin{array}{l}2.2 \text { billion cubic feet per } \\
\text { day (Bcf/d) }\end{array}$ & Approved (10-85-LNG) & Approved (10-111-LNG) \\
\hline $\begin{array}{l}\text { Freeport LNG Expansion, L.P. and FLNG } \\
\text { Liquefaction, LLC }\end{array}$ & $1.4 \mathrm{Bcf} / \mathrm{d}^{\text {(d) }}$ & Approved (10-160-LNG) & Approved (10-161-LNG) \\
\hline Lake Charles Exports, LLC & $2.0 \mathrm{Bcf} / \mathrm{d}^{(-))_{*}}$ & Approved (11-59-LNG) & Approved (11-59-LNG) \\
\hline Carib Energy (USA) LLC & $\begin{array}{c}0.03 \mathrm{Bcf} / \mathrm{d}: \text { FTA } \\
0.01 \mathrm{Bcf} / \mathrm{d}: \text { non-FTA }\end{array}$ & Approved (11-71-LNG) & Under DOE Review (11-141-LNG) \\
\hline Dominion Cove Point LNG, LP & $\begin{array}{c}1.0 \mathrm{Bcf} / \mathrm{d}: \text { FTA } \\
0.77 \mathrm{Bcf} / \mathrm{d}: \text { non-FTA }\end{array}$ & Approved (11-115-LNG) & Approved (11-128-LNG) \\
\hline Jordan Cove Energy Project, L.P. & $\begin{array}{c}1.2 \mathrm{Bcf} / \mathrm{d}: \text { FTA } \\
0.8 \mathrm{Bcf} / \mathrm{d}: \text { non-FTA }\end{array}$ & Approved (11-127-LNG) & Under DOE Review (12-32-LNG) \\
\hline Cameron LNG, LLC & $1.7 \mathrm{Bcf} / \mathrm{d}$ & Approved (11-145-LNG) & Under DOE Review (11-162-LNG) \\
\hline $\begin{array}{l}\text { Freeport LNG Expansion, L.P. and FLNG } \\
\text { Liquefaction, LLC }\end{array}$ & $1.4 \mathrm{Bcf} / \mathrm{d}$ & Approved (12-06-LNG) & Under DOE Review (11-161-LNG) \\
\hline Gulf Coast LNG Export, LLC & $2.8 \mathrm{Bcf} / \mathrm{d}^{(\mathrm{d})}$ & Approved (12-05-LNG) & Under DOE Review (12-05-LNG) \\
\hline Gulf LNG Liquefaction Company, LLC & $1.5 \mathrm{Bcf} / \mathrm{d}^{(\mathrm{d})}$ & Approved (12-47-LNG) & Under DOE Review (12-101-LNG) \\
\hline $\begin{array}{l}\text { LNG Development Company, LLC (d/b/a } \\
\text { Oregon LNG) }\end{array}$ & $1.25 \mathrm{Bcf} / \mathrm{d}^{\text {(ब) }}$ & Approved (12-48-LNG) & Under DOE Review (12-77-LNG) \\
\hline SB Power Solutions Inc. & $0.07 \mathrm{Bcf} / \mathrm{d}$ & Approved (12-50-LNG) & $\mathrm{n} / \mathrm{a}$ \\
\hline Southern LNG Company, L.L.C. & $0.5 \mathrm{Bcf} / \mathrm{d}^{(\mathrm{d})}$ & Approved (12-54-LNG) & Under DOE Review (12-100-LNG) \\
\hline Excelerate Liquefaction Solutions I, LLC & $1.38 \mathrm{Bcf} / \mathrm{d}^{(\mathrm{d})}$ & Approved (12-61-LNG) & Under DOE Review (12-146-LNG) \\
\hline Golden Pass Products LLC & $2.6 \mathrm{Bcf} / \mathrm{d}^{(\mathrm{d})}$ & Approved (12-88 -LNG) & Under DOE Review (12-156-LNG) \\
\hline Cheniere Marketing, LLC & $2.1 \mathrm{Bcf} / \mathrm{d}^{(\mathrm{d})}$ & Approved (12-99-LNG) & Under DOE Review (12-97-LNG) \\
\hline Main Pass Energy Hub, LLC & $3.22 \mathrm{Bcf} / \mathrm{d}^{* *}$ & Approved (12-114-LNG) & $\mathrm{n} / \mathrm{a}$ \\
\hline CE FLNG, LLC & $1.07 \mathrm{Bcf} / \mathrm{d}^{(\mathrm{d})}$ & Approved (12-123-LNG) & Under DOE Review (12-123-LNG) \\
\hline Waller LNG Services, LLC & $0.16 \mathrm{Bcf} / \mathrm{d}$ & Approved (12-152-LNG) & $\mathrm{n} / \mathrm{a}$ \\
\hline Pangea LNG (North America) Holdings, LLC & $1.09 \mathrm{Bcf} / \mathrm{d}^{\mathrm{d}}$ & Approved (12-174-LNG) & Under DOE Review (12-184-LNG) \\
\hline Magnolia LNG, LLC & $0.54 \mathrm{Bcf} / \mathrm{d}^{(\mathrm{j})}$ & Approved (12-183-LNG) & $\mathrm{n} / \mathrm{a}$ \\
\hline Trunkline LNG Export, LLC & $2.0 \mathrm{Bcf} / \mathrm{d}^{*}$ & Approved (13-04-LNG) & Under DOE Review (13-04-LNG) \\
\hline Gasfin Development USA, LLC & $0.2 \mathrm{Bcf} / \mathrm{d}$ & Approved (13-06-LNG) & $\mathrm{n} / \mathrm{a}$ \\
\hline Freeport-McMoRan Energy LLC & $3.22 \mathrm{Bcf} / \mathrm{d}^{* *}$ & Approved (13-26-LNG) & Under DOE Review (13-26-LNG) \\
\hline Sabine Pass Liquefaction, LLC & $0.28 \mathrm{Bcf} / \mathrm{d}^{(\mathrm{d})}$ & Approved (13-30-LNG) & Under DOE Review (13-30-LNG) \\
\hline Sabine Pass Liquefaction, LLC & $0.24 \mathrm{Bcf} / \mathrm{d}^{(\mathrm{d})}$ & Approved (13-42-LNG) & Under DOE Review (13-42-LNG) \\
\hline Venture Global LNG, LLC & $0.67 \mathrm{Bcf} / \mathrm{d}^{(\mathrm{d})}$ & Approved (13-69-LNG) & Under DOE Review (13-69-LNG) \\
\hline Advanced Energy Solutions, L.L.C. & $0.02 \mathrm{Bcf} / \mathrm{d}$ & Pending Approval (13-104-LNG) & $\mathrm{n} / \mathrm{a}$ \\
\hline Argent Marine Management, Inc. & $0.003 \mathrm{Bcf} / \mathrm{d}$ & Pending Approval (13-105-LNG) & $\mathrm{n} / \mathrm{a}$ \\
\hline Eos LNG LLC & $1.6 \mathrm{Bcf} / \mathrm{d}^{(\mathrm{d})}$ & Pending Approval (13-115-LNG) & Under DOE Review (13-116-LNG) \\
\hline Barca LNG LLC & $1.6 \mathrm{Bcf} / \mathrm{d}^{(\mathrm{d})}$ & Pending Approval (13-117-LNG) & Under DOE Review (13-118-LNG) \\
\hline Sabine Pass Liquefaction, LLC & $0.86 \mathrm{Bcf} / \mathrm{d}^{(\mathrm{d})}$ & Pending Approval (13-121-LNG) & Under DOE Review (13-121-LNG) \\
\hline Delfin LNG LLC & $1.8 \mathrm{Bcf} / \mathrm{d}$ & Pending Approval (13-129-LNG) & $\mathrm{n} / \mathrm{a}$ \\
\hline Magnolia LNG, LLC & $\begin{array}{c}0.54 \mathrm{Bcf} / \mathrm{d}: \mathrm{FTA}^{(\mathrm{i})} \\
1.08 \mathrm{Bcf} / \mathrm{d}: \text { Non-FTA } \\
\end{array}$ & Pending Approval (13-131-LNG) & Under DOE Review (13-132-LNG) \\
\hline Total of all Applications Received & & $37.02 \mathrm{Bcf} / \mathrm{d}\left({ }^{*}\right)\left({ }^{* *}\right)$ & $34.12 \mathrm{Bcf} / \mathrm{d}\left({ }^{*}\right)\left({ }^{* *}\right)$ \\
\hline
\end{tabular}



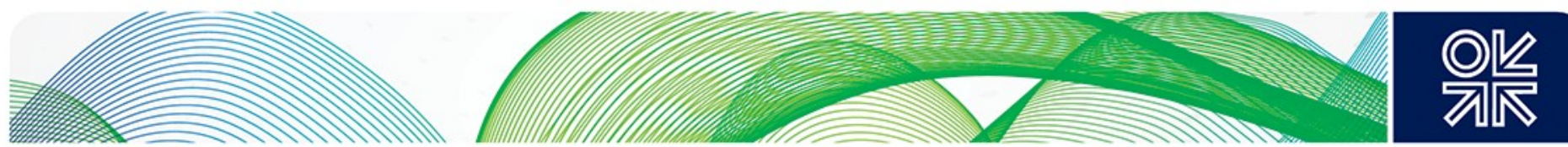

\section{Notes to Table:}

* Lake Charles Exports, LLC (LCE) and Trunkline LNG Export, LLC (TLNG), the owner of the Lake Charles Terminal, have both filed an application to export up to $2.0 \mathrm{Bcf} / \mathrm{d}$ of LNG from the Lake Charles Terminal. The total quantity of combined exports requested between LCE and TLNG does not exceed $2.0 \mathrm{Bcf} / \mathrm{d}$ (i.e., both requests are not additive and only $2 \mathrm{Bcf} / \mathrm{d}$ is included in the bottom-line total of applications received).

** Main Pass Energy Hub, LLC (MPEH) and Freeport McMoRan Energy LLC (FME), have both filed an application to export up to 3.22 Bcf/d of LNG from the Main Pass Energy Hub. (The existing Main Pass Energy Hub structures are owned by FME). The total quantity of combined FTA exports requested between MPEH and FME does not exceed $3.22 \mathrm{Bcf} / \mathrm{d}$ (i.e., both requests are not additive and only $3.22 \mathrm{Bcf} / \mathrm{d}$ is included in the bottom-line total of FTA applications received). FME's application includes exports of $3.22 \mathrm{Bcf} / \mathrm{d}$ to non-FTA countries and is included in the bottom line total of non-FTA applications received, while MPEH has not submitted an application to export LNG to non-FTA countries.

\section{Applications Received by DOE/FE to Export Domestically Produced LNG from the Lower-48 States (as of October 15, 2013) \\ All Changes Since September 19, 2013 Update Are In Red}

(a) Actual applications were in the equivalent annual quantities.

(b) FTA - Applications to export to free trade agreement (FTA) countries. The Natural Gas Act, as amended, has deemed FTA exports to be in the public interest and applications shall be authorized without modification or delay.

(c) Non-FTA applications require DOE to post a notice of application in the Federal Register for comments, protests and motions to intervene, and to evaluate the application to make a public interest consistency determination.

(d) Requested approval of this quantity in both the FTA and non-FTA export applications. Total facility is limited to this quantity (i.e., FTA and non-FTA volumes are not additive at a facility).

(e) Lake Charles Exports, LLC submitted one application seeking separate authorizations to export LNG to FTA countries and another authorization to export to Non-FTA countries. The proposed facility has a capacity of $2.0 \mathrm{Bcf} / \mathrm{d}$, which is the volume requested in both the FTA and Non-FTA authorizations.

(f) Carib Energy (USA) LLC requested authority to export the equivalent of 11.53 Bcf per year of natural gas to FTA countries and 3.44 Bcf per year to non-FTA countries.

(g) Jordan Cove Energy Project, L.P. requested authority to export the equivalent of $1.2 \mathrm{Bcf} / \mathrm{d}$ of natural gas to FTA countries and $0.8 \mathrm{Bcf} / \mathrm{d}$ to non-FTA countries.

(h) DOE/FE received a new application (11-161-LNG) by FLEX to export an additional $1.4 \mathrm{Bcf} / \mathrm{d}$ of LNG from new trains to be located at the Freeport LNG Terminal, to non-FTA countries, and a separate application (12-06-LNG) to export this same 1.4 Bcf/d of LNG to FTA countries (received January 12, 2012). This 1.4 Bcf/d is in addition to the 1.4 Bcf/d FLEX requested in dockets (10-160-LNG and 10-161LNG).

(i) An application was submitted by Gulf Coast on January 10, 2012, seeking one authorization to export LNG to any country not prohibited by U.S. law or policy. On September 11, 2012, Gulf Coast revised their application by seeking separate authorizations for LNG exports to FTA countries and Non-FTA countries.

(j) The Magnolia LNG Facility is limited to $1.08 \mathrm{Bcf} / \mathrm{d}$. FTA and Non-FTA volumes are not additive.

Source: http://energy.gov/sites/prod/files/2013/10/f4/Summary\%20of\%20LNG\%20Application.pdf 


\section{Appendix 4 - Assumptions used in Illustrative LNG demand projections}

Chapter 4 examines the future position of the five main Asian LNG importers (Japan, South Korea, Taiwan, China and India) in terms of their existing (overwhelmingly JCC-linked) long term LNG contract portfolios and their offtake agreements for US LNG export projects. Comparing these existing and prospective contractual positions with an estimate of future LNG import requirements provides insights into a) the scale of LNG imports needed above current contracted levels and b) the scope, (if these additional requirements are met by spot or LNG contracted on a price formation basis other than JCC linkage), to materially change the balance of LNG pricing away from JCC in the timescale to 2025.

Despite the importance of these markets in terms of the proportion of global LNG supply they consume and the rate at which their demand for LNG has grown since 2009 there is little in the public domain in terms of regularly updated future demand analysis.

In the absence of reliable reference points and detailed analysis, the following sets out the basis on which the 'illustrative LNG demand outlooks' for Japan, South Korea, Taiwan, China and India were derived. Data sources used to this purpose included the IEA World Energy Outlook $2011^{88}$ (for long term projections of natural gas demand and domestic production for China, India and Japan), the BP Statistical Review of World Energy ${ }^{89}$ (for production and consumption historic actuals to 2012) and Waterborne LNG (for LNG historic actuals to 2012).

Japan

Figure 27: Japan Natural Gas Demand Outlook

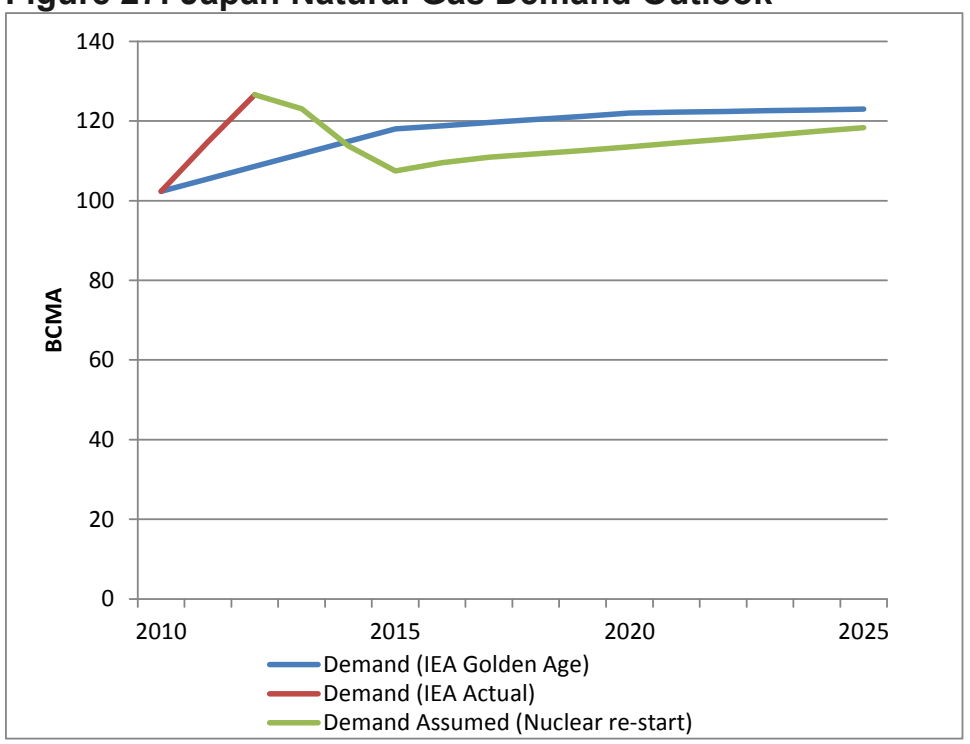

Sources: IEA (2011), IEA Monthly Gas Statistics, Miyamoto et al. (2012), Author's assumptions.

\footnotetext{
${ }^{88}$ IEA (2011).

${ }^{89}$ BP (2013)
} 
A full appreciation of the impact on gas demand in of the Fukushima disaster Japan was not available at the time IEA 2011 date was prepared (blue line). Historic data from the IEA monthly gas statistical service shows the growth of demand in 2011 and 2012 (red line). Combining this with trends from Miyamoto et al (2012) assuming nuclear re-starts over the 2014 and 2015 period is the basis for the projection of future demand (green line).

In deriving an outlook for Japanese LNG demand it is necessary to take into account domestic natural gas production, albeit modest in scale and assumed to decline in future. Combining this with actual data for LNG imports to 2012 results in the outlook for Japanese LNG imports shown in Figure 28. It should be noted that the pace and scale of nuclear re-starts is subject to uncertainty at present.

Figure 28: Japan LNG Demand Outlook

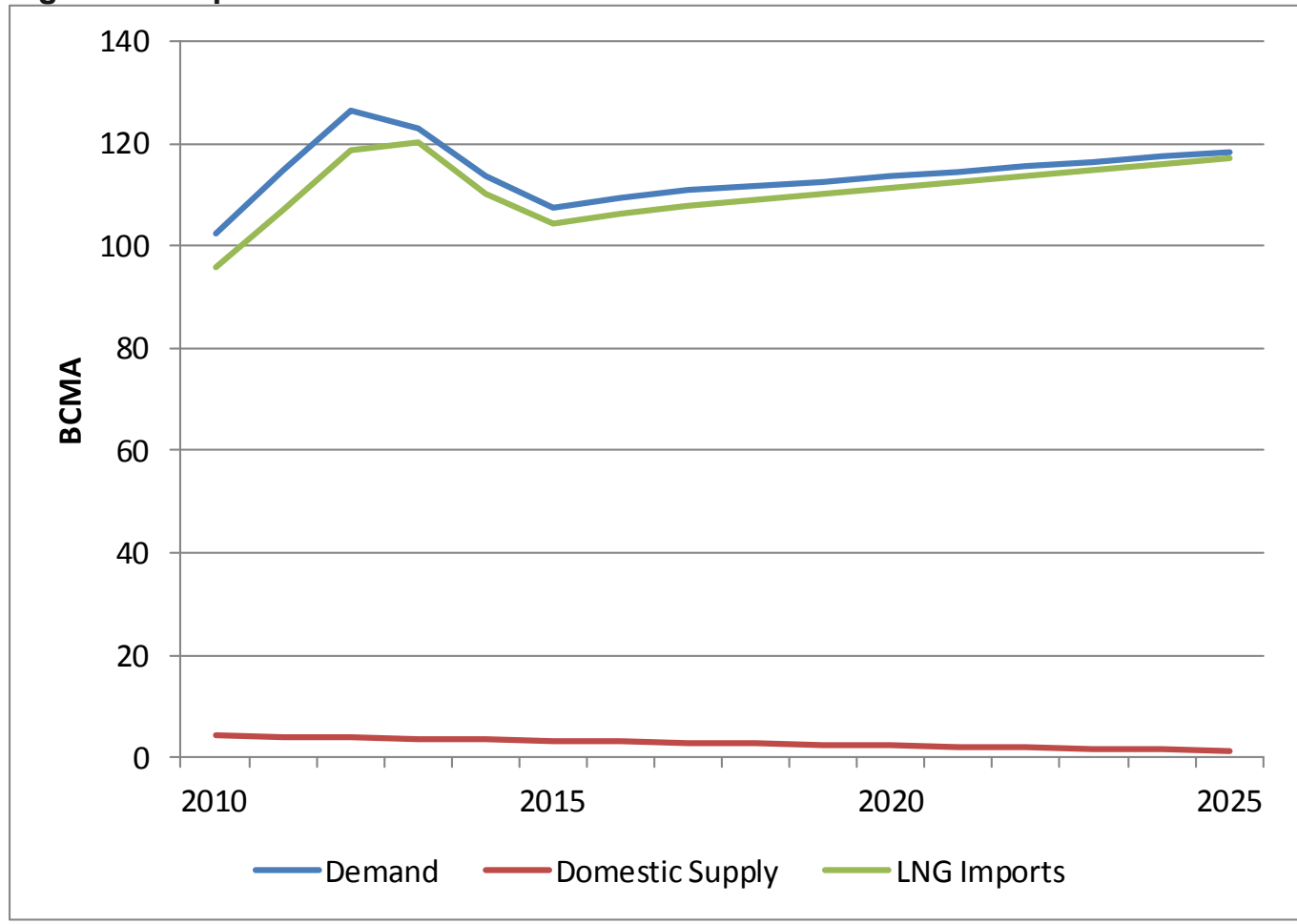

Sources: IEA (2011), IEA Monthly Gas Survey, Miyamoto et al. (2012), Waterborne LNG, Author's assumptions. Note: the apparent discrepancy between demand, domestic production and LNG imports in the 2010 to 2012 period is due to stock changes, data discrepancy and in all likelihood conversion approximations in moving from mmtpa to Bcma for LNG import quantities.

\section{South Korea}

Natural Gas Demand

The IEA does not include specific data for South Korea demand in its scenarios. Figure 29 shows historical data for the period 2000 to 2012 from the IEA Monthly Natural Gas data service (blue line). Deriving a projection of future natural gas demand for South Korea, in the absence of recent independent forecasts is made difficult due to the rapid rebound in demand from 2009 and no obvious trend. The increase in LNG consumption as a consequence of recent nuclear outages has not been quantified but influences the near-term shape of the tentative future demand line shown in red in Figure 29. 
Figure 29: Assumed South Korea Natural Gas Demand to 2025

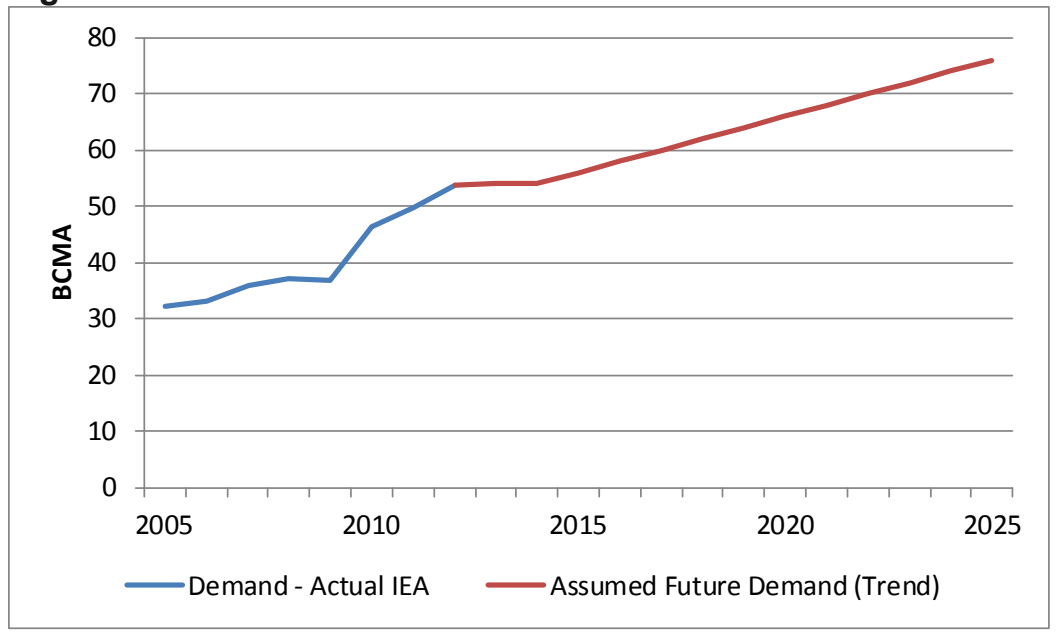

Source: IEA Monthly Natural Gas Survey.

Based on 2010 IEA data, domestic production for South Korea was assumed to continue at $0.6 \mathrm{Bcma}$ to 2025. The resulting LNG demand outlook is shown in Figure 30.

Figure 30: Illustrative LNG Demand Outlook for South Korea

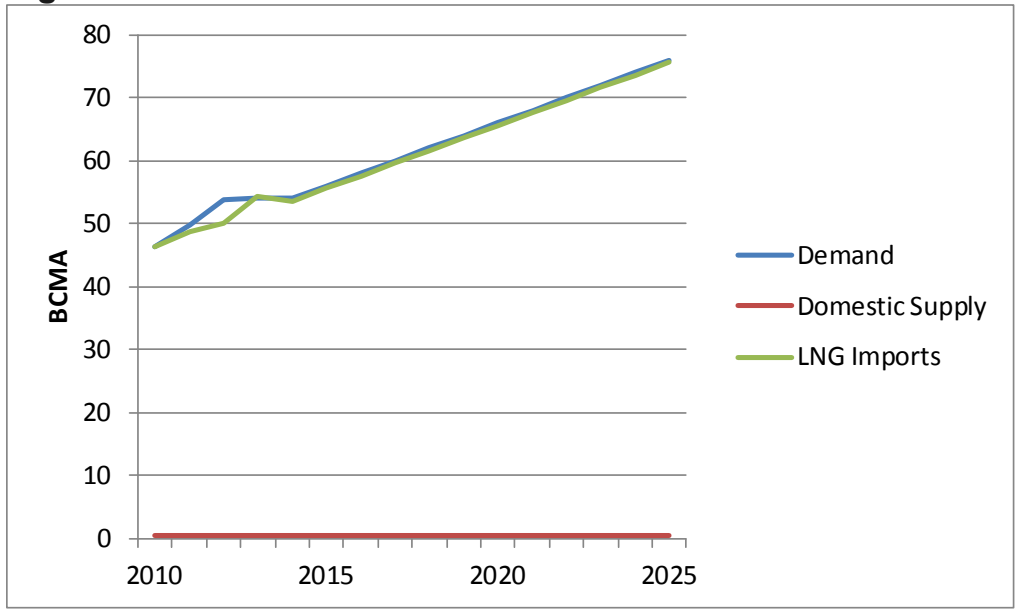

Sources: Sources: IEA (2011), IEA Monthly Gas Survey, Waterborne LNG, Author's assumptions.

\section{Taiwan}

Natural Gas Demand

Due to the lack of specific data on Taiwan in the IEA Scenarios, a tentative outlook for Taiwanese LNG imports is shown in Figure 31, based on historic data from 2005 to 2012. 
Figure 31: Assumed Taiwan Natural Gas Demand to 2025

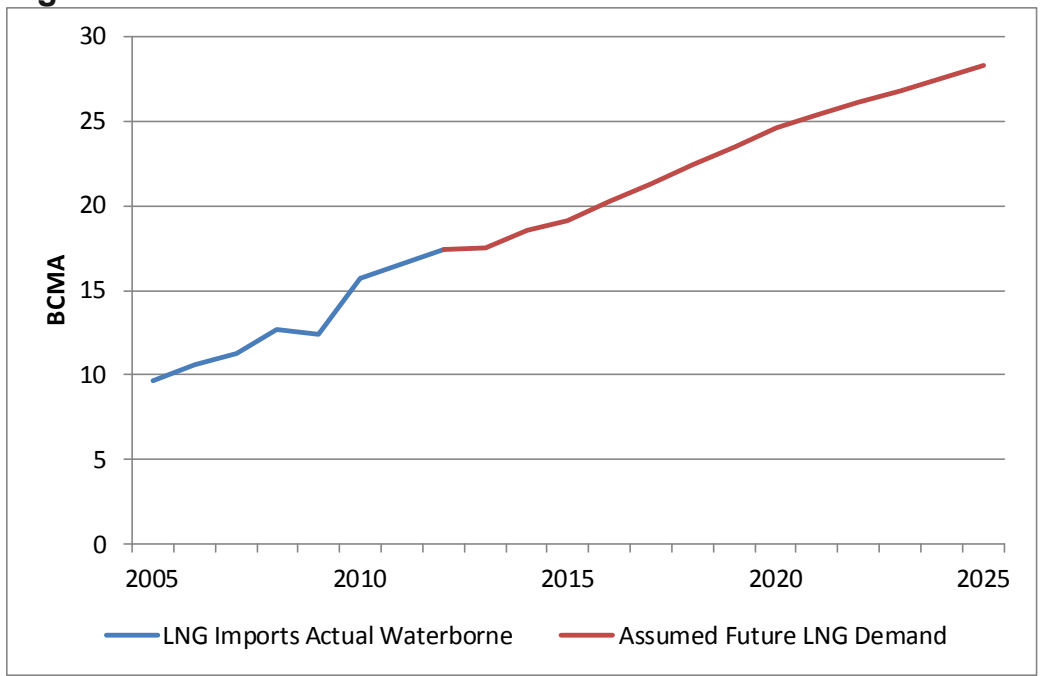

Source: Waterborne LNG, Author's assumptions.

\section{China}

Figure 32: Chinese Natural Gas Demand and Domestic Production Assumptions to 2025

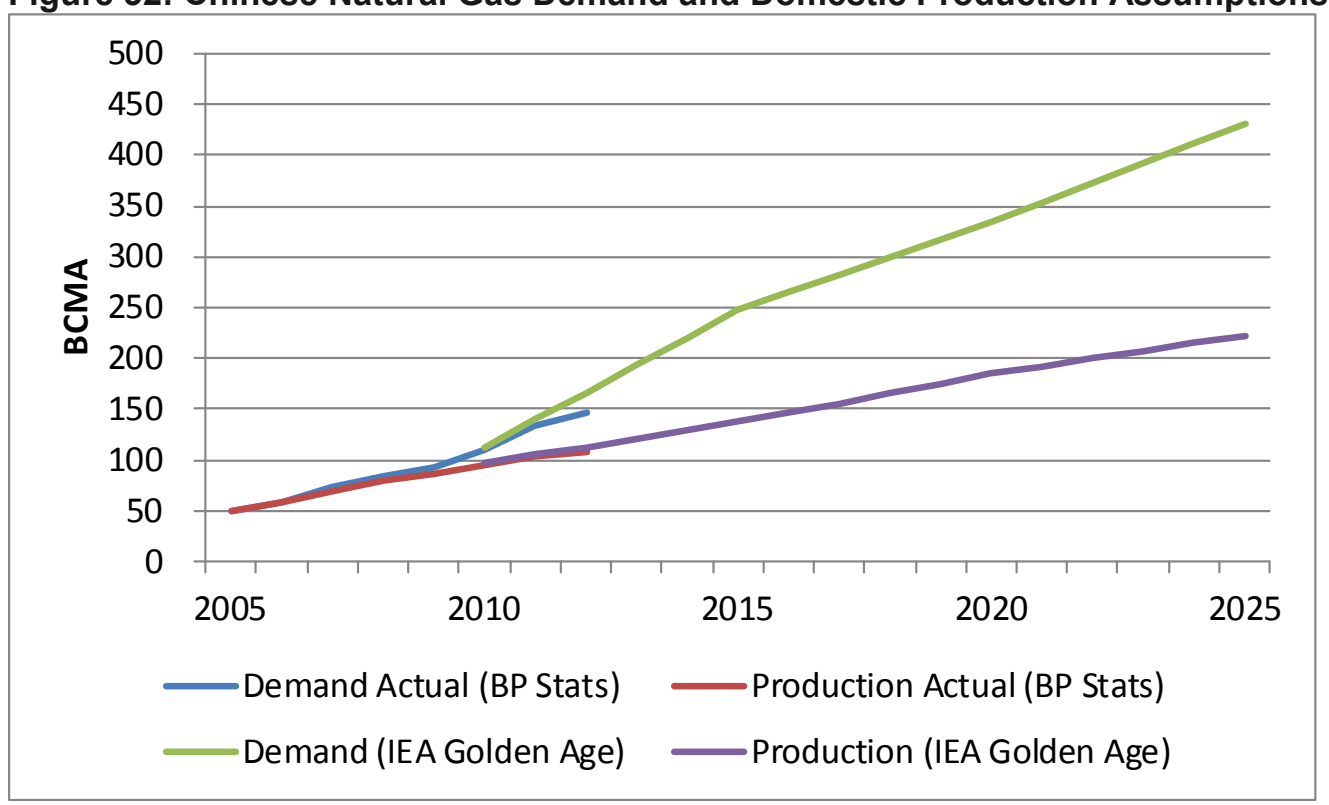

Source: BP (2013), IEA (2011).

Natural gas demand (green line) and domestic production (purple line) projections from IEA (2011) are shown in Figure 32. Also shown are historic demand (blue line) and production (red line) from BP (2013). While the IEA's domestic production trend shows good agreement in 2011 and 2012, demand appears slightly optimistic compared to 2011 and 2012 data. For the purposes of deriving an illustrative future LNG demand outlook it was assumed that Chinese natural gas demand would revert to the IEA trend by the mid 2010s. It should be noted that domestic production levels post 2020 will be influenced by the scale of potential shale gas production. 
Assumptions on Chinese pipeline supplies are:

Turkmenistan - China: the pipeline from Turkmenistan to China became operational in December 2009 and flowed 3.6, 14.3 and $21.3 \mathrm{Bcm}$ in 2010, 2011 and 2012 respectively ${ }^{90}$. Volumes, including supplies from Kazakhstan and Uzbekistan are assumed to build to $45 \mathrm{Bcma}$ (although there is a potential to reach $65 \mathrm{Bcma}$ with further investment ${ }^{91}$ ).

Myanmar - China: The $12 \mathrm{Bcma}$ pipeline from Myanmar was completed at the end of $2013^{92}$. A future flow of $10 \mathrm{Bcma}$ is assumed.

Russia - China: Gas imports from Russia have been the subject of intense though intermittent discussions and negotiations. It is assumed that such imports commence in 2020 and build to 38 Bcma by 2025 .

Figure 33: Future Chinese Demand and Sources of Supply

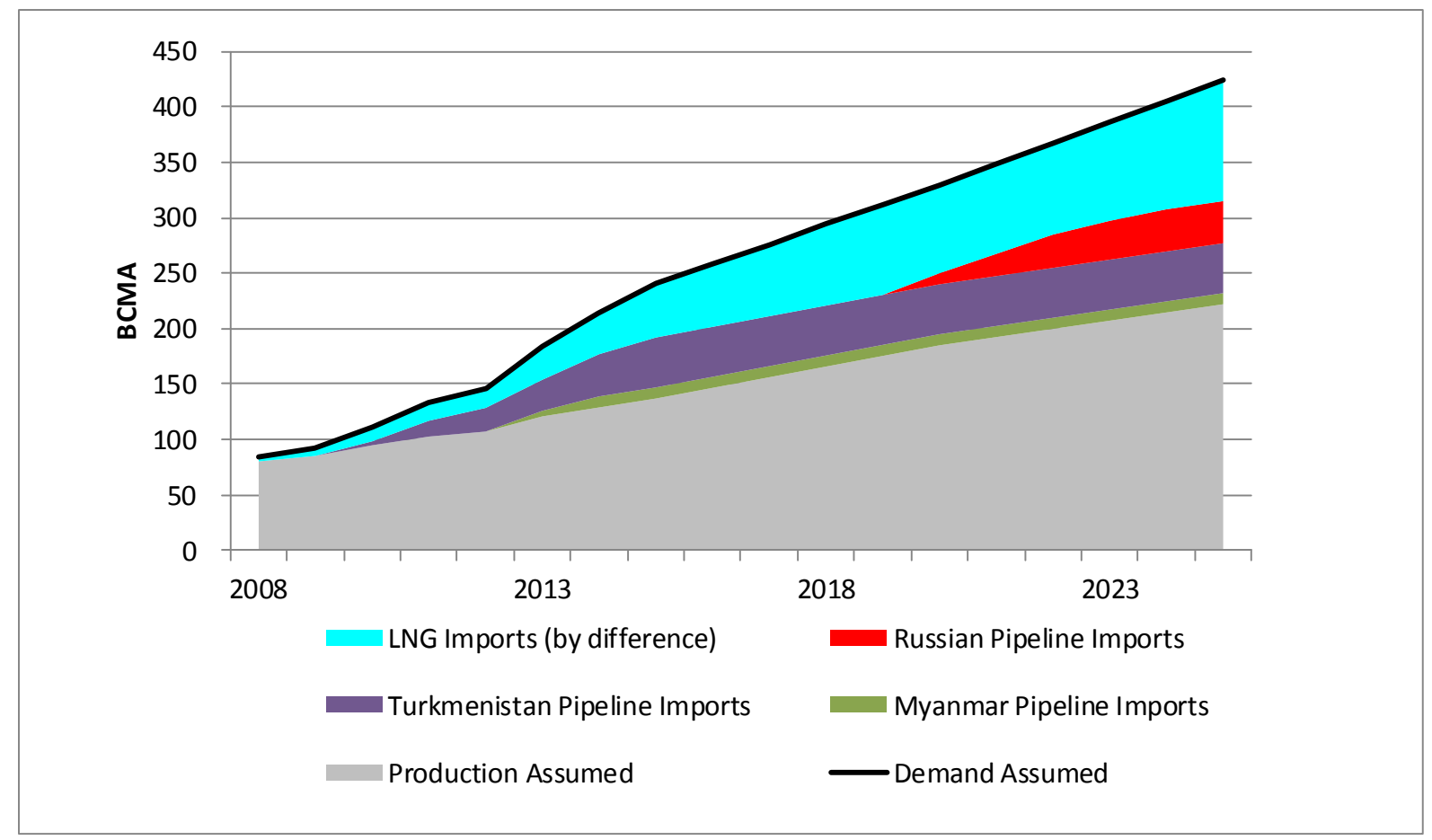

Source: IEA (2011), BP(2013), Waterborne LNG, Henderson (2011), Author's assumptions.

Combining these assumptions on natural gas demand, domestic production and pipeline imports results in the estimate of future LNG imports shown in Figure 33 (blue area). Clearly the scale of future Chinese LNG imports is the subject of many uncertainties. This is especially worth noting as by 2025 China's LNG imports have the potential to be on a par with those of Japan.

Figure 34 shows the resulting outlook for Chinese LNG imports derived from this analysis, with and without a Russian pipeline import project.

\footnotetext{
${ }^{90}$ BP Statistical Reviews (2011), (2012), (2013), Gas Pipeline Trade sheet.

${ }^{91}$ Henderson (2011), pp. 14,15

92 Henderson (2011), p 18
} 
Figure 34: Illustrative Chinese Future LNG Outlook

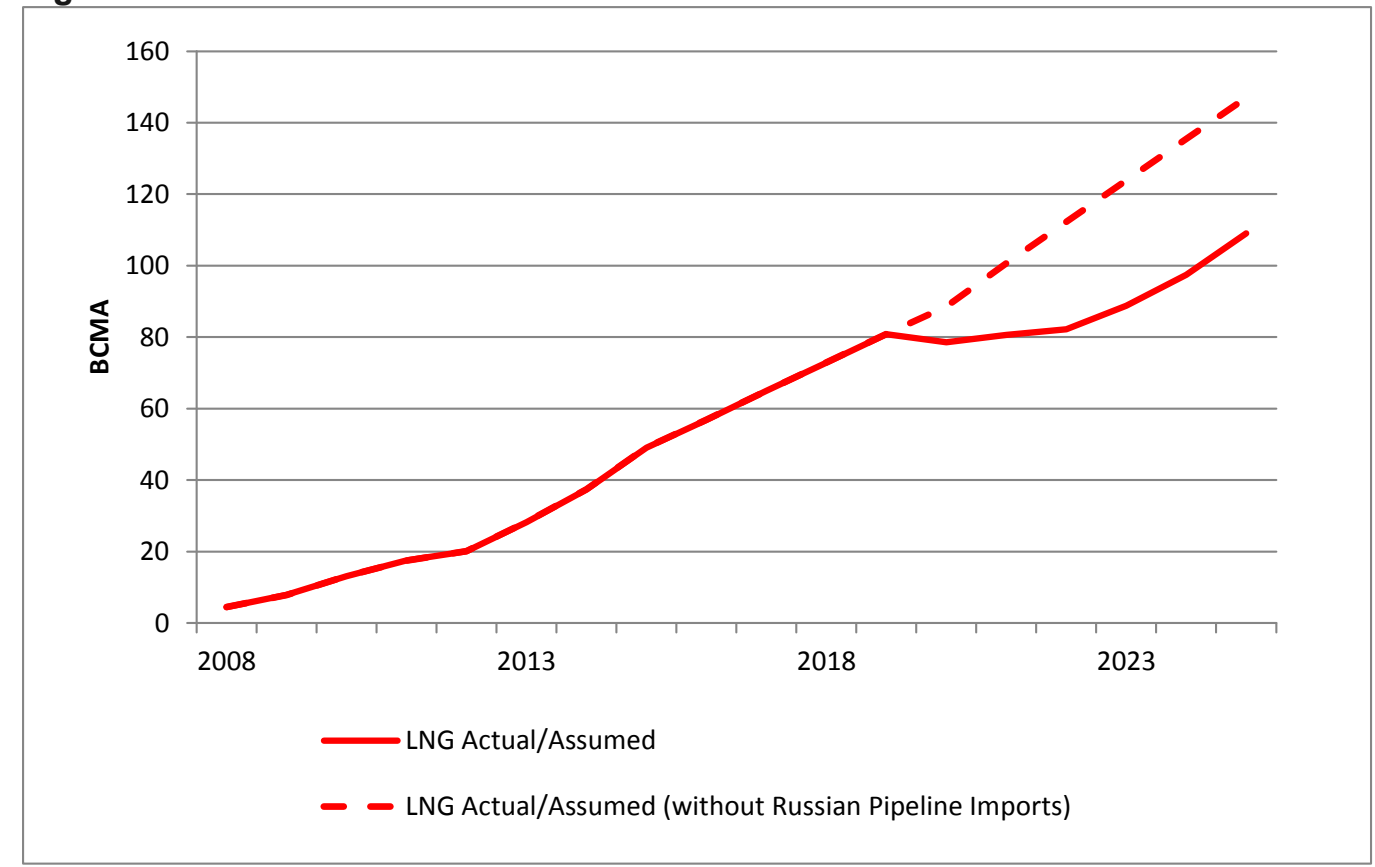

Source: Author's Analysis

India

Figure 35 shows the projections for Indian natural gas demand (green) and domestic production (purple) from IEA (2011). Also shown are historic demand (blue) and production (red) from the BP Statistical Review. The striking feature here is the downturn in production and demand in the 2011 and 2012 period as a consequence of production problems and an unwillingness/inability to fully compensate for this through higher priced LNG imports.

Figure 35: Indian Natural Gas Demand and Production to 2025

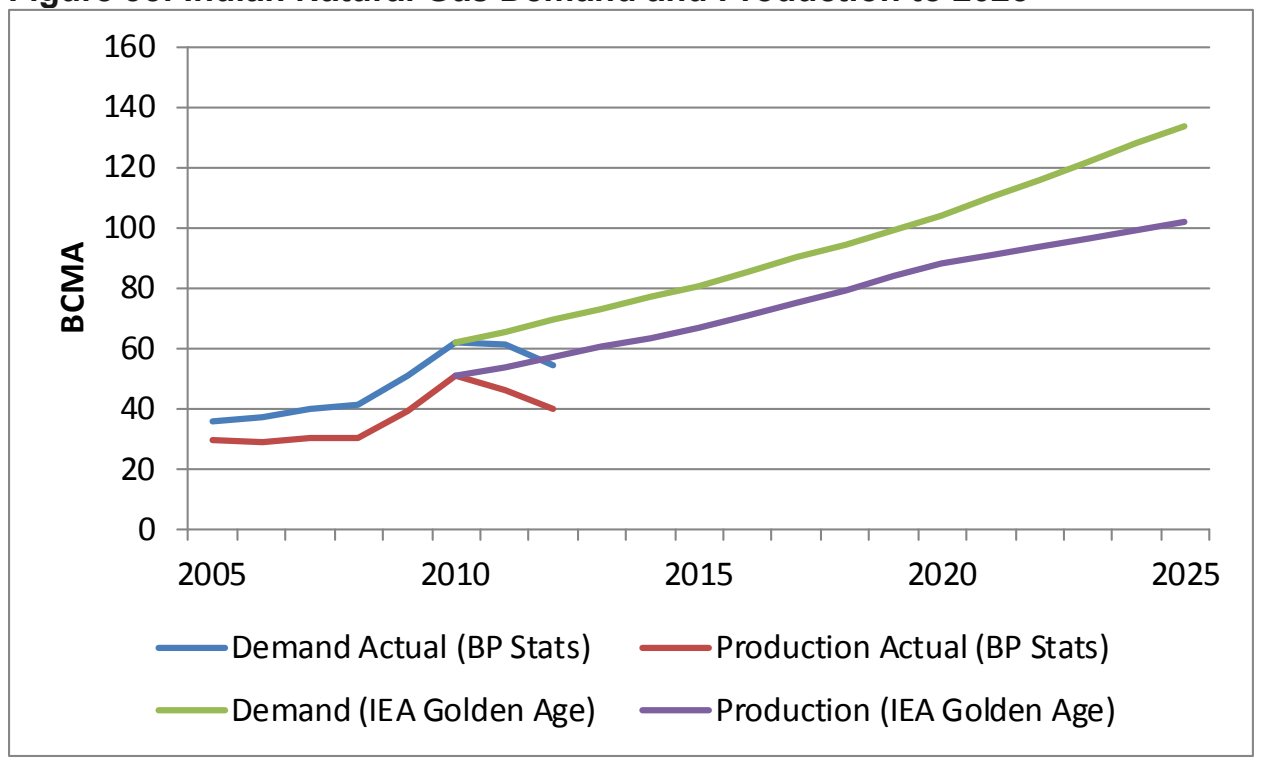

Source: BP (2013), IEA (2011) 
These developments make it difficult to construct a robust outlook for India's LNG import requirements. Figure 36 shows, in blue, India's historic LNG imports and, in green, future LNG imports implied from the IEA Golden Age of Gas report. For the illustrative outlook the red line trend was derived which honours the 'shape' of the IEA trend but which continues from the LNG import levels of 2012. Clearly this is the subject of much uncertainty.

Figure 36: Indian LNG Import Requirements to 2025

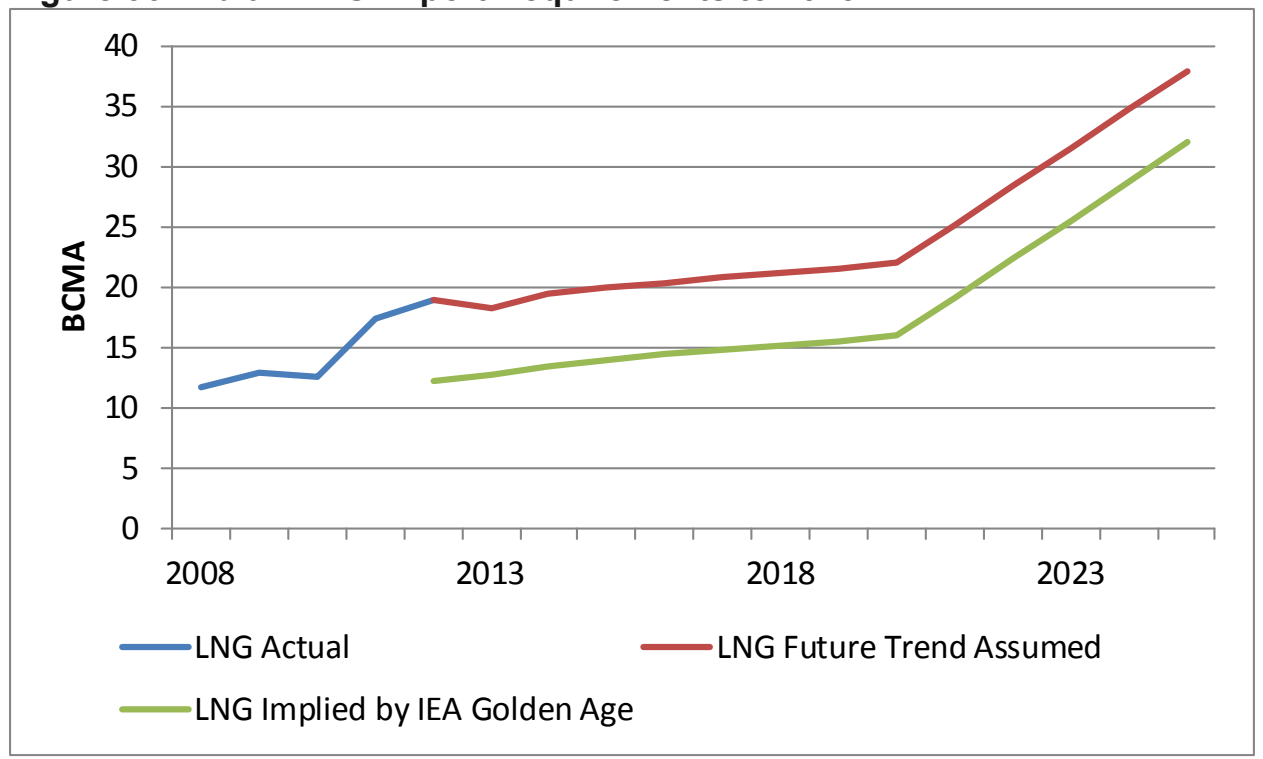

Source: BP (2013), Waterborne LNG, IEA (2011), Author's assumptions. 


\section{Glossary}

DOE - US Department of Energy

EPCO - Acronym for Electric Power (Generating) Companies (Japan)

FERC - US Federal Energy Regulatory Commission

FID - Final investment decision

FTA, Non-FTA - Relating to countries with which the US has (or has not) a Free Trade Agreement (see Appendix 2)

Henry Hub - The physical location in of the interconnection of major gas pipelines in Erath, Louisiana. It is the key (but not only) pricing point for natural gas in the US.

Hub, Trading Hub - a real or virtual point where natural gas is traded via bilateral, brokered or exchange facilitated trading platforms.

IEA - The International Energy Agency

JCC - Japanese Customs-cleared Crude Oil Prices - an internationally recognised crude oil price marker, sometimes referred to as the Japan Crude Cocktail.

LNG - Liquefied Natural Gas

MOU - Memorandum of Understanding

NBP - National Balancing Point - the UK's virtual gas trading hub.

NMV - Net Market Value

NYMEX - New York Mercantile Exchange, a commodities futures market.

S-Curve - A device for reducing the impact on gas prices in oil price-related contracts of very high or very low oil prices. 


\section{Bibliography}

Allsopp, C. and Stern, J (2012), 'The Future of Gas: what are the analytical issues related to pricing', in Stern, J.P. (ed.), The Pricing of Internationally Traded Gas. OIES/OUP, Oxford, pp. 10-39.

Argus Global LNG: This is a monthly subscription publication describing developments in international LNG supply and consumption and providing price data for LNG and other competing fuels.

BP (2013), BP Statistical Review of World Energy 2013,

http://www.bp.com/content/dam/bp/pdf/statistical-review/statistical review of world energy 2013.pdf (Note that prior versions of the BP Statistical Review of World Energy were also accessed to provide date on LNG and Pipeline gas trade-flows. These are available generally from the BP website or can be located with ease using search engines).

Cedigaz, Natural Gas in the World, Annual Surveys, http://www.cedigaz.org

Chen, M., (2012), 'Gas Pricing in China', in Stern, J.P. (ed.), The Pricing of Internationally Traded Gas. OIES/OUP, Oxford, 310-337

Chen, M., (2014 forthcoming). Chinese gas pricing development: drivers, challenges and implications for demand, OIES.

EIA (2012), Effect of Increased Natural Gas Exports on Domestic Energy Markets, US Energy Information Administration, US Department of Energy, http://energy.gov/sites/prod/files/2013/04/f0/fe eia Ing.pdf

Flower, A., Liao, J., (2012). LNG pricing in Asia, in Stern, J.P. (ed.), The Pricing of Internationally Traded Gas. OIES/OUP, Oxford, pp. 338-374.

Foss, M.M., (2007), US natural gas prices to 2015, OIES

Foss, M.M., (2011), The Outlook for U.S. Gas Prices in 2020: Henry Hub at $\$ 3$ or $\$ 10$ ? OIES.

Foss, M.M., (2012), North American Gas Pricing, in Stern, J.P. (ed.), The Pricing of Internationally Traded Gas. OIES/OUP, Oxford, pp.85-144.

Giamouridis, A. and Paleoyannis, S., (2011), Security of Supply in South Eastern Europe: the potential contribution of planned pipelines, LNG and storage, OIES.

GIIGNL (2012), The LNG Industry in 2012, http://www.giignl.org/fr/home-page/publications/

Heather, P., (2012), Continental European Gas Hubs: are they fit for purpose? OIES

Heather, P., (2010), The Evolution and Functioning of the Traded Gas Market in Britain, OIES

Henderson, J., (2011), The Pricing Debate Over Russian Gas Exports to China, OIES.

Henderson, J., (2013), The Potential Impact of North American LNG Exports, OIES.

Honore, A., (2013), The Italian Gas Market: challenges and opportunities, OIES 
IEA (2011), IEA World Energy Outlook 2011, Special Report 'Are We Entering a Golden Age of Gas?', http://www.worldenergyoutlook.org/goldenageofgas/

IEA (2012), Gas Pricing and Regulation: China's challenges and OECD experience, Paris: OECD/IEA.

IEA (2012a), World Energy Outlook 2012, Paris: OECD/IEA.

IEA (2013a), Developing a Natural Gas Hub in Asia: obstacles and opportunities, Paris: OECD/IEA.

IEA (2013b), Medium Term Natural Gas Outlook, Paris: OECD/IEA.

IEA Monthly Gas Survey, IEA Statistics. This is a subscription service provided on the IEA website at: http://data.iea.org/ieastore/default.asp

IGU (2013), Wholesale Gas Price Survey 2013 Edition. International Gas Union.

Interfax Gas Daily, China considers taking over pipeline network, 2 January 2014, p.5.

Jensen, J.T., (2004), The Development of a Global LNG Market, OIES.

Kovacevic, A., (2007), The Potential Contribution of Natural Gas to Sustainable Development in South Eastern Europe, OIES.

Miyamoto, A., (2008), 'Natural Gas in Japan', in Stern, J.P. (ed.), Natural Gas in Asia (2 ${ }^{\text {nd }}$ edition), Oxford:OIES, 116-173

Miyamoto A., and Ishiguro, C., (2009), A new paradigm for natural gas pricing in Asia: a perspective on market value, OIES

Miyamoto et al (2012), Miyamoto A. Ishiguro, C. and Nakamura, M., A realistic perspective of Japan's LNG Demand after Fukushima. OIES.

NERA (2012), Macroeconomic Impact of LNG Exports from the United States, NERA Economic Consulting, http://energy.gov/sites/prod/files/2013/04/f0/nera Ing report.pdf

Petrovich, B., (2013), European Gas Hubs: How strong is price correlation?, OIES. http://www.oxfordenergy.org/wpcms/wp-content/uploads/2013/10/NG-79.pdf

Rogers, H.V., (2010), LNG trade-flows in the Atlantic Basin, trends and discontinuities, OIES.

Rogers, H.V. (2012), The Impact of a Globalising Market on Future European Gas Supply and Pricing: The Importance of Asian Demand and North American Supply, Howard V Rogers, Oxford: OIES, http://www.oxfordenergy.org/2012/01/the-impact-of-a-globalising-market-on-future-europeangas-supply-and-pricing-the-importance-of-asian-demand-and-north-american-supplyl

Rogers, H., (2012a), The interaction of LNG and pipeline pricing: does greater connectivity equal globalisation? in Stern, J.P. (ed.), The Pricing of Internationally Traded Gas. OIES/OUP, Oxford, pp.375-423. 
Sen, A., (2012), 'Gas Pricing in India', in Stern, J.P. (ed.), The Pricing of Internationally Traded Gas. OIES/OUP, Oxford, pp. 285-309.

Societe Generale (2013). SocGen Cross Asset Research, 'European Gas and Power Drivers', 29 October 2013. https://www.sgcib.com/en/our-offering/global-markets/related-services/cross-assetresearch

Songhurst, B., (forthcoming 2014), LNG Liquefaction Costs, OIES.

Stern, J.P., (2007), Is there a rationale for the continuing link to oil product prices in Continental European long term gas contracts? OIES

Stern, J.P., (2009), Continental European Long Term Gas Contracts: is a transition away from oil product-linked pricing inevitable and imminent? OIES

Stern, J.P., (2012). 'International Gas Pricing', an historical overview, in Stern, J.P. (ed.), 2012. The Pricing of Internationally Traded Gas. OIES/OUP, Oxford, pp. 40-84.

Stern, J., and Rogers, H., (2012), 'The Transition to Hub-Based Gas Pricing in Continental Europe, in Stern', J.P. (ed.), The Pricing of Internationally Traded Gas, OIES/OUP, Oxford, pp. 145-77.

Waterborne LNG: Waterborne LNG is a subscription service providing US, European and Asian reports data and commentary on LNG cargo movements 